



\section{THE PSYCHOLOGY OF SOCIAL RECONSTRUCTION}



THE PSYCHOLOGY OF SOCIAL

\section{RECONSTRUCTION}

\section{BY}

GEORGE THOMAS WHITE PATRICK, Ph.D.

- Professor of Philosophy in the State University of Lowa; author of "The Psychology of Relaxation"

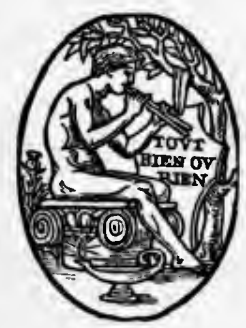

cabe niburdide pres Cambrioge

1920

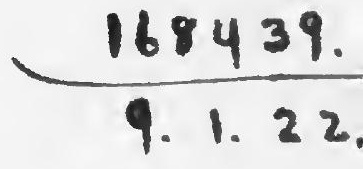

\section{BOSTON AND NEW YORK \\ HOUGHTON MIFFLIN COMPANY}


COFYKIGHT, 1920, BY GEORGE T. W. PATRICE

ALL RIGHTS RESERVED 


\section{TO}

M. L. P. 
Digitized by the Internet Archive in 2007 with funding from Microsoft Corporation 


\section{PREFACE}

M ACAUlay in his essay on Lord Bacon 1 said that it was not Bacon's purpose to make men perfect. His humble aim was to make imperfect men comfortable. This Baconian philosophy, whose aim is to exploit all the forces of nature for the comfort and convenience of mankind, and which finds happiness not in the exercise of man's highest powers but in the release and satisfaction of human desires, originally characterized only the English-speaking peoples, but has now extended to the whole world.

While personally I believe that a civilization based on such a foundation as this is artificial and ephemeral, nevertheless to write a book to prove this would be a thankless task. It would be just a sermon, fruitful of nothing but yawns. We do not now look with very much alarm at such warnings as Civilization at the Crossroads. We are not greatly impressed when we are told that the kind of society which the social reformers promise us is not such a society as we ought to have; just as the laborer is not very much impressed when the capitalist tells him that his poverty is good for him. 
But our attitude toward science is a wholly different matter. If the authority of religion, philosophy, and traditional morality has somewhat abated in these days, not so the authority of science. The emblems of authority are now all its own. I have therefore attempted in the following pages to apply certain elementary principles of psychological science to the problems of social reconstruction. For the sake of brevity, I have used the title, "The Psychology of Social Reconstruction." A more appropriate title might have been, "Preliminary notes on the application of psychology to the problem of social reconstruction as represented in certain popular movements of the day."

There is, of course, already an extensive literature on the psychology of social reform in its larger aspects. I have quoted from some of these writings in the pages which follow. While I have hoped to make a further slight contribution to this large subject, my immediate purpose has been the examination of some of the current and popular plans. for social reform in the light of recent psychological studies - particularly studies in certain forms of instinctive human behavior. The early chapters of the book are, therefore, largely negative. In the 
later chapters $I$ have tried to indicate my own thought as to the direction social reconstruction should take, if it is to conform to the facts of human nature.

Two of the chapters in this book have appeared as magazine articles in a slightly different form. I wish to thank the editors of The Scientific Monthly and Natural History for permission to use the articles entitled, respectively, "The Next Step in Applied Science," and "Our Centrifugal Society." Certain parts of the second, third, and fourth chapters were published in The Scientific Monthly in an article entitled "The Psychology of Social Reconstruction."

Iowa City

G. T. W. P.

August I, 1920 



\section{CONTENTS}

I. INTRODUCTION I

II. Psychological Factors in Social ReCONSTRUCTION

III. Psychological Factors in Social ReCONSTRUCtion (continued) 6I

IV. Psychological Factors in Social ReCONSTRUCTION (continued)

V. The Psychology of Work

Vi. Our Centrifugal Society

VII. Social Discipline

VIII. The Next Step in Applied Science 



\title{
THE PSYCHOLOGY OF SOCIAL RECONSTRUCTION
}

\author{
CHAPTER I \\ INTRODUCTION
}

7 HAT the Freudian psychology has a social 1 application no one can doubt who has carefully observed the world's progress during the last ten or twenty years. It was really about the time the dancing craze burst upon us that the reaction began. When we look back upon those tango days, they seem quite innocent and mild as compared with the present; but it was a wild orgy then.

It will be only the youngest of us who cannot recall the exalted social mood in which we lived in the early years of this century. The moral fervor of our heroic action in banishing slavery was still upon us. We were thrilled by a new zeal for breaking also the chains of alcohol. We 
were still priding ourselves upon our wonderful schools and our remarkable freedom from illiteracy. We dimly remembered the horrors of war, but we were providing against any such calamity as a great war by means of peace societies and arbitration treaties! Most of all, perhaps, we were exulting in the almost miraculous results of the industrial revolution. We had at last gained complete mastery over the forces of nature. Earth and sky and water were subservient to man. Science and invention, the marvelous bequests of the nineteenth century, were the keys to a kind of terrestrial paradise just opening to us. Best of all, the economic surplus promised to put an end forever to the old paineconomy, in which the world had always lived, and we had visions of a pleasure-economy to extend to all lands and classes. In fact we were all aglow with enthusiasm for something which we called "modern civilization."

Furthermore, we were really living up to our high ideals. We had ourselves well in hand. There was a high standard of morals and a high degree of refinement. It was relatively a period of self-control, temperance, thrift, and decency. Although beer, wine, and distilled liquors were everywhere to be had and at a moderate price, 
we were as a people temperate and restrained. ${ }^{1}$ The house of "modern civilization" looked so genuine and solid that we never suspected that what we saw was just a veneer. We were ignorant of the new psychology that tells us now of the danger when deep racial impulses are merely suppressed and not properly sublimated and redirected.

It was the first symptom of the reaction when the dancing craze burst upon us. From our puritan standpoint we were shocked when the whole world took to dancing, and not very decorous dancing at that. Some thought that the whole world had suddenly gone crazy. But this was only the beginning, for it was soon followed by the nation-wide and world-wide amusement crazes. In those staid and proper early days of the century, had some prophet foretold that ten to fifteen million people in the United States would very soon be in daily attendance upon

1 In those days we used to hear about the delicate aroma of old wines and burgundies, the rich and mellow taste of rare old whiskies, and the tonic nutritive value of ales and beers made from good barley and hops. But now all this ancient camouflage has been brushed away and men have discovered that what they want is alcohol, and the larger percentage of it the better. Even for two and three quarters per cent they have shown themselves ready to wage a determined and persistent fight. This self-revclation has been humiliating and disillusioning, but self-knowledge such as this will be valuable in the social reconstruction of the future. 
moving-picture shows exhibiting no high dramatic art, but for the most part tawdry, sensational, and erotic, the story would have been as incredible as that in fewer years than twenty there would be a great world war whose direct and indirect cost would be estimated at the unbelievable sum of three hundred and thirtyeight thousand million dollars and in which fifty-nine million men would be called to arms and seven and one half million killed.

Had the curtain been drawn still farther aside, revealing the hosts of shameless profiteers and the sudden rush for new wealth both during and after the war; revealing still further the harsh and ugly picture of post-war conditions, the scramble for territory and power in Europe, the avarice, the cynicism and the deceit, the sacrifice of human rights to national aggrandizement, the low cunning of European diplomacy, ${ }^{1}$ the frenzy of spending as well as the greed for gain in America, the sacrifice of great world reforms to petty politics and party, the silly and childish behavior of many of our American people when their self-made dry-laws began to

1 Compare articles by E. Alexander Powell, "The New Frontiers of Freedom," Scribner's Magazine, January, February, and March, 1920. 
close down upon them, in their absurd scramble for a last drink or for a stay of the enforcement of the laws, if only for a few weeks or days had all these things been foreseen, those good people of just one short generation past would have said that such sudden madness of men could be explained only by some new and strange astronomical influences.

But the explanation is much simpler. It was a case not of stars but of brain cells. It was a case of a certain kind of culture spread over the surface of a great body of deep racial instincts and desires. It was a case of getting civilized too rapidly, when civilization is understood merely as a kind of social decorum. In those days society was simply being given a course in manners, instead of having its deep latent energies redirected into healthy channels by moral, æsthetic, and social ideals. These energies being suppressed were still working subterraneously, resulting in a social "complex," which took the form of the violent outbreaks mentioned. Society, as well as individuals, may be subject to nervous disorders and have its suppressed "wish."

But what is to happen? Were these waves of 
frivolity and this "dose of savagery" a kind of "fling," which was necessary to restore the social balance, and has society suffered a sort of katharsis, which will leave it purified and harmonious? Was it merely a case of social tension, which has now been relieved by a period of excess? Are the suppressed desires now "working themselves off," so that we may soon expect a return to normal healthy conditions?

- Although neither the analogy of the Freudian psychology nor the social experience of the past warrants such a hope, nevertheless something like this may take place. There are hopeful conditions, as we shall presently see, that greatly redeem the outlook. I am not interested here in predicting either a great social disaster or the speedy return of social calm and serenity. Probably neither will happen. I am interested only in noting the amazing change which has taken place in respect to our confidence about the future. Formerly a few croaking pessimists and alarmists used to amuse us by predicting the downfall of our civilization. We were amused rather than alarmed by these predictions, because we had been taught to believe, and with boundless pride, that we were just entering upon a glorious period of human progress under the 
safe guidance of science and the mechanic arts and through the final long-sought freedom, equality, and fraternity. Now we are suddenly told and not by alarmists nor pessimists, but by some of those who represent the clearest thought of the day - that our whole western civilization is in grave danger, if not near its end.

A writer in a recent number of the "Manchester Guardian" says of the present times, "It is the kind of situation in which former civilizations have gone down." The Rt. Hon. C. F. G. Masterman, writing in the "Atlantic Monthly" for August, I9I9, after a long and careful review of the situation in England, uses these significant words:

The shadows lie heavy on the hills. It will be years, it may be decades, before these shadows are dispelled. It may be that never will they be completely dispelled. These four years of mad destruction may have struck a blow at Europe's prosperity from which it will never recover. Some of the greatest of the Dominion statesmen have expressed to me their conviction that the result will be a permanent change. They foresee a great and increasing migration from Great Britain, and indeed from all the war-tortured countries, of people fleeing from national bankruptcy in a region haunted by evil dreams. From such a migration they anticipate the building-up of huge white communities in still unsettled lands, which will give a new orientation to the world's future his- 
tory. Canada, South Africa, Australasia, will take the place in this war which was taken by the West after the Civil War in America. However this may be, at home we are in for troublous times. Reconstruction far more vital and profound than anything contemplated by the present Parliament alone can insure internal tranquillity.

Similar testimony could be quoted from a long list of careful writers whom no one would call alarmists.

In discussing a question of this kind preliminary to our study of reconstruction, we must avoid on the one hand a too easy optimism such as prevailed two decades ago, and on the other hand an unnecessary pessimism due to the results of the war. In these chapters I wish to study certain social and psychological forces which were at work before the war and which will go on hereafter whatever the result of the war may be. I am considering here not any kind of temporary reconstruction which shall reinstate economic conditions as they were before the war, but social reconstruction in the broader sense of social, political, and economic movements designed to correct evils inherent in our modern life. We live in the hope that Europe may be able to recover herself after her terrible convulsion, and that America may in part escape the 
price which Europe must at any rate pay. We may, therefore, here omit the darker picture of conditions in European capitals which so many writers have so vividly drawn, ${ }^{1}$ and do so in the hope - a hope perhaps not fully justified - that the waves of crimes both of passion and of violence, the unrestrained and unashamed revelry and frivolity, the reckless extravagance and foolish spending, the barbaric and childish display, the apparent complete loss of the sense of social obligation, are merely manifestations of an acute ncrvous disease due to the strain of those terrible years of war and that the healing will speedily come. As the war passes into the background, as production is resumed, as order is restored, these things will cease to be so much in evidence. Possibly for that very rcason we may become forgetful of certain real dangers that threaten the integrity of our modern society.

What are these dangers? That they are real and threatening even the most optimistically inclined cannot doubt. What has seemed to us sometimes the most imminent danger, the triumph of Bolshevism, Communism, or Anarchy,

1 Compare, for instance, the article by Sisley Huddleston, in the Atlantic Monthly for May, I920, entitled "The Menace of the World." 
may be really the least of the dangers which threaten our civilization. In a country brought to the very verge of ruin by war, it is conceivable that these movements might be the occasion of the final downfall, but the real cause they could hardly be. If Bolshevism and similar movements may occasionally have the opportunity of trying themselves out, we shall soon learn how quickly they fuse into old social orders, how human nature triumphs over economic theory, how the old social and political relations and the old evils, too, remain much the same.

The real dangers lie deeper; they lie even deeper than war, although we are beginning to learn that it may indeed be war which will overthrow our civilization. War has lost all its glamour. In primitive times, and to some extent throughout human history, war has had a vitalizing and salutary effect on the human race, encouraging manly virtues and eliminating the weak and unfit. Now all this is changed. A modern war is a human scourge. It is a decivilizing agency. Its effects are deadening and paralyzing. It eliminates not the unfit but the fit. It selects for its slaughter the prime young men of all the nations. Its cost is so terrific that it buries pos- 
terity under a crushing debt. It idealizes all the mediæval virtues - physical bravery, personal sacrifice, unbounding sympathy, and group antagonism. It retards perhaps for a hundred years the virtues upon which the health and integrity of modern society depend - commercial honesty, sexual purity, international amity, temperance, and thrift.

And it is doubtful whether the effect of a modern war upon the vanquished is worse than upon the victors. The pitiful picture of poverty, the impoverishment of land and of natural resources, the waste and depletion of human vitality, the despair and discouragement of the vanquished are not much worse than the hate and revenge, the greed and the avarice, the profligate spending and the moral deterioration of the victors. Another great war may reduce the world to barbarism.

But there is another danger even greater than war which threat,ens our modern civilization, and that is decadence - physical, mental, and moral. There is evidence of all of these which no thoughtful man can ignore. There is danger that physical degeneracy will follow upon our sedentary manner of living, upon the increase , of wealth, ease, and luxury. There is danger that 
mental degeneracy will follow upon the reversal of the law of survival which in the past has eliminated the mentally unfit. There is danger of moral degeneracy in the period of readjustment from religious to purely ethical sanctions of conduct. ${ }^{1}$

The decline of the birth-rate among our effective stocks, the disastrous results of modern philanthropy upon racial health, the rapid increase of subnormals, defectives, and ineffectives of all kinds, the devastation of racial values by the war, the exhaustion of racial reserves such as in ancient times replaced the decadent

1 The most serious aspect of this moral decadence is seen in the wave of bad music which has been sweeping the country and the world. The psychology of the jazz music - that is, the ground of its powerful appeal - has not yet been worked out. When this is done its explanation will probably be found to rest on anthropological grounds. It is barbaric music - literally, not figuratively. It recalls echoes of the ancient camp-fire with its barbaric syncopated strains and its accompanying dance, in which the sex element is predominant. The dancing craze of the present time, and the rag and jazz, are not, then, to be regarded merely as one phase of the moral decadence which follows a war, nor passed by whimsically as a temporary craze, having, to be sure, disastrous moral consequences, but condoned or excused as a passing fad. They are to be considered as reversions to a primitive culture and to primitive morals indicating that the upward urge of progress is ceasing. If this interpretation of the case be correct, it is a most serious indictment of our times and our civilization. Let us hope that it is not true, but that it is due to a temporary social fatigue of the higher brain centers resulting from the pressure of our tense and rapid living. 
Romans, - all these present problems compared with which the economic questions of the day appear unimportant. According to Mr. Seth $\mathrm{K}$. Humphrey, ${ }^{1}$ if it could be conceived that society should so arouse itself to its dangers as to see to it that the two million defectives and the three million border-liners or ineffectives in the United States should, either by sequestration, or in other ways, be prevented from further contributing to the deterioration of our racial stock, while we should be saved from the danger of racial degeneracy, we should still be condemned to mediocrity, owing to our increasing number of "racial slackers."

Without passing judgment here upon the accuracy of these views, we see that taken all together there are dangers enough which threaten our civilization. Other civilizations have perished under circumstances not essentially different.

Of course at this point the question might be raised whether our civilization is, anyway, worth saving. If it is not, we need trouble ourselves no further. Lately there has been a general awakening to the fact that our so-called modern

${ }^{1}$ See his recent book entitled The Racial Prospect. 
culture is after all nothing very wonderful. Even before the war we had begun to doubt whether the great hopes of the nineteenth century for the regeneration of the world through science, invention, and the conquest of nature, and through the economic surplus, were to be realized. What are the final tests of a high civilization? If they are found in a social system which offers a just distribution of wealth and opportunity, we are told that our present system is a failure. If they are found in art and morals, we have neither in high degree. If they are found in peace and social stability, what we see is war and social unrest. If they are found in physical stamina and racial health, we recall the humiliating revelations of the physical examinations of our five millions of drafted soldiers, showing one third of them physically unfit. If they are found in universal education, we remember that twenty-five per cent of our young men called to the colors were found to be illiterate. ${ }^{1}$

1 "Illiteracy suddenly revealed itself as a national handicap when we found that the two hundred thousand illiterates drawn into the training camps appreciably delayed our military preparations. The pitiable inefficiency of a school system in which one fourth of all the teachers are scarcely more than boys and girls themselves finds an ominous parallel in the fact that one fourth of the drafted men were reported as being unable to write an intelligible letter or read'a newspaper intelligently." (W. C. Bagley, in The New Republic, December 17, 1919, p. 89.) 
Is such a civilization worth the saving? No one with the slightest acquaintance with history will hesitate in his answer to this question. We may realize to the full the defects of our civilization, we may realize the much advertised inequalities of our social system - nevertheless every one knows that our civilization is worth saving and must be saved. When all is said, there has been for some centuries a rather steady growth in the things which we have come to prize - freedom, opportunity, security, physical comforts, medical, surgical, and dental service, control of contagious diseases, household conveniences, conveniences of travel and communication, a world-wide news service, the passing of fear and superstition, educational facilities for our children, constantly increasing rights and privileges of women, and so on through the long list. We should not care again to face hunger and cold and constant fear, nor should we be willing to sacrifice the security which law and order during the longer and longer intervals of peace have gained for our women and children and for our lives and property. When radical social reformers clamor for the overthrow of our present social system and arraign it as a system of slavery and poverty and cruel injustice, it is 
evident that they use these terms relatively, having in mind some ideal social order in which all our present freedom and security and our comforts and conveniences are to be retained and the glaring imperfections removed. Comparing our present well-being with any epoch in the past, we are certainly happy in our possession' of all those things which we most prize. If on every side we see greed and jealousy and inequality and injustice and poverty and want and crime and unrest, it is only necessary to look back over the road that mankind has traveled to find at every station of the journey more of each and all of these. It would be wholesome for us more often to look back and compare the degree of social welfare which we enjoy with that of former times. It was not many centuries ago, for instance, that the English peasants lived in hovels with dirt floors, slept on a pile of straw, and were afflicted with vermin.

Far more noteworthy than the security, the freedom, and the comforts of the present age which themselves may be indirectly sources of danger - are its idealism and its visions of better things. When, for instance, we think of our disappointed hopes in the Treaty of Versailles, when we are humiliated by the spectacle of 
hatred, greed, ${ }^{1}$ and revenge, and the display of narrow and selfish nationalism which displaced the fine idealism of the early years of the war, we are ready to despair of any progress and to condemn our whole modern civilization. But we forget that hatred, greed, and revenge are familiar things in the history of the world, while the idealism itself is something new. In the year I9I4 the world was stirred to its depths by an idealism which was the very fruitage of twenty centuries of Christian civilization; that this revolt against autocracy, this mighty cry for fair play and justice and democracy which later was embodied in the fourteen points was possible at all as a great world movement redeems the picture, at any rate to some extent, and holds out great promise for the future. In spite of our selfish strife for personal advantage, there is gradually emerging a social conscience. In spite of our frenzied nationalism, there is slowly arising a spirit of international brotherhood.

But our civilization is redeemed not merely by its idealism, not merely by its material blessings, but even more by its charity, its sympathy, its faith, and its heroism. Grossness there is indeed

1 "Imbecile greed" is what John Maynard Keynes calls it. See his book, The Economic Consequences of the Peace, p. 147. 
a plenty, but "above all this grossness there towers a sweetness and beauty of thought, and an earnestness of purpose, a sincerity of effort, which makes the present time fuller of moral purpose, fuller of desire to be clean and to help others to be clean, than graced any previous period in the history of either England or America." 1

One of the reasons that our civilization seems so fraught with danger is the startling rapidity of social changes at the present time. The changing social order has become a commonplace in speech and writing, but although the world is at present changing with kaleidoscopic, yes, with cinematographic rapidity, it is comforting to observe that up to the present there is nothing in these changes to be greatly alarmed about. Some of them, such as the enormous burden of bonded indebtedness being piled up now by states, cities, corporations, etc., and the apparent growing laxity in some departments of morals, are causes for apprehension certainly. These changes have to do with rather profound aspects of our social life and may stand in the way of progress or result in some kind of social

1 Samuel C. Schmucker, The Meaning of Evolution, p. 256. 
stagnation, not catastrophic so much as insidiously weakening. But when we contemplate the actual changes in our social order up to date, we must admit that for the most part they are changes for the better.

Consider, for instance, the actual steps that have been taken in the socialization and democratization of the world. However sinister or beneficent the extreme socialization and democratization which is proposed may be, what has really happeried thus far is a change for the better. Favorable also are the actual steps which have been taken in the securing of social justice by establishing a legal minimum wage; in conceding the right of labor to organize and act collectively; in putting increased taxation upon large fortunes, incomes, and inheritances; in the institution of numerous successful plans for harmonizing the interests of capital and labor in many large manufacturing concerns; in making and enforcing laws against child labor; in providing adequate and sanitary houses; in banishing the unsightly and evil-smelling saloon from American towns and cities; in the enfranchisement of women and in their greatly enlarged sphere of action and influence in society; in the noteworthy steps which have been 
taken in physical training, particularly for women and girls; and in the advent of some degree of common sense in respect to dress. This list of happy changes could be greatly enlarged, as everybody knows, and these grateful facts, even though we are still convinced that our civilization is in danger, may ease our anxiety a good deal. ${ }^{1}$

Then there is another alleviating consideration. It may be that it is not so much that our social evils have increased, as that sensitiveness to them has increased. Long before the war it had come to be believed that society was on the sick-list, needing drastic treatment, if not a major operation. We had become painfully conscious of certain social "evils," and our attention was fixed more and more upon certain loudly advertised "cures" for them. Among these evils were the unequal distribution of wealth and opportunity, the constant clashes between labor and capital, the unjust exclusion of women from political and economic privileges, the alcohol evil, social diseases, poverty,

${ }^{1}$ Whoever is pessimistically inclined about social progress should read that excellent little book by Edward A. Ross, What is America, and also the book by Walter E. Weyl, The Nero Democracy, especially, chapter xrv, and the recent work of Nicholas Murray Butler, Is America Worth Saving? 
crime, and the falling birth-rate. Among the proposed "cures" were the further extension of Democracy, Socialism, Syndicalism, Votes for Women, National Prohibition, Coöperation, and Industrial Democracy.

Then came the war, and at once our attention was focused upon this as the worst evil of all. That such an awful calamity could suddenly befall the world increased still further our distrust of our whole social system, and we began at once to search for some cure for this further evil, and hoped to find it in a League of Nations, international agreements, and the self-determination of peoples.

It is characteristic of our age to be peculiarly sensitive to its evils. This sickening feeling that the world is in a very bad way and needs redemption is illustrated in the book written by Alfred Russel Wallace shortly before his death, in which he bewailed the degeneracy of the times, dwelling upon the prevalence of poverty and crime, and frightful social diseases, and social injustice, in a note almost of despair. ${ }^{1}$

Certainly it is a hopeful sign that we have become so sensitive to injustice, so conscious of social evils, so intolerant of wrong-doing, so

${ }^{1}$ Social Environment and Moral Progress, chaps. viII-xit. 
repelled by the horrors of war, that our own era, which is really clean and wholesome and peaceful and righteous as compared with past periods in human history, seems to us so imperfect. Thus there is, at any rate, this element of hope in the situation that there must be some spark of divinity in the human mind, since we compare the present, not with the real past, but always with an ideal future.

The special characteristic of our time is, therefore, not the presence of evils, of which, to be sure, there are quite enough, but the peculiar consciousness of them and the resolute will to cure them - a will so persistent and so determined that it is certain that the twentieth century will see profound changes in our social order. But it does not follow necessarily that these changes will be beneficial. They will be experimental, and the prophet of social catastrophe may well question whether the radical experiments which it is proposed to make in social reform may not prove to be destructive of the civilization which we have. This is the first time in history that man has consciously and with determined purpose entered upon the task of directing his own fortunes. Hitherto he has been a puppet in the hands of cosmic forces - evolution, climate, the 
struggle for existence; the industrial revolution wrought by mechanical inventions and by the discovery of coal, iron, and petroleum; and, finally, the retroactive influences of the American and Pacific frontiers. Now the period of conscious control has come.

But is this conscious control to be intelligent control, or is it to be the kind which the newly rich suddenly acquire over their material surroundings? So far as we can see at present, the era of intelligent control lies far in the future, and the control which is to mark the twentieth century will spring from an impulsive idealism characterized by a keen sensitiveness to our present social evils, rather than by a comprehensive grasp of the whole situation. We are to enter upon the deliberate attempt at social reconstruction, but with a kind of adolescent impetuousness, and a fatuous, almost fanatical, faith in the magic of certain symbols to cure social evils. This is, no doubt, a necessary stage in the progress of social control, but it is not without its dangers. We have gained the power to remodel our social order; have we gained the necessary poise, the scientific, historical, and psychological knowledge that will make our meddling safe? 
There is, in all the discussion of evils and the cures for them, a singular disregard of the psychological and historical factors of the situation, and a strange forgetfulness of the fact that however important social and political readjustments may be, the world cannot be made over as long as the human material - the minds and bodies of men - remains the same. The relatively greater importance of education, of physical and mental health, of racial integrity, of universal intelligence and self-control is overlooked.

Our efforts at reconstruction will, therefore, probably be impulsive and childlike. They will be directed to the obvious and superficial evils of our age rather than to the deeper and more serious ones. They will be directed against industrial rather than moral and racial evils. When we think of the graver aspects of the social situation, when we look beneath the idealism, the faith, the charity, the hopefulness of the age, to its deeper troubles - such, for instance, as the declining birth-rate, the excessive and demoralizing wealth, the lessening sense of individual responsibility - we are still oppressed with a certain fear and dread for the future.

But all these evils may be averted. We have still to reckon with the creative power of the 
human mind. We have still to reckon with the possibility of the organization of intelligence. Despite the dangers of decadence, this is by no means a decadent age; it is quite the opposite. It is an age of unbounded energy and intellectual vigor. If we can find some way of redirecting this tide of energy into channels which lead directly to human welfare; if we can discover some means of giving full expression to deep human instincts and interests, and sublimate and redirect those which are harmful; if we can discover a social order based on human needs and human nature and not merely on commercial, industrial, and economic motives, a social order in which there shall be higher values than work and wages, comforts and luxuries, and frantic demands for more and more rights and liberties, - why, then progress rather than decay may lie ahead of us in this twentieth century. The human mind is indomitable when it essays to navigate the air, to raise monster armies, to communicate by wireless, to connect two oceans, to master contagious diseases. Why should it falter at the problem of human welfare?

Philosophers have been defined as those who can think in terms of the whole. This is just what we need now, social philosophers who can think 
in terms of the whole of society; not merely in terms of political ascendancy and commercial and industrial expansion - but in terms of life.

Projects for saving society from the dangers which now threaten it there are many. In the following chapters $\mathrm{I}$ wish to refer to some of these, not in the usual attitude of the advocate or critic, who has in mind the solution only of certain economic problems of the day, but rather in the attitude of the student of ultimate values. I am particularly anxious to know whether the reconstructive movements of the day have been planned to make men better, or whether their aim is the more humble one of Francis Bacon to make imperfect men comfortable; and if the latter should prove to be their aim, I am interested to know whether they will work. In other words, I am concerned not so much with the ultimate outcome of a philosophy of peace and plenty, as with its psychological foundations. 


\section{CHAPTER II}

\section{PSYCHOLOGICAL FACTORS IN SOCIAL}

RECONSTRUCTION

JO one is much interested in social recon1 struction in the abstract, but we are all greatly interested in the concrete forms which it is now taking, such as Socialism, of which there are countless varieties both evolutionary and revolutionary, Syndicalism, Communism, Bolshevism, Anarchism, the I.W.W., the NonPartisan League, Social Democracy, Collectivism, Coöperation, Industrial Democracy, Votes for Women, Feminism, Prohibition, the Single Tax, the League of Nations, etc.

To the casual student of social problems these plans for reform seem like many different and, to some extent, rival movements - some of them Utopian, some of them full of promise for social welfare, and nearly all of them characterized by deep sincerity and zeal for human improvement. To such a student it has not, perhaps, occurred that these movements are all very much alike; that a common philosophy of life lies at the basis of all of them; that they are all directed 
against certain well-known evils in our present social order; and that the social ideals toward which they all are striving are very much the same.

It is no part of my purpose in these pages to study any of these movements individually. There are tons of books that do this. Neither is it my primary purpose here to inquire into the philosophy of life which binds these movements together, a philosophy quite clear, definite, and attractive. Incidentally I shall refer to this philosophy of life, this, "economic rationalism," as it has been called, this essentially Baconian conception of the world, this endless release of human desires with its never-ceasing effort to satisfy them, and compare it with totally other and different conceptions of life and society.

But for the present it is not the philosophy of these movements that I am interested in, but their psychology. I am interested in inquiring to what extent the new social order which is typified in these movements has a rational basis in human nature; whether it is a social order in which human beings, mentally constituted as they are, will be able to live and work. I am interested in studying social reconstruction, not from the economic point of view, but from the psychological and psychogenetic standpoint. 


\section{PSYCHOLOGICAL FACTORS}

In practice our current social-reconstruction movements start with the presence of certain evils in society which it is desirable to cure. Very commonly it is assumed that the presence of these evils is due, not to any moral, mental, or physical defects in the individuals which make up society; nor to any defects in our racial stocks; nor to any defects in our system of education, our schools or our teachers; nor to any defects in our public press or our philosophy of life; but wholly, or at least in large part, to our political and economic institutions. It is proposed, therefore, to change these institutions or to modify them in such a way that the aforesaid evils shall be absent, or, more simply still, to make laws abolishing these evils. ${ }^{1}$

The evils are principally the following: the unequal distribution of wealth, the unequal distribution of opportunity, clashes between labor and capital, the unjust exclusion of women from economic and political privileges, wars between states (very little is said of civil war or internal

1 "Nothing is more foolish than to imagine that all the defects in people flow from defects in society and will vanish if only we organize society on right lines. Some of the traits developed in man a hundred centuries ago make trouble now and will have to be allawed for arons hence." (E. A. Ross, Principles of Sociolugy, cliap. Iv, on "Original Social Forces.") 
disorder), the alcohol evil, and the presence everywhere of social and economic injustice in our midst. Autocracy, special privilege, poverty, etc., are corollaries of the above evils.

The programme, therefore, of practically every reconstruction movement includes: The abolition of war between states, the more complete democratization and socialization of governments, the socialization and democratization of industries, the harmonization of capital and labor (or the abolition of capitalism), the greater equalization of wealth and opportunity, the complete emancipation of women both political and industrial, the suppression of alcohol, and the securing of social and economic justice.

Certainly if this ambitious plan could be realized, we should seem to have all the conditions for the social millennium. It has probably occurred to few to doubt that if these things could be realized, our troubles would be over. To still fewer, perhaps, has it occurred to ask what would happen to a people whose troubles were over. A discussion of this question would involve us in the problem of the conditions of social progress and the causes of social stagnation. Omitting here any reference to this subtile point, we may observe that the value of this 
programme would depend upon the interpretation of the phrase "social justice." If social justice is included in our plans for reconstruction, and if social justice is understood in its widest sense, for instance in the Platonic sense, ${ }^{1}$ surely the programme would be a perfect one.

In practice, however, our reconstruction movements have a much narrower aim, especial emphasis being laid upon the more equal distribution of wealth and opportunity, the abolition of poverty, the securing of an adequate scale of living for all classes, the political and economic emancipation of women, and the abolition of alcohol. The new world as we usually picture it will be perfect in proportion as it realizes these ends. We have thus a kind of Apostles' Creed of social reconstruction, often held as persistently and dogmatically as was ever re-

1 Justice in the Platonic sense is a situation in which every part of man's personality is developed to its normal function, but at the expense of no other part of his personality. Social justice is a situation in which every person has and does that which belongs to him to have and to do, and does not have or do that which belongs to another to have or to do. Specifically this involves a situation in which each generation shall not have or do anything which belongs to the next following generations to have or to do. We should certainly have here the highest test of reconstruction movenents. There might prove to be a startling discrepancy between this notion of social justice and the prevailing use of that term to mean a more equal distribution of wealth and opportunity. 
ligious crecd. The faith in it is naive to the point of childlike confidence. One would suppose that the doubt has simply never arisen in our minds that all of our fundamental social problems will be solved as soon as we get wars between nations stopped, property more equitably distributed, capital and labor harmonized, opportunity equalized, women enfranchised, and alcohol abolished.

And this is not merely the paper programme of idealists, nor a dreamy, philosophical picture of an ideal social state like Plato's "Republic" or Saint Augustine's "City of God" or More's "Utopia," but the actual working plans of a great number of social reforms of intense vitality and unlimited enthusiasm. And even this does not indicate the strength of this movement. It is in the air; it is in the spirit of the age; it is in the unquestioned drift of events. So unbounded is our faith in the supreme value of this programme that to attain it we believe that the price even of the late awful war was not too great to pay. Even in the untoward event of the victory of the Central Powers, all these social aims would, as many believe, eventually have been realized, because of the powerful social forces moving in this direction throughout the world. 
Neither is this programme to be criticized because it is Utopian. Too many Utopias are being realized in this marvelous age to borrow any trouble on that account. Nor is it my purpose here to criticize it on the ground that the ends set forth are not the supreme ends which society should try to realize or that they are not the things in which we are most deficient. It might, to be sure, be maintained that the things here set forth as social ideals, while they are of great value, are not the things of supreme value nor the things which the world at the present time most lacks, nor the things which should become of prime importance in our social reconstruction. Conceivably, it might be argued that there never was a time in the world's history when there was so little real suffering from want of the necessities of life, nor so many enjoyments and comforts by every class in the community, nor so much freedom and opportunity, nor so little intemperance, nor so many privileges, opportunities, and rights for women. It might perhaps be reasoned further that while we are still deficient in these things, we are vastly more deficient in other, no less vital, or still more vital things, such for instance as art, morals, manners, culture, brotherhood and coöperation, re- 
ligion, temperance in the sense of moderation, thrift, health, racial integrity, organized intelligence, a rational system of education, an integrated community:life, social stability, conservation of food, soils and forests, and conservation of racial values. I can well imagine that the whole programme of social reconstruction at the present time might be open to such criticism, were one disposed to view it from this angle; but all this is not the drift of my present criticism of our current plans for social reform. What I am asking now is whether the kind of social order which the above proposals offer is a social order that men want at all. We are trying desperately hard to get it. Will it be something that we want when we get it? In other words, has this programme of social reform a psychological basis? Will it meet our human needs? Does it conform to human nature?

The trouble is that all of these social reorganization plans have been worked out too largely from the political and economic standpoint rather than from the psychological standpoint. Any workable plan for social reconstruction must be based on an accurate knowledge of the human units which are to constitute the new society. No social system has any chance of success 
which is not planned with immediate reference to the material of which society is composed. A bridge-builder has to give quite as much attention to the strength of material as he has to the use and beauty of his structure. Human beings are the material of our social order; but our theoretical social-reorganization schemes are often planned simply to accomplish certain ends or banish certain evils, with very little consideration of the strength or the weakness of the material with which they have to build.

The gist of the matter is simply this: We are living in an economic and political age and our minds are obsessed by economic and political ideas. When we turn to the subject of social reconstruction, we are apt to take into account only economic and political relations, and, in spite of many warnings to the contrary, we are apt to neglect the human motive, the character of the units of which society is composed. In other words, we disregard the vital and allimportant psychological factor. Our theoretical social structures may, therefore, be just aircastles, in which actual human beings could not live. Our social-reconstruction schemes may be of little value until they have been revised in the light of the teachings of psychology, history, and 
anthropology. This is so obvious that it is hard to understand how the psychological and historical factors could be so neglected in these studies. 1

It may be that our current reconstruction plans are designed for ideal rather than for practical human beings. It may be that they depend too often upon the obsolescent hedonistic and utilitarian philosophy of Bentham and the happiness-economy of Lester F. Ward. It may be that they assume too readily that mankind is naturally peace-loving and labor-loving, needing only justice and opportunity, and that the road to happiness is through science, invention, and the increase of wealth to the end that all men may come into their rightful inheritance, this rightful inheritance being an adequate and comfortable scale of living. Consequently it may be that they are too ready to see in increased pro-

1 This applies to the great current of thought on the subject of social reconstruction as it is reflected in the movements of the day. Notable exceptions there are, of course, many among books of the more thoughtful class such as Graham Wallas's The Great Society, and Human Nature in Politics; Walter Lippman's A Preface to Politics; Wesley C. Mitchell's "Human Behavior and Economics," Quarterly Journal of Economics, vol. 29, pp. 1-47; Helen Marot's The Creative Impulse in Indusiry; F. W. Taussig's Inventors and Money-Makers; W. Trotter's Instincts of the Herd in Peace and War; W. E. Hocking's Human Nature and its Remaking; and other books mentioned below. 
duction of wealth and its equitable distribution a solution of the social problem. It is significant, too, that this increased production is always quantitatively, not qualitatively, considered.

Our social-reform movements seem to have a somewhat romantic character. They represent restless endeavors to realize certain ideas which stand as symbols of our age for ultimate desired ends - such as wealth, liberty, opportunity, equality, and peace. The agitations for these things have a dramatic character which perfectly typifies the action of the human mind; but it remains an open question whether that form of social organization by which it is proposed to realize these ideas would appeal strongly to human nature. Just as the economic interpretation of history is giving way to the synthetic and psychological interpretation, so we are coming to see that social reconstruction must be conceived in its larger psychological aspects. If there is to be a new social order, it must be more than an order in which certain evils, such as war and poverty and inequality, are absent. It must be an order in which fundamental human instincts and interests shall be satisfied. It must be an order in which human beings can live. The attention of our social re- 
formers will have to be centered less upon wealth and more upon life.

The World War and still more the actual behavior of men since the war have opened our eyes to the almost infinite complexity of the social problem, because of the infinite complexity of human motives, human passions, instincts, and interests. Just recently a mass of facts in social, dynamic, and behaviorist psychology has become available and made our current schemes of reconstruction very visionary. Even without a knowledge of the writings of Carleton $\mathrm{H}$. Parker, Thorndike, Ross, McDougall, Thorstein Veblen, Watson, Freud, Cannon, and Ordway Tead, the spectacle of human behavior, as it was exhibited on the political and diplomatic battle-field of Europe after the armistice was signed, would show that any plans for the reconstruction of society on purely economic lines will not work in practice. If by eugenic selection or by education a race of men could be produced which would live contentedly in such a society, it is questionable whether it would be worth while.

Our current reconstruction plans proceed on the general assumption that eight hours of wellpaid work (or possibly six, or even four), eight hours of leisure for recreation and self-improve- 
ment, and eight hours for sleep are what men want; and that when these are provided for all, and when all shall be given an equal opportunity, and when all shall do their share of the work, and when all shall have an equal voice in public affairs, then all will be happy, peaceful, docile, and contented, and social unrest will be a thing of the past. And if the disquieting question does still arise in anybody's mind whether man will behave in this docile fashion when work and leisure and sleep and adequate wages are provided, one class of romancers say that he will do so provided all access to alcoholic liquors is forbidden him; another that he will do so provided his wife and sisters have the right to vote; another that he will do so provided the reins of government are completely in his own hands; another that he will do so provided there is communal ownership of land and capital that is, Democracy, Votes for Women, Prohibition, Socialism are the magic wands which are to banish unrest from the world.

Every student of race psychology knows how life is determined by a great mass of inherited instincts, interests, and passions. ${ }^{1} \mathrm{Few}$ question

1 I refer to biological inheritance; but if any one wishes to make the claim that the inlieritance of these interests is social or cultural 
the fact that the political and economic inequalities of the present must be corrected, but they can only be corrected in a social order which shall meet the minimum demands of the mass of human instincts and interests that determine life, and a social order which shall have a degree of permanence and stability that shall not sacrifice the political and economic justice of the next generation to that of this one.

The following quotation from an article by Carleton H. Parker will illustrate the close dependence which must exist between social reconstruction and psychological analysis:

We economists speculate little on human motives. We are not curious about the great basis of fact which dynamic and behavioristic psychology has gathered to illustrate the instinct stimulus to human activity. Most of us are not interested to think of what a psychologically full or satisfying life is. We are not curious to know that a great school of behavior analysis called the Freudian has been built around the human instincts. Our economic literature shows that we are but rarely curious to know whether industrialism is suited to man's inherited nature, or what man in turn will do to our rules of economic conduct in case these rules are repressive. The mo-

- this has very little bearing on the argument to follow. Such social inheritance is very persistent and can be changed slowly by education. 
tives to economic activity which have done the major service in orthodox economic texts and teachings have been either the vague middle-class virtues of thrift, justice, and solvency; or the equally vague moral sentiments of "striving for the welfare of others," "desire for the larger self," "desire to equip one's self wcll"; or, lastly, that labor-saving deduction that man is stimulated in all things economic by his desire to satisfy his wants with the smallest possible effort. All this gentle parody in motive theorizing continued contemporaneously with the output of the rich literature of social and behavioristic psychology which was almost entirely addressed to this very problem of human motives in modern economic society. Noteworthy exceptions are the remarkable serics of Veblen books, the articles and criticisms by Mitchell, Fisher, and Patten, and the significant small book by Taussig entitled "Inventors and Money-Makers." It is to this complementary field of psychology that the economists must turn for a vitalization of their basic hypotheses. There awaits them a bewildering array of studies of the motives, emotions, and folk ways of our pecuniary civilization. Generalizations and experiment statistics abound ready-made for any structure of economic criticism. The human motives are isolated, described, compared. Business confidence, the release of work energy, advertising appeal, market vagaries, the basis of value computations, decay of workmanship, the labor unrest, decline in the thrift habit, are the subjects treated.... The stabilizing of the science of psychology and the vogue among economists of the scientific method will not allow these psychological findings to be shouldered out by the careless a-priori deductions touching human nature which still dominate our 
orthodox texts. The confusion and metaphysical propensities of our economic theory, our neglect of the consequences of child labor, our lax interest in national vitality and health, the unusableness of our theories of labor unrest and of labor efficiency, our careless reception of problems of population, eugenics, sex, and birth control; our ignorance of the relation of industry to crime, industry to feeble-mindedness, industry to functional insanity, industry to education; and our astounding indifference to the field of economic consumption - all this delinquency can be traced back to our refusal to see that economics is social economics, and that a full knowledge of man, his instincts, his power of habit acquisition, his psychological demands were an absolute prerequisite to clear and purposeful thinking on our industrial civilization. McDougall, the Oxford social psychologist, said in direct point: "Political economy suffered hardly less from the crude nature of the psychological assumption from which it professed to deduce the explanations of its facts, and its prescriptions for economic legislation. It would be a libel not altogether devoid of truth to say that the classical political economy was a tissue of false conclusions drawn from false psychological assumptions." 1

So far as the science of economics is concerned, Professor Parker was no doubt speaking of a generation already past. Our present-day economists are fully alive to the vital connection between their science and the science of human

1 Carleton H. Parker, "Motives in Economic Life," Proceedings, American Economic Association, 3oth Meeting, December, I917, pp. 2I4, 215. 
conduct, but it is quite otherwise as regards the economic theories which are presupposed in the popular reconstruction plans of the time. It is a very distinct philosophy of life upon which they rest; but it is a purely speculative, a-priori philosophy, which, although highly optimistic and captivating, lacks basis in concrete reality.

It sounds very well to reason, somewhat after the manner of Mr. Lester F. Ward, as follows: The end to be sought in human society is the maximization of pleasure and the minimization of pain. The pain-economy under which the lower animals live is no longer necessary for man, who, under the guidance of science and the mechanic arts and by means of the economic surplus, may. now enter upon a pleasure-economy. Every one, including the hitherto exploited classes, exploited not because of lack of intelligent capacity, but for lack of opportunity, is entitled to and can attain to an adequate and comfortable scale of living, providing not only the necessities of life, but a reasonable number of comforts and luxuries. There is not, however, at the present time, wealth enough in the world, even if it were equally distributed, to provide such a scale of living for all. It is therefore necessary to increase still further the wealth of the 


\section{4

world. To this end let all extant knowledge be freely imparted to all people. This will result in a vastly increased number of effective men of special ability, for ability depends upon opportunity more than upon birth. This again will bring about an advance in science and invention, which will effect a great increase in wealth and opportunity, and these being equally distributed will promote universal comfort and happiness. In this society of the future, productive labor will be universal, for when the stigma be removed from labor, labor itself will bring the greatest happiness to mankind, since pleasure is found in the exercise of normal function. ${ }^{1}$

This sounds very familiar to us. To many, indeed, it seems, no doubt, to be the very gospel which it was the mission of the nineteenth century to proclaim and of the twentieth century to. realize in our new social order. If this gospel fail, hope is lost. But as a matter of fact almost every article in this creed is open to question. It was the World War itself which first shook our faith in this modern gospel of a pleasure-economy. It has been the behavior of the world since the war that has brought further discredit upon it.

3 Compare Lester F. Ward, Applied Sociology, part i, chap. in ff. 
Neither biology nor psychology has been able to establish a foundation for the hedonistic philosophy upon which this creed of the pleasure-economists could stand. We have discovered that there are higher values than the maximization of pleasure and the minimization of pain. We have discovered that there are higher conceptions of education than the diffusion of knowledge. We have discovered that in social reconstruction what we have to deal with is not certain abstract concepts such as pleasure, happiness, leisure, wealth, labor, and opportunity, but an immense number of intensely human men and women actuated by powerful instincts and passions. We have discovered that what men really want is life and self-realization, and that self-realization involves a network of vital social relations and the functioning of a great mass of powerful human instincts and interests.

When the older writers talked about the escape of mankind from the old pain-economy to a pleasure-economy, it was probable that what they had in mind was the vindication of man in his struggle for self-realization against the old theological notion of ascetic repression of natural impulses. Thus far they represented a great step forward. But every statement of this 
emancipation in terms of a pain and pleasure economy lacked a sound psychological and sociological foundation. It should never be forgotten that the value of life is not lessened by the presence of tragic elements. In the following pages I shall make some attempt to discover in what self-realization actually consists, whether in work or play, whether in pleasure or the fulfillment of normal function; and if in the latter, whether normal function consists in work, as $\mathrm{Mr}$. Ward thought, or in the life of instinctive activities. Here I am only trying to point out the failure of our current reconstruction plans to take account of psychological motives. I am not here attempting to write constructively on social reorganization, but only to show that whoever will do so must from now on take careful and detailed account of human instincts, impulses, and interests.

The trouble is that the terms "social welfare" and "the public good" are not usually carefully defined. Some general phrase, such as "the full, free, and abundant life," or "the satisfaction of our organic cravings," usually suffices. But it is just this need of finding out what life really is that makes a psychologicalviewpoint necessary. 
Here, I think, we shall find it hard to improve upon Aristotle's conception of the highest good as the activity of our powers. Aristotle, from his Greek intellectualistic viewpoint, considered thought as the highest and best form of activity. Surely he was nearly right here, but among our energetic northern races and with our emphasis upon Will and Vital Impulse, we interpret it to mean something like initiative, enterprise, achievement, adventure, organization, invention, scientific discovery. Our bent is in these directions, so that our problem becomes one of finding a social order in which the greatest number of individuals in the present and in future generations may have a fair field for their activities - a fair field for thought, action, control, and achievement. But such a fair field for activity for all members of the group, and for successive generations, involves an integrated and stable social life, and that involves a high degree of self-control and social discipline. The problem of social reconstruction, if such a thing be attempted, becomes, therefore, an extremely complicated one, requiring a profound insight into the instincts and motives of the human units of which society is composed, and at the same time an accuratc historical knowledge of social 
institutions and the conditions upon which social integration depends.

In our popular social-reconstruction movements we pay too little attention to any of these fundamental things. We are concerned, rather, in a vaguely sympathetic way, in releasing human desires and then in devising means of satisfying them. We are supremely interested in providing for everybody an adequate scale of living, and then in intensifying our already feverish industrial system to the end of satisfying these desires. We have little interest in studying into the actual instinctive needs of men, into what is required to enable them to fulfill their normal function, while our attitude toward discipline is almost wholly negative, forgetting the conditions which make an integrated and abiding social life possible, but reveling rather in a kind of sentimental adoration of liberty and equality. We seem to forget that there are coming generations whose desires are to be satisfied and for whom a field for achievement is to be left.

We are engaged in the relatively superficial task of devising some political or social machinery which shall distribute more evenly certain material goods, or in finding some new form of social or industrial organization which has 
scarcely any further aim than the increased production of such goods and their just distribution. We see that people desire certain things and, moved by an unbounded sympathy, we propose some plan of social reconstruction which shall satisfy these desires. ${ }^{1}$ In this we carry over the theory of economic value into the field of social and ethical values. It is not, indeed, mere wealth that we prize so highly - although in practice this is the dominant idea - but wealth and opportunity. By opportunity, however, we mean nothing more than opportunity for individual material and spiritual expansion, opportunity for leisure, for culture, for recreation, for entertainment, for art.

We are wholly engrossed, therefore, in finding some kind of machinery which shall insure to everybody (usually everybody in this generation) these satisfactions. Our mouths are full of phrases which are names for the several parts of this so-

1 For an extreme statement of this view that social organization should tend toward the maximum production of all that may be useful or agreeable to man with the minimum of effort, sec the pamphlet by G. Barnich entitled Principes de Politique Positive après Solvay. It is beyond understanding how psychological and evolutionary facts are left out of consideration in works of this kind. On the fundamental place of effort in the mental life of man, compare the article by John J. B. Morgan, entitled " $\Delta$ n Analysis of Effort," The Psychological Review, vol. 27, no. 2, March, 1920. 
cial and industrial machinery, such as industrial democracy, collective bargaining, coöperation, profit-sharing, social insurance, a minimum wage, an eight-hour day, better housing, industrial education, terminal markets, trades unions, shop councils, and so on through the familiar list.

All these proposals are excellent; that is, they are excellent within the narrow circle of our industrialized and commercialized thinking. But when we begin to talk about social reconstruction these categories are no longer sufficient. I anticipate that this method of social reconstruction will, in the near future, give place to a more psychological, historical, and psychogenetic method. We shall turn our thought to evolution and human nature, and we shall realize that reconstruction, if it is to result in a stable social structure that shall insure happiness, not to certain classes for a few years, but to all of us and to our children and to their children, will require long and patient scientific study of history, psychology, and human institutions.

The science of psychology has in recent years been most helpfully enriched by the study of the original elements in the nature of man. The at- 
tention of psychologists is no longer centered on pain and pleasure, on sensation, or on thought, but rather on instinct, on the conative impulse, on the wish pulse, the pulse of energy. ${ }^{1}$ It is the vital impulse, the conative tendencies, the will to live, the will to power - it is life itself which now holds the center of interest in the $s$ udy of mental being. These are the ultimate facts of mental life not to be referred to any simpler elements. $^{2}$

1 Compare S. N. Patten, "The Divided Self," Monist, April, 1919, p. 223 .

2 "The instinctive impulses determine the ends of all activities and supply the driving power by which all mental activities are sustained; and all the complex intellectual apparatus of the most highly developed mind is but a means toward these ends, is but the instrument by which these impulses seek their satisfactions, while pleasure and pain do but serve to guide them in their choice of the means.

". . These impulses are the mental forces that maintain and shape all the life of individuals and societies, and in them we are confronted with the central mystery of life and mind and will.

"... We may perhaps describe all living things as expressions or embodiments of what we may vaguely name, with Schopenhauer, will, or, with Bergson, the vital impulsion (l'elan vital), or, more simply, life; and each specifically directed conative tendency we may regard as a differentiation of this fundamental will-to-live, conditioned by a conative disposition. At the standpoint of empirical science, we must accept these conative dispositions as ultimate facts, not capable of being analyzed or of being explained by being shown to be instances of any wider, more fundamental notion." (William McDougall, An Introduction to Social Psychology, pp. 44 and $j 61$. 
The soul of man is found in the capacity to do, in "the form of a natural body endowed with the capacity for life," in the Aristotelian phrase." Longing, striving, aspiration are the deep and significant things in human nature. ${ }^{2}$ The essential and basal fact in human life and human society is the will to live, the will to power, the inner disposition. Man is a striving animal. $\mathrm{He}$ always strives for something; but social psychology must fix its attention less upon the things striven for and more upon the striving itself.

Happiness is not found in the satisfaction of our desires, but in the activity of our powers; not in the means of gratifying our tastes, but in the gratification of them; not in the experiencing of pleasure, but in the harmonious exercise of human faculties. Hence it follows that an ideal social order is not one which will best furnish its people with the means of satisfying their desires, but one that will best provide a field for their activities.

Particularly in our modern times has it come to be true that mental life takes more and more the form of striving. It seems as if a new pulse of cosmic energy has flowed into the souls of men.

1 Compare E. B. Holt, The Freudian Wish, chap. I.

2 Compare C. G. Jung, The Theory of Psychoanalysis, p. $40 \mathrm{ff}$. 


\section{PSYCHOLOGICAL FACTORS}

The modern man is tremendously virile and forceful. Outwardly there are no signs of human decadence. ${ }^{1}$

Professor George Plimpton Adams in his recent book, "Idealism and the Modern Age," 2 has brought into remarkably clear relief the characteristics of the times in which we live. The ancients, he says, looked without toward an objective ideal order which they wished to appro-

1 This by no means indicates a situation of biological stability or biological fitness on the part of our western races. It means only that the human mechanism now displays an immense amount of kinetic energy. It is a masculine age in which we live, an expansive, centrifugal age, an age of great energy and endeavor. Even our churches have become no longer bodies of worship and prayer, but societies of Christian endeavor. It is not an age of calm and rest and conservation of forces.

Statistics show that the annual per capita consumption of sugar in the United States has increased from thirty-five pounds in I 866 to ninety-two pounds in 1919 , the total consumption being 4,500 ,$\infty 00$ tons. Sugar is a food that is quickly converted into available energy. One cannot but wonder whether this craving for sugar does not indicate that we are living or beginning to live a kind of handto-mouth existence, expending an abnormal amount of energy and demanding quick and expensive means of supply. The remarkable increase in the consumption of coffee, tea, and tobacco, and the craving for alcohol strengthen this suggestion. The abandon with which our western children play, as compared with children of the Orient, the impetuousness of our devotion to baseball, football, and other athletics, the extravagance of our dancing - all this suggests that these phenomena may not after all be an index of life and vitality, but of mere nervousness - may indeed indicate a lack of real life and real vitality.

2 Page $79 \mathrm{ff}$. 
priate or possess. They did not seek to make their ideal world. They sought to participate in objective, significant structures which were given to men to know, to contemplate, and to worship. But now in our modern democratic world all this is changed. The modern man wishes to create his own world. Activity, control, achievement have superseded contemplation and worship. The significance of things now lies not in any absolute value which they have, but in the response and success which they have offered to man's endeavors. "The life and thought of men grow, indeed, out of attitudes and experiences in which not contemplation but activity, not intelligence but will and feeling, not æsthetic and philosophic theoria but ethical striving and emotional aspiration express man's dominant interests." 1

1 Compare the following quotation from Wesley C. Mitchell:

"'There can be no question,' wrote a distinguished psychologist in 1909 , 'that the lack of practical recognition of psychology by the workers in the social sciences has been in the main due to its deficiencies. ... The department of psychology that is of primary importance for the social sciences is that which deals with the springs of human action, the impulses and motives that sustain mental and bodily activity and regulate conduct; and this, of all the departments of psychology, is the one that has remained in the most backward state, in which the greatest obscurity, vagueness, and confusion still reign.'

"Happily, the preceding reviews justify the belief that this situ- 
The overthrow of psychological hedonism gives an entirely new cast to our plans for social reconstruction. Practically all of these plans rest upon the tacit assumption that that socicty will be best which shall best furnish a means of satisfying human desires, and these desires are economically interpreted as desires for wealth, for material benefits, for an adequate scale of living. Hence the necessity for increasing the production of wealth; hence the need of a more equal distribution of material goods. With the passing of the old hedonistic philosophy and the

ation is changing for the better. For Parmelec and Thorndike, Wallas, Veblen, and Lippmann, cren in a mcasure Sombart and Walling, are endeavoring to cxplain how men act. Studies of tropisms, reflexes, instincts, and intelligence; of the relations between an individual's original and acquired capacitics; of the cultural rôles played by racial endowments and social institutions are vastly more significant for economics than classifications of conscious states, investigations of the special scnses, and disquisitions on the relations between soul and body.

"It was because hedonism offered a theory of how men act that it exercised so potent an influence upon economics. It is bccause they are developing a sounder type of functional psychology that we may hope both to profit by and to share in the work of contemporary psychologists. But in embracing this ofportunity economics will assume a new character. It will ccasc to be a system of pecuniary logic, a mechanical study of static cquilibria under nonexistent conditions, and become a science of human beharior." (Weslcy C. Mitchell, "Human Behavior and Economics," Quartcrly Journal of Economics, vol. 29, pp. 46, 47. Quotation is from McDuugall, .In Introduction to Social Psychology, pp. 2, 3.) 
coming of the new dynamic conception of life this notion of society and of social welfare must be changed. ${ }^{1}$

Every vigorous man needs some kind of contest, some sense of resistance overcome, in 'order to feel that he is exercising his faculties. Under the influence of economics, a theory has grown up that what men desire is wealth; this theory has tended to verify itself, because people's actions are more often determined by what they think they desire than by what they really desire. The less active members of a community often do in fact desire wealth, since it enables them to gratify a taste for passive enjoyment, and to secure respect without exertion. But the energetic men who make great fortunes seldom desire the actual money: they desire the sense of power through a contest, and the joy of successful activity. ${ }^{2}$

Society must be so organized as to provide directly for the exercise of man's inherent and instinctive faculties. That there must be an adequate scale of living and a more equitable distribution of goods is of course taken for granted; but these are too often considered as ends in themselves, as if society should be reorganized

1 The problem of the motivation of human conduct appears not to have been well thought through either by our economists or by our social reformers. B. M. Anderson's book on Social Values, especially chapter $\mathbf{x}$, should be read by all; also Professor W. G. Everett's book on Moral Values.

2 Bertrand Russell, Why Men Fight, p. 100. 
with this particular end in view. Indeed it appears that our social-reform movements are often planned solely with reference to this end: namely, to provide peace and plenty and an adequate scale of material comforts. What men desire, it is reasoned, is peace and plenty and leisure and work and opportunity.

It may be replied that many of the social-reconstruction movements of our time, while they do lay great stress upon peace and plenty and work and adequate comforts, expressly stipulate that there shall be opportunity for self-improvement and spiritual development, thus apparently emphasizing the very kind of activity which modern psychology declares for. But the trouble is that in these platforms opportunity is a mere phrase. It seems to be assumed that, given peace and plenty and leisure, something vaguely called spiritual development will follow. Biologists will tell us that what will probably follow will be degeneration, or, at the best, social stagnation. ${ }^{1}$

${ }^{1}$ It is interesting to read McDougall's account of the peaceful and warlike tribes of Bornco whom he has personally studied. "It might be supposed," he says, "that the peaceful coastwise people would be found to be superior in moral qualities to their more warlike neighbors; but the contrary is the case. In almost all respects the advantage lies with the warlike tribes. Their houses are better 
This does not mean that we are to abate our efforts to establish a society free from that form of social suicide such as the modern war has become. It means only that the scientific reorganization of society is an affair of infinitely greater difficulty than we at present realize. It will not do to say that the instinct of pugnacity is evil and that we will organize our society so that this evil will be absent, by means, for instance, of arbitration treaties, peace societies, and a League of Nations. ${ }^{1}$ If by these means we could perhaps abolish war between states or lessen its frequency, there are other forms of war known to history. Indeed, history records the fact that

built, larger, and cleaner; their domestic morality is superior; they are physically stronger, are braver, and physically and mentally more active, and in general are more trustworthy. But, above all, their social organization is firmer and more efficient, because their respect for and obedience to their chiefs, and their loyalty to their community, are much greater; each man identifies himself with the whole community and accepts and loyally performs the social dutiss laid upon him. And the moderately warlike tribes occupying the intermediate regions stand midway between them and the people of the coast as regards these moral qualities." (McDougall, An Introduction to Social Psychology, p. 289.)

1 References to the League of Nations in several places in this book should not be interpreted to indicate any hostility to the plan. I am heartily ashamed of the selfish and unenviable position taken by our Senate on this matter. As everybody that I have talked to on the subject seems to hold the same views, one cannot help wondering how much public opinion our boisterous Senators who opposed the League had behind them. 


\section{PSYCHOLOGICAL FACTORS}

civil wars have been quite as great a menace to human progress as wars between nations, and even apart from civil war, internal dissensions and disorders as a result of innate pugnacity are always threatening social stability. McDougall calls attention to the fact that when a pugnacious people is brought under a strict system of legality, litigiousness greatly increases.' We have lately learned something of the impotence of peace societies and arbitration treaties in the face of raging human passions, all of which goes to show not the uselessness of such efforts nor the hopelessness of a League of Nations, but the absolute need of supplementing these endeavors by the application of psychological principles to social reconstruction. The instinct of pugnacity cannot be suppressed. It must be sublimated, as Professor James well knew when he proposed a substitute for war. Nor would it do to say that if men are well fed they will not fight, for history refutes this at every turn. That a virile, well-fed nation will wage a war of offense recent history shows.

In fact, we have right before our eyes at the present time a great international movement illustrating the persistence of the decp, instinc-

${ }^{2}$ McDougall, An Introduction to Social Psychology, p. 279. 
60 SOCIAL RECONSTRUCTION

tive love of some kind of physical conflict; for in spite of the democratic theory of government which is supposed to be extended to wider and wider circles of the earth, the use of violence by one class against another is openly advocated by certain of our social reformers. 


\section{CHAPTER III}

\section{PSYCHOLOGICAL FACTORS IN SOCIAL RECONSTRUCTION (continued)}

T $T$ is not my purpose here to take up the spe1 cific human instincts and impulses and attempt to catalogue them, nor to show in detail how these specific instincts and impulses fail to be provided for in our current reconstruction plans. The first has been done by many recent writers, ${ }^{1}$ and the second is beyond the scope of the present work. Neither is it worth while to wrangle over the nomenclature. ${ }^{2}$ Those who distrust the word "instinct," or bewail its lack of exact connotation, or those who deny the existence of any instincts at all, may, so far as the

1 Compare Edward L. Thorndike, "The Original Nature of Man," Educational Psychology, vol. I; William James, Principles of Psychology, vol. Ir, chap. xxiv; William McDougall, An Introduction to Social Psychology, chaps. III, Iv, v; Carleton H. Parker, "Motives in Economic Life," Proceedings, American Economic Association, 3oth Meeting, December, 1917, pp. 212-31; Ordway Tead, Instincts in Industry.

2 Compare Graham Wallas, The Great Society, chaps. II, III; F. W. Taussig, Inventors and Money-Makers, pp. 5, 6; Thorstein Veblen, The Instinct of Workmanship, Introduction; Symposium on Instinct, British Journal of Psychology, November, 1919; W. Trotter, Instincts of the IIerd in Peace and $\mathrm{W}$ ar, p. $94 \mathrm{ff}$; W. E. Hocking, Human Nature and Its Remaking, part II. 
present discussion is concerned, substitute the name most acceptable to them, such, for instance, as propensities, dispositions, rooted dispositions, predispositions, proclivities, persistent interests, Urveranlagungen, automatic impulses, original nature of man, persistent reflexes, or exceedingly stubborn forms of behavior. For brev ity I shall use the word instinct. ${ }^{1}$

It will be sufficient for my purpose to take any list of human instincts or predispositions, such as that given by Carleton $\mathrm{H}$. Parker, ${ }^{2}$ or a part of them, and we shall at once see to what extent these primal tendencies of human nature are neglected or ignored in popular social-reconstruction movements. Dominant among our instinctive proclivities not thus provided for are

1 Professor John B. Watson, in his recent book entitled Psychology from the Standpoint of a Behaviorist, limits the number of human instincts rather narrowly. Nevertheless the following quotation from his book illustrates very well the persistence and the dominance of certain human dispositions, and this is all that I need to emphasize, so far as my present argument is concerned: "Many individuals' will not give twenty-five cents for a charitable purpose, but at any charity gathering they will eagerly take one of a dozen twenty-five-cent chances on almost any object the total value of which need not be greater than the cost of a single chance. So uniform is the response to lottery schemes that they have oftentimes become national mediums for raising government funds." (Pages 3 and 4 . The italics are mine.)

2 In the work cited. Compare also the lists given by McDougall, James, and Ordway Tead. 
the instinct of constructive workmanship, curiosity and manipulation; the instinct of ownership, individual possession, acquisition, and collecting; the instinct of pugnacity; the instinct of gregariousness; the instinct of emulation and rivalry; the instinct of loyalty and devotion; the instinct of parental bent and motherly behavior; the instinct of thought, invention, and organization; the housing or settling instinct; the homing and migratory instinct; the hunting instinct, love of adventure and change; the instinct of leadership and mastery, and the love of dominion; the instinct of subordination and submission; and the instinct of display, vanity, and ostentation.

These and other instincts belong to the equipment of the individual with which he enters the arena of life. The individuals thus equipped are the material of which society is made. It is useless to say that this equipment is rusty, out of date, an inheritance of savagery, which the social reformer does not need to take into account. It represents the actual material which is to be used in social organization, and the strength and stability of the structure will depend upon the strength or weakness of the material. The undue repression of any of these instinctive tendencies 
will result in irritability, "balked disposition," 1 and that very unrest which we are trying to diminish. No doubt human nature is plastic and indefinitely modifiable, but we must remember that in the modification of human nature we have to do with ages, not with decades or even centuries. Anthropologists tell us that there has been little change in human instincts for thousands of years. ${ }^{2}$ It becomes evident, then, that in the comparatively short period of the next twenty-five, fifty, or one hundred years, social reconstructionists will have as their material human beings whose mental constitutions will be much the same as during the long record of

1 Compare Graham Wallas, The Great Society, pp. 64, 65 .

2 "Changes in the institutional structure are continually taking place in response to the altered discipline of life under changing cultural conditions, but human nature remains specifically the same." "Such limitations imposed on cultural growth by native proclivities ill suited to civilized life are sufficiently visible in several directions and in all the nations of Christendom." (Thorstein Veblen, The Instinct of Workmanship, p. 18.)

For an extreme statement of the plasticity of human nature, a theme dear to the heart of the present-day writer on social topics, see Professor Todd's Theories of Social Progress, pp. 1, 2. But it is evident that Professor Todd is not writing here of man's original nature, his native equipment of feeling, desire, impulse, but of his "totality of mind," his social self, his finished and perfected ego, the result, to a large extent, of course, of his education, and his family and social life. I am speaking of "the deeper functional demands that belong to one's racial history." 
the past. If, however, human nature is to be modified to the end of climinating undesirable traits and with the view of adaptation to a civilization whose watchwords are commercial and industrial efficiency, coöpcration, liberty, and peace, why, then, evidently it is education which must be the central thought in all our efforts rather than new political and social institutions and new laws. But relatively little is said about education in the social-reconstruction movements of the day. Although our teachers are overworked and underpaid, ${ }^{1}$ it is the under-

1 "A careful and complete survey made this year, covering the year 1917, in a Massachusetts city paying very nearly the maximum salaries for the country, discloses these facts: The cost of living in that eity increased 65 per cent during the past five years, while teachers' salaries increased II per cent. The result is that nearly all of the 318 teachers employed report a relative deficit in their pay ranging from $\$ 25$ to $\$ 280 . \ldots$ Out of 80 grade teachers in this eity, 73 are obliged to do outside work to make both ends meet; 39 do both sewing and laundry work, 5 sewing, 3 laundry work, 12 tutoring, 6 playground work; 20 board themselves or live at home. Not only do stenographers and bookkeepers receive higher salaries than many teachers, but even women day laborers are better paid. Domestic servants, even in the smaller cities, receive from $\$ \$ 7$ to $\$ \$ 5$ per week and their board. The untrained woman who does scrubbing and work by the day in the city of Springfield, Massachusetts, receives $\$ 2.12$ a day and one meal, which is nearly twice the average pay of teachers in the United States, and about equal the average salary in the enlightened State of Massachusetts. In 1917 the average freight brakeman received around $\$ 100$ a month. In the same year the average salary of 19,017 teachers in the city schools, including 388 high-school 
payment of the industrial worker that focuses our attention.

Our social reformers should go to the psychologist and ask the following question: We are attempting great and radical changes in our social and political life to cure certain crying evils. How rapidly may we expect the human mind to change to adapt itself to the new order? For it will offer a very different environment from that which has existed hitherto, involving as it may, perhaps, the substitution of an industrial for a political society; the substitution of internationalism for nationalism; possibly the abolition of the whole capitalistic system; a complete and radical change in the position of women; the

teachers, was less than $\$ 700$ a year. The elevator girls in one of the smaller New York hotels receive $\$ 60$ a month and one meal; the telephone operator is paid $\$ 70$ with one meal. I know a graduate of one of the best New England colleges, with two years' experience, who is paid for teaching in a high school less salary than these women receive. This is simply an impossible economic situation. No class of workers can continue long on less than a living wage. These figures ought to bring a sense of shame to every American and cause the resolve that this injustice shall be righted speedily." (The Outlook, September 24, 1919, pp. 134-35.)

Since the above was written the situation has become worse. An investigation in a great and wealthy Mid-West State revealed the fact that carpenters, plumbers, and brick-layers received twice as much pay per year as high-school teachers and hod-carriers about twelve per cent more. For further alarming facts about our schouls, see below, p. 226. 
universal abstinence by legislative enactment from all indulgence in alcohol; and the wider and wider extension of industrial labor in place of the original craftsmanship of primitive people.

The psychologist's reply will perhaps be somewhat as follows: Everything changes; human nature changes; human instincts change; but they change very slowly. The present age is one of very slow changes in man's physical and mental constitution. Evolution now is taking other directions. There has been little change in the human body or in the human mind since the history period began. Man has no more mental ability now than he had in the days of Aristides or Themistocles, ${ }^{1}$ and his passions, instincts, and impulses are much the same. Possibly the same could be said if we go back not two thousand years, but twenty-five thousand. The picture of the man of the Old Stone Age as drawn by Professor Osborn ${ }^{2}$ reveals a tall, straight, and finelooking being with a brow like that of a modern Englishman and a cranial capacity slightly greater than that of the average European of to-day. From century to century man's social

1 Compare Francis Galton, Hereditary Genius, p. 330.

${ }^{2}$ H. F. Osborn, Men of the Old Stone Age. Compare also Madison Grant, The Passing of the Great Ruce. 
inheritance has been enormously enriched, his natural inheritance very little. ${ }^{1}$

Here, continues the psychologist,-arises a peculiar situation which should be of especial interest to the sociologist. While the human unit has changed so slowly, society has changed with startling rapidity. We are living in an age of bewildering changes in our social, economic, and industrial life. Thus, while organic evolution tarries, social evolution proceeds with a dizzylike rapidity; hence disharmonies result which it should be the purpose of our conscious control of human society to lessen.

The instinct of gregariousness, ${ }^{2}$ for instance, has been in the early history of man of vital necessity to his survival. In our modern life excessive urbanization of society, proceeding from the same instinct, has become a social danger.

1 "Changes are going forward constantly and continually in the institutional apparatus, the habitual scheme of rules and principles that regulate the community's life, and not less in the technological ways and means by which the life of the race and its state of culture are maintained; but changes come rarely - in effect not at all - in the endocoments of instincts whereby man is enabled to employ these means and to live under the institutions which its habits of life have cumulatively created." (Thorstein Veblen, The Instinct of Workmanship, p. 35. The italics are mine.)

2 "Experience has shown that the instinctive desire of the soldier with an hour of free time is to go to town, if only a crossroads." (From $W a r$ Department Report on Training-Camp Activities.) 
Another instinct upon which survival has been conditioned is that of pugnacity. Even until lately in human unwritten history war has acted to preserve the strong and eliminate the weak and unfit. Now, under modern conditions, war has become an unspeakable calamity, bringing irreparable damage to progress and civilization; but the warlike instinct persists, a subconscious fire ready to be fanned into flame when the occasion arises.

Again, under primitive conditions group loyalty was an indispensable human sentiment. Now it issues in periods of excessive nationalism to which any demagogue may appeal to checkmate movements toward international amity demanded by modern financial and industrial conditions. ${ }^{1}$

Hence, continues the psychologist, the goal in social reconstruction now is not the production of more wealth and its equal distribution, nor the gaining of more liberty, equality, and opportu-

1 Compare the action of Italy in the months following the armistice of the World War when industrial reorganization was imperative for a completely disorganized society, but when the whole thought and passion of the nation was directed to the matter of national aggrandizement; or compare the action of our own Senators in delaying for long, weary morths action on the League of Nations by an appeal to a narrow and selfish nationalism. 
nity, of which we have a degree which would have surpassed the fondest hopes of those living but a short time ago; but the adaptation of our social order to the men who are to live in it; for when disharmonies occur, unrest is increased.

Man's original nature cannot be changed very much in the years to come as we measure time, but his instincts, so far as they seem to us bad, may be redirected and sublimated, and so far as they are good we may use all our efforts to conserve or create a social order that is in harmony with them. The method of repression is fraught with danger.

Modern science and the industrial age have already effected such changes in man's social and material environment that serious disharmonies are resulting, since he is compelled to live under new conditions for which evolution has not prepared him. The surface of the earth happened to be underlaid with iron, coal, and petroleum, and man happened to discover them and devise ways of using them, and they have suddenly made for him a totally new environment. For instance, the use of gasoline, steam, and electricity has solved the problem of transportation without the healthful exercise of walking and carrying burdens. Electricity has enabled man 
to work and play at night, when formerly he had been sleeping. The construction of air-tight, steam-heated dwellings has lulled him into comfort, while inducing new diseases. The discovery of alcohol has provided an artificial but damaging quietus for the disharmonies caused by his new manner of life and his new efforts at thought. Finally, certain discoveries in hygiene have lengthened life and decreased infant mortality so considerably that, despite the decreasing birth-rate and despite the extensive emigration to the newly discovered Americas, the population of the principal countrics of Europe has increased from I I0,000,000 in I780 to $325,-$ $\infty 00, \infty 00$ in $191 I^{1}$ a situation which from the standpoint of sustenance is beginning to create grave difficulties.

The result of all these circumstances is that man in modern society finds himself in a position somewhat like that of the proverbial bull in the china shop. For a few minutes he seems to contemplate these objects of art with quite an æsthetic interest - until he begins to move, when the destruction begins. The economic and social world in which man lived before the war, with its accumulated wealth, its culture, its refine-

1 See Fairchild, Outlines of Applied Sociology, p. 215. 
ment, and its dangerous ease, was a china shop in which for a time he lived quite placidly, his real nature concealed under a veneer of civilization, till suddenly a very slight movement took place, the murder of an archduke somewhere, when instantly confusion reigned and the awful destruction began. It was man's original nature asserting itself, his primitive instincts finding expression; and since we may becertain that they will continue to find expression for hundreds of years, it will be well to build our house of civilization to fit the man who is to live in it. ${ }^{1}$

Illustrations could be multiplied. The unbelievable flood of profanity and vulgarity that burst out in our American army, both among the officers and men, almost from the day of induction, was not a universal tradition of war; for we are told that it was much less in evidence in the armies of other nations. It seems to have been, in part at least, a reaction from the repressions of an over-refined veneer of civilization in our American homes where it is a crime

1 I am not at all forgetful of the part played by secret diplomacy and the machinations of so-called statesmen and munition interests as causes of the war; but, on the other hand, wise leaders throughout history have constantly restrained the people from war and this has indeed happened frequently in Europe since the armistice. 
to leave your spoon in your coffee-cup or omit the baby's daily bath.

In the midst of this same "refined" society, in a large city of the Middle West, at a time of great national prosperity, when work was abundant and well paid and the saloons closed, a large body of citizens both men and women formed themselves into a mob, lynched a negro, burned his body, filched shreds of his clothes from the fire for souvenirs, and attempted to hang the mayor of the city who tried to enforce the law. ${ }^{1}$

Where are we to seek the cause of this stain upon the dignity and good name of our country? Clearly not in bad economic conditions, nor in capitalism, nor in poverty, nor in alcohol, nor in inequality, but in unbalanced brains, in a resurgence of savage nature, in a kind of volcanic outburst of primeval impulses which our schools and social institutions have not known how to lead off in harmless directions.

1 The Chicago Tribune of September 30, 1919, gives the following figures taken from a statement of the National Association for Advancement of Colored People: "Between January ist and September 14th, 1919, 43 negroes and 4 white men were lynched in the United States and 8 negroes burned to death. The total lynchings from 1899 to 1918 in the United States were 2522 negroes and 702 whites. Less than 24 per cent of the negroes were charged with attacks on white women."

The total number of lynchings in 1919 was 82 , of which 75 were negroes. In the year 1892 there were 208 . . 
In our modern social-reconstruction schemes the way to cure evils is to abolish them by the method of the "legislative mill." But this method has its limitations. Human nature repressed suddenly asserts itself. The evils of alcohol were so great and the American saloon so offensive that we have been forced again into the method of repression to cure this evil. It will be well, however, if we must depend upon this method rather than the method of substitution, sublimation, and education, to see that these laws are never relaxed, not even in the distant future; for if they are, we may expect an orgy of dissipation such as the world has never known, since no inner power of resistance against the appetite has been built up either by education or by natural selection, but only opportunity for indulgence denied. The notion that a sober nation may, by the lapse of time, be "weaned" from the desire of alcohol is not well borne out by observations upon the ravages of alcohol among primitive stocks. The "don't" method has been pretty generally discredited in the education of children, but it is still popular in social reconstruction.

In like manner we may "cure" contagious diseases, not by constructing in the human body 
an inner barrier of constitutional resistance to them, but by erecting an outer barrier of protection against the germs of disease. But we must make sure that these outer barriers never break down, for if they do the enemy will find easy victims.

Another evil that it is attempted to cure by "abolishing" it is the evil of capitalism. Exceedingly serious abuses have grown up around this institution. We have become very conscious of these evils, but our proposed methods of cure have often exhibited an inexcusable ignorance of the human motives upon which capitalism is based. Sometimes they take the crude form of a proposal to abolish capital, since it is an "evil," either by majority vote or by forceful occupation on the part of the non-capitalistic classes. But here we have to do with one of the most powerful of human instincts, and this method of repression may not work well in practice. It is the instinct of acquisition, of ownership, the collecting instinct, the instinct to save. As Mr. McDougall says, "The importance of the instinct of acquisition, from our present point of view, is due to the fact that it must have greatly favored, if it was not the essential condi- 
tion of, that accumulation of material wealth which was necessary for the progress of civilization beyond its earliest stages." I It is one of the anomalies of our reconstruction methods that we exalt the importance of wealth, wish to increase production, quarrel over the unfair distribution of it, and then propose to stifle by collectivistic schemes the very instinct that has led to the production of wealth.

This is because the abuses of capital have become so apparent that we desperately grasp at the most obvious, if least scientific, method of curing them. But here again it will be well to cansult the psychologist and proceed by other methods than the method of repression. Substitution and sublimation will again be safer and will require long years of careful study of the human mind and its relation to industrial life. We may by an act of legislation abolish private property, but the instinct of ownership can be abolished by no human power, and if there is no outlet for it we may again have the condition called "balked disposition," and then something socially unpleasant is likely to happen. A man, for instance, wants to own his land, not to till some acres of state-owned land;

- An Introduction to Social Psychology, p. 322. 
and he will work any number of hours a day to gain the ownership of his bit of land. As Professor Parker says:

Man lusts for land, goes eagerly to the United States, to South America, to Africa for it. It is the real basis of colonial policy and gives much of the interest to peace parleys. A landless proletariat is an uneasy, thwarted, militant proletariat. ... The social menace in the American labor world is the homeless migratory laborer. Russian peasants revolted for land, and this is the single consistent note in the anarchy chaos in Mexico. Man, much of the time, acquires for the mere sake of acquiring. A business man is never rich enough. If, however, making more money uses his acquisitive capacities too little, he may throw this cultivated habit activity into acquiring Van Dykes or bronzes or Greek antiques, or, on a smaller and less æsthetic scale, postage stamps, signatures, or shaving-mugs. Asylums are full of pitiful, economic persons who, lost to the laws of social life, continue as automatons to follow an unmodified instinct in picking up and hoarding pins, leaves, scraps of food, paper. The savings banks in large part depend on this inborn tendency for their right to exist. ${ }^{2}$

This does not mean that there is something called "human nature" which demands that particular form of society known as "modern capitalism." It only means that these current

1 Carleton H. Parker, "Motives in Economic Life," Proceedings, American Economie Association 30th Meeting, December, 1917, p. 222. 
social-reconstruction plans which have been designed to supplant capitalism have been worked out with such complete disregard of human psychology that it is highly improbable that they could provide any stable or satisfying society. With a virile people unrest might be multiplied a hundred-fold.

Then there is another group of instincts for which no adequate provision is made in the society of the future, as we are planning it to-day. I refer to such instincts as those of leadership and mastery, the love of dominion, the love of adventure and change, and the lust for gambling.

It is true that man longs for wealth and comforts and luxuries: he even longs for peace and quiet and regular work; and in his quest for these things he will undergo any hardship or deprivation. Hence, it is naively assumed that a society which shall provide him with these things will be an ideal society, forgetting that a good society will be one in which men can live, and that life consists, not in the enjoyment of peace and wealth and comforts and luxuries, but in the longing for them and the struggle, pursuit, and capture of them. "The good things of the world must be won afresh every day." 
But even this conception of life is narrow and academic. The real man, revealed to us by the study of psychology and of history, is wholly different from the man for whom the social reforms are planned, who is to live presumably in the enjoyment of regular work, plentiful food and clothing, a comfortable home, and social stability and peace. The real man acts impulsively rather than rationally and his primal impulse is to dominate. It is gain and glory that he wants more than bread and clothing. It is a career that he desires more than peace and safety. It is adventure that he craves more than work.

It is instructive to look back upon the history of the development of man in society. He is not by nature a worker, but an exploiter. Sustenance he must have, but it has always been easier to gain it by plunder than by work; and so, as far back as we may go in history, as at the present day, social group has fought against social group, one bent on robbery, the other on selfdefense; and within the group, when unrestrained by the stern hand of the law, individual has preyed upon individual, master upon slave, and class upon class. When the life and safety of the group as a whole have been threatened by 
some rival group, then so much of law and order has prevailed within the group as was necessary for social integration, because only by social solidarity within could the group itself be saved.

It is not quite accurate to say that men love to fight. In time of war they long passionately for peace. But they love to dominate, and fighting is incidental. The military impulses lie very near the surface and their roots extend deep. If human progress is to be illustrated by a figure, it is not the figure of a man climbing a ladder, but of one elbowing his way up in a crowd. Men aspire always to something different and better. They love to gamble, to take a chance, to risk something and gain or lose. It is contrary to deepseated human racial habits to work steadily and monotonously.

The alarming presence of gambling in its silliest and 'most childish forms in the great military camps of our country during the war was a shock to our people. The men themselves could see plainly enough that after every pay-day a few quick-witted men gathered in the precious dollars; but the gambling went on. The ordinary everyday life of the average man in time of peace offers some expression of the gambling in- 
stinct in its better forms: he can at least invest a part of his earnings in some scheme that he thinks may pay; but the flat monotony of the army life was unnatural and unendurable.

Nowhere is the dreamlike character of our social schemes seen so plainly as here. There is no provision of any kind for an expression of the gambling instinct. It is not to be sublimated or redirected; it is apparently not even to be repressed by the stern force of the policeman's club. In childlike naiveté we ask, Why! who would wish to gamble when all are well-fed, well-clothed, and well-housed, and have abundant leisure for culture and self-improvement?

The conquest of a great and new country like America will keep a people busy and contented for a century. When it is conquered, we assume that they will rest and enjoy it; but really that is when unrest begins. In the last years the world has become rich and prosperous, but unrest has grown, being increasingly manifest even before the war. In the recent years in America work has been plentiful, the times prosperous, while comforts and luxuries have abounded in a degree never hitherto dreamed of; but murders and bank robberies show no signs of abating and strikes have become almost an obsession. The 
American frontier, so long as it existed, was the best peacemaker for our nation. It has now been reached and conquered; and unrest will increase.

How different the reality may be from the vision of the social idealists! In rich and fertile America we have looked forward to a land teeming with happy and contented citizens, free from war, free from foreign oppression, free from autocracy within, free from grinding poverty, free from class oppression, free from decimating disease, free from vice and intemperance. The nearest approach to this elysium which history has seen was in Germany before the war. Here was a land of beautiful cities, well-governed and orderly; a great people, well-fed, well-clothed, well-housed, well-educated, well-behaved, with a fruitful agriculture, busy shops, successful industries, and a vast and profitable commerce yet this same Germany broke bounds and went out to conquer. It is not peace and plenty that man wants, but dominion. And yet in our complacent theories of society, we take no account of this instinctive and inherent lust for power, and we innocently assume that a people will be happy and contented if poverty is abolished, the labor problem solved, opportunity secured, and 
science and inventive genius given a free hand to increase wealth and material comforts. ${ }^{1}$

"Two things," says Nietzsche, "are wanted by the true man - danger and play." There is just enough truth in this to set us thinking. The standardized world that is planned for the future offers us safety and work. In all the ages of man's slow development he has never known safety. He has lived under the insecurity of war, of robbers, of plunderers, of tyrants, of flood and

1 "In any serious attempt at political reconstruction, it is necessary to realize what are the vital needs of ordinary men and women. It is customary, in political thought, to assume that the only needs with which politics is concerned are economic needs. This view is quite inadequate to account for such an event as the present war, since any economic motives that may be assigned for it are to a great extent mythical, and its true causes must be sought for outside the economic sphere. Needs which are normally satisfied without conscious effort remain unrecognized, and this results in a working theory of human needs which is far too simple. Owing chiefly to industrialism, many needs which were formerly satisfied without effort now remain unsatisfied in most men and women. But the old unduly simple theory of human needs survives, making men overlook the source of the new lack of satisfaction, and invent quite false theories as to why they are dissatisfied. Socialism as a panacea seems to me to be mistaken in this way, since it is too ready to suppose that better economic conditions will of themselves make men happy. It is not only more material goods that men nced, but more freedom, more self-direction, more outlet for creativeness, more opportunity for the joy of life, more voluntary coöperation, and less involuntary subservience to purposes not their own. All these things the institutions of the future must help to produce, if our increase of knowledge and power over Nature is to bear its full fruit in bringing about a good life." (Bertrand Russell, Why Men Fight, pp. 40, 4I.) 
storm and famine. A safe world appears to him very attractive, but it would be a foreign world. "One longs for the day," sighs a recent writer, "when the house of civilization shall be completed, so that we can dwell in it in peace." Well, when it is completed, angels not men will be its denizens. Men grow and struggle and develop; and this is life. The other is death. Life is found in adventure and change, in the struggle for supremacy and position, in the joy of leadership, in loyalty to our leaders. It is realized in the battle and the victory, not in the fruits of victory. It is realized, not in the steady enjoyment of good wages, but in the successful struggle for higher wages. It is not wealth that people want, but only more wealth or more than their neighbor has. The joy of wealth would largely vanish if our neighbor had a fixed and equal amount.

We are told that unrest is due to inequality, inequality of wealth and opportunity. We can in imagination picture a world where there is no inequality, but it would not be life. ${ }^{1}$ Heaven was formerly pictured as a place of eternal rest, and

1 "The mortal defect of Utopias is that they are too static. The kingdom of heaven on earth is always a permanent, unchanging, perfect, and unalterably stupid place, than which our present society, with all of its imperfections, is vastly superior. Utopias break down because they represent attainment, fulfillment. But society 
for a hard-working man or woman that would be bliss - for the first few days. After that the walls would have to be patrolled with guards with rifles to keep us in. The writer was recently talking with a young girl of character and sobriety who had been an art student in a metropolitan city. "Is n't it wonderful," I said, "that in this safe country of ours an attractive girl can go alone to a great city and nothing happen to her?" "Yes," she said, "that's just the trouble. Nothing ever happens!"

Our modern reconstruction schemes are built too much on the Chautauqua plan. Their philosophy of life is of the early-to-bed-and-early-torise-make-a-man-healthy-wealthy-and-wise order. The modern boy who says that this is just hot air, and that such a person misses lots of fun, is in the wrong, no doubt, from every sane and sober and logical point of view; but he is right as an exponent of human nature. The actual man, as known to the psychologist and to the historian, and as revealed to us in real life in peace and war, will not live and work contentedly in

does not strive toward fulfillment, but only toward striving. It seeks not a goal, but a higher starting-point from which to seek a goal." (Walter E. Weyl, The New Democracy, p. 354.) 
a standardized economic world under scientific management and the rule of efficiency. By the inheritance of a half-million years he is adapted to a different life, and while in the end his instincts may be changed, this cannot be done in half a century. Our instinctive life will not find adequate expression in the reign of universal peace, universal labor, universal equality, and economic prosperity that our social-reconstruction plans contemplate.

What man wants is not peace, but a battle. He must pit his force against some one or some thing. Every language is rich in synonyms for battle, war, contest, conflict, quarrel, combat, fight. Our sports take the form of contests in football, baseball, and hundreds of others. Prize-fights, dog-fights, cock-fights have pleased in all ages. When Rome for a season was not engaged in real war, the Emperor Claudius staged a sea-fight for the delectation of an immense concourse, in which nineteen thousand gladiators were compelled to take a tragic part, so that the ships were broken to pieces and the waters of the lake were red with blood.

You may perhaps recall Professor James's astonishing picture of his visit to a Chautauqua. Here he found modern culture at its best: no 
poverty, no drunkenness, no zymotic diseases, no crime, no police - only polite and refined and harmless people. Here was a middle-class paradise, kindergarten and model schools, lectures and classes and music, bicycling and swimming, and culture and kindness and Elysian peace. But at the end of a week, he came out into the real world, and he said:

Ouf! what a relief! Now for something primordial and savage... to set the balance straight again. This order is too tame, this culture too second-rate, this goodness too uninspiring. This human drama, without a villain or a pang; this community so refined that ice-cream soda-water is the utmost offering it can make to the brute animal in man; this city simmering in the tepid lakeside sun; this atrocious harmlessness of all things - I cannot abide with them.

What men want, he says, is something more precipitous, something with more zest in it, with more adventure. Social reformers paint the life of the future as a kind of giant Chautauqua, in which every man and woman is at work; all are well-fed, satisfied, and cultivated. But as man is now constituted, he would find such a life unendurable. It would be intolerable ennui and boredom. If forced upon him, either unrest would increase or social stagnation follow.

Man is not originally a working animal. Civi- 
lization has imposed work upon man, and if you work him too hard, he will quit work and go to war.

Thus our social-reform schemes are wrongly conceived. They are all based on a theory of pleasure-economy. But history and evolution show that man has come up from the lower animals through a pain-economy. He has struggled up - fought his way up through never-ceasing pain and effort and struggle and battle. ${ }^{1}$ In the society of the future man has ceased to struggle. He works his eight hours a day - everybody works - and he sleeps and enjoys himself and cultivates his mind the other hours. But the citizens for such an ideal social order are lacking. Human beings will not serve. ${ }^{2}$

Our present society tends more and more in its outward form, in time of peace, toward the Chautauqua plan, but meanwhile striving and passion burn in the brain of the human units, till the time comes when they find this insipid life unendurable. They resort to amusement crazes, to narcotic drugs, to political strife, to epidemics of crime, and finally to war. ${ }^{3}$

" "Man is at his best when rowing hard against the stream." (J. Arthur Thomson.)

2 Compare Sorel's Social Myth Theory.

- Some paragraphs are here used from my book, The Psychology of Relaxation, pp. 249, 250, 251. 
We have here an instructive illustration of the failure in our plans for social reorganization to take account of psychological as well as economic forces. The society which we are planning for the future lacks the element of zest. Some shadow of romance it must have, if it is to abide; and this element of romance or zest cannot be gained by providing eight, or indeed ten, hours a day for recreation and culture. It is life that the people want, not recreation and culture. What do the reformers of our social order usually have in mind for these eight or ten hours of the day not spent in labor or in sleep? Libraries, no doubt, and art galleries and theaters and Chautauqua classes and moving pictures and gymnasiums and athletic games. But even a little knowledge of psychology should show us that these things do not satisfy human needs. All men and all women long for some kind of dominion, long to display their personal power, their personal charms, their personal genius. What they want is a career, a sphere of influence, a sphere of action; and in striving for these things they are restrained by no fear, not even the fear of overturning the social order. 


\section{CHAPTER IV}

\section{PSYCHOLOGICAL FACTORS IN SOCIAL}

RECONSTRUCTION (continued)

THAT our social-reform movements are

1 based on sentiment and on certain highsounding phrases, such as equality and liberty, rather than on an accurate knowledge of the human mind and the human body and human history, may be illustrated again if we consider another group of instincts, including the instinct of sex and the parental bent. The destructive inroads which modern industrial methods have made upon the institution of the family, the spread of the vice of prostitution and of disgusting social diseases, the increase of divorce and the alarming decline of the birth-rate among the better classes of people, as well as the apparent threatening increase in feeble-mindedness and neurotic tendencies, should long ago have focused the attention of our social reformers upon the problem of racial integrity. Instead of this it has been focused upon "votes for women." Our sense of justice has been affronted by the discrimination against our women in forbidding 
them the right of suffrage, while we have overlooked the far more serious injustice done them by the presence in society of such evils as those above mentioned. Of course there are plenty of societies for the prevention of these evils, but the attention of the world is not focused upon them. It is focused upon such things as rights, equality, freedom, a living wage, etc.

The relation between the sexes and the position of women in society are the profoundest of human problems. They go down deep to the very roots of our social life. They involve the fate of the most sacred of human institutions, the family. They have to do with the most powerful of humán instincts. They involve customs and language and habits that go back into the remotest historic regions. Upon these relations depends the physical integrity of society. Upon them depend the health, the sanity, and the welfare of the race.

To the solution of these great problems should be called all the aid of all the sciences - of history, anthropology, physiology, psychology, sociology. But what in fact is the method of our social reconstructionists here? Virtually it amounts to this: We call together the men of the nation and say, "All those in favor of the equal- 
ity of the sexes say 'aye.' Those opposed the same sign. The motion is carried. Inequality between the sexes is abolished." Our trust in mere political institutions is pathetic. We have not solved the problem of inequality between the sexes. We have not even begun to study it. Nor have we solved the problem of injustice. The glaring injustice of conferring the franchise upon many ignorant and vicious men and denying it to many intelligent and worthy women, we have indeed partly corrected. The still greater injustice to our children and to the women of coming generations resulting from our neglect of racial hygiene has scarcely entered our minds. The spectacle of a woman - that is, any kind of woman - being debarred from the polls arouses us to a kind of frenzy; but, to take a single example, the increasing cigarette habit in women merely excites in us a sort of levity. ${ }^{1}$

We seem to be deeply impressed by the fact that women have the obvious right to vote and to an equal wage for equal work and to enter freely into industrial and economic relations;

1 The habitual narcotizing of the higher brain centers by means of tobacco may possibly have no serious degenerating influences on racial health, so long as it is confined to one sex; but the intermarriage of individuals with narcotized brains presents a problem that we have not even begun to study. 
but we seem to be blind to certain deeper rights of women to certain immunities from industrial and political functions in the higher interests of motherhood and the sacred institution of the family.

Our doctrine of rights to which we are so sensitive rarely gets beyond the momentary aspect. The right of our children and of our children's children to be well-born has never troubled us much. Custom and convention, with which we are so impatient, and human instinct, have better protected the purity of women and been a safer guardian of the physical and mental integrity of the social group.

From now on we have got to think of social welfare in terms of the present and the future. We have, indeed, outgrown at last our narrow individualism, and we talk now of the community and of society and of the collective good; but we still too often think of these as being the community of the present moment. We are thinking only of the present generation. But we must begin to think of social stability. We need a movement in social reconstruction which shall center around the conservation idea. It will concern itself less with economic justice and more with social justice in the sense just mentioned 
- in the sense of conserving for the benefit of the abiding community our soils, our forests, our fuel, and far more our heritage of health and morals.

But even apart from the question of racial health and sanity and the racial stability which is dependent upon them, have we any reason to believe that the society of the future as we are planning it will give the necessary expression to the reproductive and parental instincts? I do not mean here necessary in the sense of maintaining the physical continuance of society. This question has been fully discussed by many writers. I mean to ask whether the masculine society which we are planning will have a psychological basis, so that it will work. The modern age is already an intensely masculine age and the tendency of the feminist movement would seem to be to make it more so. What we see everywhere now is energy and activity, the desire to create, control, exploit, achieve, master. It is a time of great endeavor, of expenditure of effort, of change - a tense and nervous age. All these are masculine motives. Never before, therefore, has there been so great need to balance all these with those traits that belong to woman - poise, reserve of power, relaxation, calm, conservation, 
and conservatism. Ancient and mediæval civilizations tended more to emphasize these other phases of human life - restraint, limitation, self-control, 1 the possession and appropriation of things of objective worth, the contemplation and enjoyment of things of beauty and objective value. $^{2}$

Clearly what this age needs is another kind of feminism than the one in vogue. Women do not need to become like men. The whole age needs more of the motive which belongs to woman, the centripetal motive. If now women had become more masculine, why, then we should perhaps be justified in fitting our social institutions to their new character. But they have not. They are in their real nature just as womanly as ever, and no change of social institutions or wave of industrialism and commercialism will make them different in future years as we measure time; and for this we may be thankful. They can, of course, adopt the masculine habits of the age. They can enter politics and the industrial and commercial life. They can accept men's jobs and adopt men's dress, but the total social results tend to friction and discord because happiness is

1 Compare Ferrero, Ancient Rome and Modern America.

- Compare George P. Adams, Idealism and the Modern Age. 
found in the fulfillment of function, and social welfare is found when social institutions conform to human instincts.

It is in this way that we can explain certain social phenomena that have perplexed our social reformers. When we thought that a new "dignity" had been laid upon women, with new responsibilities and new political and industrial opportunities, when society seemed to be rising to a high level of morals and manners, then suddenly a wave of peculiar sex consciousness and sex exaggeration has burst upon the world even during and after the war, manifested in extreme forms of dress, in crazes of erotic dances and erotic moving pictures, and revealed in a new wave of sex fiction in literature and upon the stage. Evidently the method of repression does not work. Our plans for social reconstruction must proceed here as everywhere along lines laid down by nature.

Then there is another group of human instincts which must be considered in social reconstruction, the instincts of loyalty, devotion, and sacrifice. The society of the future, planned so largely from the economic point of view, makes little provision for two of the most power- 
ful of human motives, loyalty and devotion. Scientific management and efficiency are to take their place. Our minds are so constituted by our long racial history that we want and need to be loyal to some one or some thing and devoted to some one or some thing, and only in this way is the best that is in us drawn out. As has so often been said, a man is never so much himself as when he gives himself to some cause outside himself. ${ }^{1}$

In times past the sentiment of devotion has found fitting and satisfying objects in the State and in the Church and in the Family. For his flag, his religion, his wife or children, a man pours out his devotion or sacrifices his life, and indeed the instinct itself traces its origin to the survival value of these institutions. In this great complicated modern life of ours our interest in the Church lags, the State becomes so large and safe, and indeed almost lost in the industrial and commercial world, that only at times - for instance in time of war-does it enable us to give expression to this ancient instinct, while the "emancipation" of woman and her descent into the arena of politics and industry lessen our former chivalric devotion to her.

1 Compare James Jackson Putnam, IIuman Motives, p. 59. 
What in the new society is to take the place of these sacred objects of our allegiance, loyalty, and devotion? When a State becomes large and safe so that the defense of the flag no longer calls for devotion and heroism, we find this devotion drawn off to a large extent to all kinds of parties and organizations within the State. As party loyalty takes the place of loyalty to the State, we remain loyal to our political parties even when they no longer stand for any particular cause. Then appear all kinds of organizations, societies, clubs, unions, brotherhoods, federations, parties, sects, fraternal orders, lodges, syndicates, leagues, councils, and committees, which command our loyalty and obedience, allowing us to give expression to these instincts.

During the age-long history of man on the earth he has lived in small communities, and during much of this time his survival has depended upon this group solidarity and upon his faithful devotion and loyalty to the group and its leaders. This profound instinct must have its appropriate expression. During the Middle Ages, when the spirit of nationalism was at its lowest point, devotion to the Church took its place, calling out in the service of God and the Church all that was best in man, the demand for the 
supreme sacrifice never failing of faithful response. Sometimes, when again the Church became large and powerful and safe from attacks of enemies, allegiance was transferred to the smaller monastic orders. Still later Chivalry and the Feudal System gave expression to the same instinct of loyalty and sacrifice.

At the present time the craze for organizations of every conceivable kind is in part explained by this need of the human mind to express its loyalty and devotion in concrete form. We begin to hear it said that the world is overorganized. We have societies for the accomplishment and prevention of everything under the sun. Before the war, little dreaming of the unspeakable horrors that awaited us just ahead in the trenches and under the sea, we had societies for the prevention of cruelty to animals, and anti-vaccination and anti-vivisection societies, and societies for converting the heathen, and so on without end. Organizations multiplied on every side, each with its president, vicepresident, secretary, and treasurer. Even the infants in our churches have organized under the name of junior endeavor societies, each with its infant president and its infant secretary, not to speak of the Cradle Roll. We seem to live in a 
world of organizations. From the lips of our people throughout this great land we listen in vain now for the good old words, "Our Father which art in heaven," and instead we hear the familiar call, "All those in favor of the motion say 'aye.' Those opposed the same sign. The motion is carried."

It is the ancient instinct of group solidarity, upon which survival once depended, which is manifesting itself in this way. The primary political group to which we belong has become in a way too remote to provide the needed expression for this instinct. So innumerable smaller groups within the group are formed, and when there is no common enemy to fight they contend with one another, or, more fatally, against the group as a whole.

The various reconstruction movements themselves are examples of this instinct. Movements such as Socialism, Syndicalism, Bolshevism, and the I.W.W. become cults to which their followers offer a loyalty and devotion that is symbolic of the whole life of man in history. If these cults meet with opposition, if there is a little mystery about them, if they inspire a little fear, if there is a kind of underground communication between the members, if there are certain secret 
symbols, if there is even a chance for something like martyrdom, if there exists a strong feeling of brotherhood within the organization, the spirit of loyalty and devotion burns brightly. But the peculiar fact here is that we who are adherents of any of these movements never suspect that in our devotion, our enthusiasm, our loyalty, our sacrifice, and even our fanaticism, we are simply living, that we are experiencing life's great realities themselves, that we have here the fulfillment of function. We do not understand that this expression of our instinctive life is life itself. We think that we are engaged in a movement which shall prepare men for life. We think that when that particular kind of social order which we are striving for is realized, then we shall live. To us there is a slight element of tragedy in the matter. We think that we are enduring that others may enjoy.

Thus these movements are all good. They give expression to our fundamental needs. It is unfortunate, perhaps, that just at the present time the actual aims and ideals of these movements are not of the highest type - resting as they do very largely upon an industrial conception of life, picturing social welfare in terms of an equitable distribution of physical goods and 
an equitable distribution of opportunity for winning these goods. It is perfectly conceivable that the same degree of enthusiasm might be directed to wholly different ends; for instance, to education, to the development of the fine arts, or to the application of science to the physical, mental, and moral improvement of man.

Another unfortunate fact about some of these movements in their extreme form is that in their excessive zeal to cure the evils of the day they would go to the extent of trying to overthrow the whole order of government and society under which we live. It is probably true that America in the last two hundred years has offered, and does to-day offer, a more perfect field for the exercise of human faculty in its characteristic and instinctive forms than any other age or country. There have been, and still are, opportunities unparalleled in the history of the world for the expression of every instinct, the migration and homing instinct, the housing and settling instinct, the instinct of ownership, the collecting and acquiring instinct, the instinct of workmanship, manipulation and curiosity, the instinct of leadership and mastery, the instinct of display and ostentation, and the instinctive love of freedom and impatience with restraint; 
and as for riches, comforts, and luxuries, the least favored of to-day are like the most favored of former times. ${ }^{1}$

I was speaking recently with a woman engaged in constructive social work in one of our cities. I asked her if there was much poverty in her city. She replied that she thought there was a good deal. She mentioned one family, where the father was getting only twenty-one dollars a week, where she felt sure that the family was not properly nourished. I asked her finally whether, if there were fifty people in the city who did not have enough to eat, she would say that there was a good deal of poverty there. Yes, she said, even if there were only one. I then inquired how many people there were in the city, and she said about sixty thousand. It is our fine idealism and our optimism that bid us always forget the fifty-nine thousand nine hundred and fifty that are well-fed, well-housed, and well-clothed, and fix our attention upon the fifty that are not. But as long as we have done practically nothing to improve our natural inheritance in respect to physical stamina, to make healthy brains in

1 On the rapid advance of every class in America toward social prosperity see Walter Weyl's The New Democracy, especially chapters XII, XiII. 
healthy bodies, one wonders what conditions of environment and of social and political institutions could have produced a social welfare on the whole so marvelous. It is partly the powerful development of sympathy in our modern Christian age which has brought us into the frame of mind where we see only the misery of our times and are blind to its wonderful prosperity. ${ }^{1}$

The real menace to our social well-being now is not poverty, of which there is relatively little in America, but the superfluous wealth of the very wealthy, of which there is an enormous amount. As life is pictured in these pages, realized as it is in the fulfillment of function, in the exercise of our powers, in activity and striving, in the living out of our instinctive nature, the rich are not the ones who live. We who work and organize and strive are the ones who live.

1 No doubt there were far more than fifty people in this city of sixty thousand who were not properly fed and clothed according to our present notions of food and clothing, as measured in calories and hygienic standards. Among the causes economic conditions do not figure prominently, as the records of any bureau of associated charites would show. Ignorance, vanity, improvidence, and disease are the prominent causes. Some of the improper feeding is due to improper clothing, the money for the former going to the latter. Both improper food and improper clothes are found among the rich. "Scanty" clothing is not confined to the poor. 
To rebuild society so that we may all be rich, have every desire satisfied, would be of all mistakes the most fatal. True enough, we all need to have opportunity, but opportunity for what? Not opportunity to "go to school," to get on, to work up, but opportunity to live, and life is found in the activity of our powers, involving among many other things this instinct of loyalty. Man is so constituted that he must have some cause to live for or to die for - some religion, some state, some flag, some woman, some lodge or labor union, or even some gang or band of outlaws. He wants to be, he must be, drawn out and away from himself to something which stands for an idea. This is life. The social Utopias provide for existence, but not for life. It is the precipitous element that is left out of the reckoning.

A stable society in which there is a dreary routine of work and amusement will present problems as serious as those of the old system. A society in which there is no God to worship, no women to adore and protect, no state to defend, no wine to drink, no parties to fight for, no king to be loyal to, no classes to exploit, and no new lands to discover and conquer, might have some kind of happy beings for its citizens, 
but not human beings. They have a different history.

But, it will be asked, what will happen in such a society, for the march of events is surely and steadily in this direction? There are no more new lands to discover and conquer; kings and autocrats are out of date; alcohol has been condemned, and rightfully; women have demanded, and with seeming justice, the life of industrial activity and political equality; the God idea no longer enters deeply into the daily life of the people; wars between nations will, after our recent terrible war, no longer be endured; the laboring classes rightfully refuse to be exploited; and internationalism is steadily supplanting nationalism. Well, surely no one knows what will happen, but it is conceivable that things may happen which will be worse than the evils we escape from. For instance, social unrest may increase until civil war takes the place of wars between states. What would happen in such a society could at best be predicted only if one knew whether vitality remained or did not remain among the people. Complete stagnation might ensue. Physical degeneracy might follow upon the increase of bodily comforts, and there might be an increase of 
morbid sexuality, surrender to sensuous enjoyment, dancing crazes and moving-picture crazes, epidemics of crime, and vagaries in religion and literature.

We are told that if war be abolished, some substitute for war will have to be found. Yes, some substitute for war, and some substitute for alcohol, and some substitute for the state, and some substitute for the king, and some substitute for God, and some substitute for woman - and these substitutes will have to be provided still thousands of years, until the mind of man, five hundred thousand years in the making, is made over.

Literature, poetry, the fine arts, will apparently have little place in the new social order, as it is planned. It is always assumed that they will be present and are to be enjoyed. But who will create these works of art? Art and literature spring spontaneously from life in all its tragic incompleteness, not from an economically prosperous existence. They depend upon sacrifice, upon loyalty and devotion, upon courage and victory, upon sorrow and suffering, upon pain and renunciation, upon ministry and service to the sick and wounded. The question whether a world without so much sorrow and suffering 
would not be better, even if it should be a world without literature and art, is not the question we are here discussing, but only the question of adapting our new social order to the beings who are to live in it.

A certain wise teacher said that a man's life consisteth not in the abundance of the things which he possesseth. It consists partly in selfsacrifice. In our facile plans for the future of society, no place is found for sacrifice; yet in all the long history of mankind sacrifice has had a conspicuous part. "Man has sacrificed himself for the State, woman has sacrificed herself for man." 1 No doubt the answer will be that it is precisely this unnecessary sacrifice to which we wish to put a stop. But here much depends upon the meaning of the word "unnecessary." It may be economically unnecessary, but it may be spiritually, morally, even socially or racially, altogether necessary. It is possible to gain many worthy economic values and lose many still greater spiritual values - to gain the whole world and lose our own souls. There is at least some truth in the saying that he who loseth his life shall find it.

1 Thomson, Introduction to Science, p. 198. 
What conclusion, then, are we to draw from this consideration of psychological forces, as against the economic, social, and political forces which rule the thinking of our time? Is the old society good enough, with its political rivalries and its incessant wars, with its drunkenness and crime, with its women as ornaments and dolls? Some of these things, at any rate, are outgrown. War is now racially, as well as economically, too expensive. Alcohol is a narcotic and poison, not a stimulant, as was once believed. Woman has outgrown the doll stage. We shall not go back to these things. But, nevertheless, it is a misconception of life that places the emphasis of the future upon peace and plenty, upon economic expansion, upon equality, upon comforts, luxuries, wealth, and leisure, no matter how equitably the wealth is distributed.

Can we watch the tendencies of the present and doubt how this wealth and leisure would be spent? It requires no great exercise of the imagination to see larger and larger streams of people flowing to the moving-picture shows, longer and longer lines of automobiles going nowhere in particular, bulkier and bulkier editions of the Sunday newspapers filled with things neither interesting nor important, more and more pages 
of advertisements of the latest fashions in dress. That art, literature, religion, patriotism, and morality, that any of the higher values of life, would spring from the wealth and leisure of such an industrial society is a pure assumption. In the past they have sprung directly out of the storm and stress of life.

Mr. Charles H. Pearson evidently had a picture of this industrial life of the future when he wrote in his "National Life and Character":

Our morality will then be the emasculate tenderness of those who shrink from violence, not because it is a transgression of order, but because it is noisy and coarse; and having outlived strong passions and the energy by which will translates itself into act, we shall plume ourselves on having abolished vice. Our intellectual discipline will be derived from the YearBook and the Review and our intellectual pleasure from the French novel. Yet there seems no reason why men of this kind should not perpetuate the race, increasing and multiplying, until every rood of the earth maintains its men and the savor of vacant lives will go up to God from every home.

The modern individual is a very complicated being, and it is doubtful whether he will live peacefully and contentedly in a standardized world, in a society based on work and wages and the philosophy of equalitarianism. The attempt to put him into such a harness might result in an 


\section{PSYCHOLOGICAL FACTORS}

increase rather than a decrease of unrest. The real man is restless, aggressive, and aspiring. He is not a being who enjoys labor and leisure and wealth. Nor can it really be said that he profits by them. What he enjoys is the struggle for these things, and this is what in the end he profits by. The real man of the present day likes to speculate and gamble. He wants to take a chance, to risk something and gain or lose. $\mathrm{He}$ loves the city rather than the country and prefers electric light to sunlight. He likes excitement and the company of his fellows. He is fond of rapid transit by motor-car or railroad. He delves eagerly into new problems of science and invention. He exploits new lands and new routes of trade. He invents new guns and explosives and poison gases. He delights in organizations of all sorts, societies, clubs, unions, orders, fraternities. He is very sensitive to his rights and emotionally sympathetic with all whose rights are invaded. He is an explorer, inventor, exploiter. He has unlimited energy, is frank, courageous, and hopeful. He loves sport and play, but will work indomitably upon whatever he wishes to achieve. This is the real man of our modern world. This is the material which the social reconstructionist has to deal with, 
and his new society must be adapted to this material. What this real man wants is achievement, not work and wages and leisure and sleep. America during the past hundred years has offered an almost perfect field for this real man's endeavors, and he has built up here, not, to be sure, a great civilization, for that would demand a more artistic genius and a different temperament, but certainly a notable one, and the social system in which he has worked has been on the whole admirably adapted to his nature.

It is very doubtful whether what is called social unrest will be lessened by increasing wages and decreasing hours, no matter how far this may go. Your really happy man is not the one whose hours of labor are shortened to six or eight a day, but one who is working twelve hours on something that he is really interested in, say the construction or invention of a machine that is to give him fame or fortune, or the promotion of some new enterprise, or the organization of a new trust or labor union.

We are trying to find some political or social machinery to make men happy, but the only way to be happy is to be busy.

If we think of man as a being who strives rather than as a being who works, eats, and 
sleeps, the problem of social reconstruction takes on quite a different aspect. History looks with approval upon the men who have striven, not the men who have enjoyed. None of the heroes of the past would fit into the standardized world of the future. Only efficiency is to count there. History has been a series of struggles for political liberty, for civil liberty, for religious liberty, and now it is a struggle for economic freedom. To the sentimental, unthinking mind this constant and unending struggle seems pathetic. It is a pity, we say, that these things should have been withheld from man and that he is obliged with such bitterness to win them, and it always seems to us that the forces he is contending against are malevolent forces viciously denying him his rights, just as the laboring classes at the present time look upon the capitalistic classes as malevolent beings who could, if they chose, will that all these evils should cease.

The ideal man, as he is pictured in the writings of the day, is the workman. We see him in his artisan's clothes, tall, straight, strong, and clear of vision, confident of his rights, smarting under the injustice of our social system, representing the dignity of labor. Opposed to him is 
the capitalist, well-dressed, his car waiting at the curb, his home elegantly furnished, his sons and daughters in college, but his eyes shifty and his confidence disturbed. To our minds the workman represents the higher intrinsic value, but the prizes have gone to the capitalist. This is social injustice.

The injustice, indeed, is obvious and intolerable, but the whole picture is based on fictitious values and unsound psychology. Society is not made up of two hostile classes composed of selfish capitalists and labor-loving artisans. It is made up of great masses of everyday people, few of them loving work and all of them loving power. Wrongs many, indeed, there are, but the proposed method of righting them is superficial and unpromising.

The theory is that the workman's contribution to industry being at least equal to the capitalist's, he should also enjoy the prizes, the prizes being conceived as material comforts and educational advantages. Since obviously there is not wealth enough in the world to be distributed to all on such a scale, increased production is the first necessity, involving more and more industrial labor, larger and larger shops and factories, faster and faster means of transportation, 
bigger and bigger centers of trade, more and more industrialized colleges.

But such a civilization is not worth the creating. In itself it would have no ultimate worth. It would not satisfy any basic human instincts or interests, and, worst of all, it would dispel unrest only at the cost of vitality and progress. It rests upon the theory of the intrinsic value of industrial labor and upon the intrinsic value of comforts and luxuries and that kind of education which promotes them. It is only because we have come to put so high a value upon material comforts that industrial labor has taken so high a place in our estimate of worth. But industrial labor is not in itself an ultimate value. It is rather in itself an evil, which our worship of wealth has forced upon us. It is drudgery. The only labor which is of intrinsic value is creative work which satisfies the instinct of constructiveness. As Professor Hocking says, "Manual labor which is robbed of all mental interest is degrading."

From every point of view, therefore, we see the failure of the argument that since the total wealth of our land, if it were equally distributed among all, would not suffice for an adequate 
scale of living, poverty is to be cured only by increasing production. The constant rise of the scale of living, the constantly growing tendency to include more and more comforts and luxuries in an adequate scale of living, involves the endless increase of industrial labor.

The fault in our reconstruction plans is not in the attempt to correct social injustice, but in our erroneous estimate of what constitutes the real prizes of life. Are our so-called upper classes really upper in any sense? Has it been proved that they have attained life's real values, or have they merely gained a certain number of comforts which are really racial and social dangers? Before it could be shown that they are real values they would have to meet two conditions: first, it should be shown that they satisfy fundamental human interests, and, second, that they conduce to social welfare and stability. It is doubtful whether they can meet either of these conditions.

It would seem, therefore, that our present social-reform movements promise merely to intensify the evils of our present system. They rarely rise to the contemplation of a social order which shall offer really higher human values. They center eternally about the injustice of an 
inequality which debars a portion of the people from the so-called prizes of life, the prizes themselves being of no real value and of doubtful benefit to mankind. The real menace to our future happiness is not poverty, slavery, tyranny, oppression, and inequality. These things, like the idle rich, are of course an offense to our age and will steadily be eliminated. But the real dangers of the future are the mediocrity and stagnation which would ultimately fall upon the mere increase of wealth and its even distribution. This would be to settle upon all classes of society the devitalizing and enervating effects of mere comforts, conveniences, luxuries, and leisure.

What we have to do is to find a social order which shall save all classes from the deadening influences of wealth and leisure, and which shall give so much scope to basic human interests and instincts as shall redeem our new world from becoming stale and uninteresting. This new social order will not come by sudden revolution, but by education and patient effort.

Really the social problem of the future is to reconcile the love of romance with the needs of practical life. The picturing of social Utopias, the agitations of our political parties, the organization of labor unions, particularly the novel 


\section{SOCIAL RECONSTRUCTION}

and exciting strikes, provide the dramatic element in life which the human heart demands. The labor crisis in which we live fulfills in a way this romantic longing, but to the participants themselves as well as to the onlookers it seems a bitter though necessary struggle for a future good. But when we calmly examine this future good, this Socialistic or Syndicalistic or Bolshevistic or Non-Partisan League society of the future, we discover that it is a picture of a wholly $\mathrm{drab}$ and uninteresting existence from which all shadow of romance has departed. In such a society, if vitality remained, unrest would increase. If vitality did not remain, stagnation and physical and moral degeneracy would be sure to follow. 


\section{CHAPTER V}

\section{THE PSYCHOLOGY OF WORK}

$\mathrm{N}$ the last chapter we have seen that if society is to be reconstructed to the end of diminishing social unrest, it must be reconstructed on the basis of life, and not on the basis of an adequate scale of living, material comforts, wealth, or efficiency. The aim must be to furnish a field for human activities and to satisfy instinctive needs, these essentially human dispositions being disciplined, suppressed, or sublimated only to a degree necessary to insure such an integrated and stable social life as shall guarantee to succeeding generations a like opportunity.

Dr. Cabot, in his book "What Men Live By," says that real life consists of four things: work, play, love, and worship. The latter two I have considered under other names in the preceding chapters. It will be interesting now to think of work under its psychological aspects. If psychology should be able to throw any light whatever on this problem of labor which is convulsing the world, it is certainly time that this should be done. It may be able to throw little light on such questions of the day as how to re- 
duce the hours of labor and still get the world's work done, how to harmonize capital and labor, or how to reorganize society so that all shall be laborers, because such questions, as they are now discussed, presuppose a certain industrial system which might not itself rest on a psychological basis. On the other hand, psychology ought to be able to make some contribution to the place of labor in the life of man, and until this is settled we cannot hope to determine the place of labor in society.

To be sure, much has been written lately about the psychology of work, but from quite another standpoint: namely, the standpoint of efficiency. Even the human instincts have been tabulated for the purpose of showing what appeal can be made to the worker through his instincts to further his efficiency. ${ }^{1}$ This is surely the last word in exploiting the laborer for the material aggrandizement of society. "Et tu, Brute," the laborer might say to the psychologist. In this age of excessive capitalism it seems a pity to attempt to capitalize even the human instincts.

In all the reconstruction movements of the

1 Compare Walter Dill Scott, Increasing Human Efficiency in Business; Hugo Münsterberg, Psychology and Industrial Efficiency. 
day an extreme emphasis is placed upon work. It is hoped that the idle rich and idlers of all kinds will get to work. It is hoped that an everincreasing number of the men of the world will lend $a$ hand in the work of the world. In some of the proposed social reforms it is planned, not merely that society shall rest upon an industrial basis, but that it shall actually be composed of industrial workers and of no others. Since this is an industrial age, and since there is an immense amount of industrial work to be done, and since the life of the industrial worker is now of such a kind as to cause constant friction and discontent, it becomes imperative to examine very carefully into the relation of industrial labor to the human mind.

Is man by nature a laborer? If not, what will happen in a social order in which man is essentially and primarily a laborer? Among the instincts we did not discover any instinct of labor, although we did discover an instinct of workmanship, and even this was only one of a long list of instinctive activities. What is the relation between workmanship as it appears among the instincts, and labor as it appears in the industrial world of to-day or in the programme of social reformers? 
We recall that labor was imposed upon Adam as a curse, and we recall Carlyle's siren song about man's finding in labor his final glory and only real joy, ${ }^{1}$ and we are a little perplexed as to what the real place of labor is in man's natural life. This fundamental problem needs to be worked out.

Notwithstanding Dr. Cabot's praise of work and Carlyle's adoration of it, work seems to have played a very unimportant part in the history of the world if we may judge by the chronicles of history. Poetry, fiction, painting, sculp-

1 "The latest Gospel in this world is, Know thy work and do “it. 'Know thyself': long enough has that poor 'self' of thine tormented thee; thou wilt never get to 'know' it, I believe! Think it not thy business, this of knowing thyself; thou art an unknowable individual: know what thou canst work at; and work at it, like a Hercules! That will be thy better plan.

"It has been written, 'an endless significance lies in Work'; a man perfects himself by working. Foul jungles are cleared away, fair seed-fields rise instead, and stately cities; and withal the man himself first ceases to be jungle and foul unwholesome desert thereby. Consider how, even in the meanest sorts of Labour, the whole soul of a man is composed into a kind of real harmony, the instant he sets himself to work! Doubt, Desire, Sorrow, Remorse, Indignation, Despair itself, all these like hell-dogs lie beleaguering the soul of the poor day-worker, as of every man: but he bends himself with free valour against his task, and all these are stilled, all these shrink murmuring far off into their caves. The man is now a man. The blessed glow of Labour in him, is it not as purifying fire, wherein all poison is burnt up, and of sour smoke itself there is made bright blessed flame!" (Carlyle, Past and Present, p. 197.) 


\section{THE PSYCHOLOGY OF WORK}

ture, and even the history of peoples give us a picture of other forms of human activity than work. Man is represented not at work, but at war, at the chase, at worship and magic, at lovemaking, at contests and athletic sports, at legislation and politics, at study, prayer, and contemplation, or in travel and exploration. Cain, the tiller of the soil, did not find favor with Jehovah. The "twelve labors of Hercules" turn out upon examination to be for the most part very exciting adventures. The gods of all nations, who supposedly typify the happy and ideal life, are seldom represented as working. The Greek gods did not work; they banqueted, intrigued, fought, and loved women. Only Hephæstus worked, and he was the joke of the Greek Pantheon. ${ }^{1}$ Our own God is not pictured as working, at least only six days. He is a king, warrior, legislator, judge, and enjoys praise and song. ${ }^{2}$

${ }^{1}$ Compare Gilbert Murray, Four Stages of Greek Religion, pp. $65,66$.

2 To be sure, as Thorstein Veblen points out, as the early predatory culture gave place to an industrial civilization, the conception of God as craftsman has supplanted the old notion of God as sovereign; but it should be added that his craftsman-like activity is limited to the work of creation and is of the spontaneous creative kind. (Compare Thorstein Veblen, The Instinct of Workmanship, p. $255 \mathrm{ff}$.) 
Work is not a racial habit, and it is unlikely that the whole world is going to settle down amiably and peaceably to industrial labor, as some of our social reconstructionists would imagine. As Professor Ross says, "Our ancestors, the primitive Germans, passed their time in drinking, gaming, and brawling, leaving industry to women and thralls." "The songs, ballads, proverbs, and tales that well up from the heart of the folk are instinct with a frank delight in meat and drink, in hues and sounds, in revel and song, in love and war, in freedom and danger." 1

It seems thus a little incongruous in the light of history - this extravagant claim of the proletariat, sometimes put forth, to be the only people - this plan to put the whole world to work at manual labor. It shows how completely the spirit of modern industrialism has taken possession of our minds, how tamely we have submitted to be ruled by a new idea without stopping to inquire into its historical and psychological justification. The now rapid weakening of the economic interpretation of history may be the beginning of a saner interpretation of life. Surely if human ideals or human habits as revealed in history count for anything, Mr. Lester

1 Edward A. Ross, Social Control, pp. 355, 336. 
F. IVard was wrong when he described the society of the future as a society of workers, on the ground that work is normal function, since happiness is found in the exercise of normal function. ${ }^{1}$ But he was certainly right in saying that happiness is found in the exercise of normal function.

It would seem, therefore, to be the very first step in planning the society of the future to find out what the normal function of man is and plan our society with a due regard to the materials we have to work with. We must find out whether man is by nature fitted for an industrial society. We must not too readily take it for granted that an industrial organization of society is inevitable. ${ }^{2}$ If it is inevitable, and if man is not by nature an industrial worker, we must inquire how rapidly human nature can be made over to adapt itself to an industrial order. If we assume that an industrial order is inevitable, and that industrial work is drudgery, and that therefore every man must be forced to do this kind of work for a certain limited number of

1 Compare Lester F. Ward, Applied Sociology, p. 336.

2 Herbert Spencer, in his Autobiorraphy, says that our modern age has so associated duty and labor that a man is praised in proportion as he toils, "but the whole thing is a superstition." "Life is not for work - but work is for life." (Vol. II, p. 478.) 
hours each day, and then be set free to do as he likes the remaining hours - as appears to be the favorite view among social reformers now - it is necessary to inquire whether such a divided life will in any sense be a rational or natural life, and to inquire also what the man will do in the hours of leisure thus provided.

Let us examine somewhat more carefully the position of labor in man's instinctive life. Turning back to our list of instincts we find that after all there is one kind of work which is natural for man, although perhaps the word "work," as we understand it now, does not accurately express it. There is one kind of work, however, closely related to play, under which man does not fret nor manifest unrest. It is creative workmanship. It is typified in the planning and making of something which he needs, the kind of labor in which he himself uses what he makes and makes what he himself wishes to use, such for instance as a spear-head, a bow and arrow, a canoe, a dwelling, or a dress. He experiences first a need of it; he plans and patterns it; he uses and enjoys it. Later, as the social impulses develop, he plans and fashions something as a work of art which shall win praise and approval because of its 
beauty, or strengthen the bonds of sympathy with his fellows. Man is by nature a craftsman, but not a toiler. In such craftsman-like work he will put forth every power of mind and body, deriving therefrom the keenest pleasure and making no demands for higher wages or shorter hours. When we see children working unprompted and with might and main at some selfplanned enterprise and gaining at the same time new vigor and new ability, but on the other hand wilting quickly under some lesser task imposed by parents, we speak of the perversity of child nature; but there is no perversity about it, and there is no perversity either in the unrest which follows enforced regular and uninteresting industrial labor. The key to the situation in both cases is found in racial history and habit.

Closely related to this instinct of workmanship there is a group of impulses such as those of thought, mental activity, and the creative and inventive impulse. It is largely to these that in our modern times are due the comforts, conveniences, and luxuries which to many minds stand for civilization, and which in our reconstructed society of the future are always taken for granted. The instinct to explore, devise, invent, discover, and thereby to gain for one's self com- 
fort or fame or fortune or social approval, has sent men to every part of the world, exploiting the resources of nature, uncovering stores of mineral and coal, tunneling mountains, draining marshes, finding new routes of trade, opening new markets, building new roads, projecting new commercial enterprises, inventing new processes and new machines, and devising and perfecting every conceivable device for locomotion and transportation.

It is in this kind of activity that man finds his real life. This initiative, this "exercise of genius," this foresight and daring, this instinctive effort to win fame and fortune, this delight in the testing and spanning of our powers - is it work or play? Anyway, it is life. In this essentially human activity a man is happy because he lives. Incidentally he wins fame, and - perhaps unhappily - he wins fortune, and then the trouble begins. He uses his fortune, which now we call capital, sometimes well and sometimes ill very commonly he uses it as he used his mental and physical faculties, to increase his power over men, and when this power has greatly increased, we justly fear his over-lordship, and we turn to the State to save us from this new tyranny, planning the socialistic State to equalize the. 
social status. But with this new organization of society the man becomes a toiler, subject to the state officials, instead of a creative genius. This is the great dilemma in modern social reconstruction.

In this instinctive workmanship we see man at his best. We see him exercising his normal function. It is not work as we commonly understand work, nor is it play, ${ }^{1}$ but it partakes of both and is best described as normal function. In activities of this kind the human machine is at its best. ${ }^{2}$ The attention, fixed upon the desired and idealized end, is self-developing. It is maintained by interest and not by sheer deadlift of will. The mind works smoothly and easily and with a minimum of friction and irritation. There is a maximum of physical and mental activity, but a minimum of physical and mental strain. Although great physical activity may be

1 On the fundamental distinction between work and play, compare the author's Psychology of Relaxation, chap. II, "The Psychology of Play."

2 "To be mentally active, to do something, is instinctively satisfying. Much of invention springs costless from a mind thinking for the sheer joy of it. Organization, plans in industry, schemes for market extension, visions of ways to power, all agitate neurones in the brain ready and anxious to give issue in thought. A duty of the environment is not only to allow, but to encourage, states in which meditation naturally occurs." (Carleton H. Parker, op. cit., p. 223.) 
present, it is unconscious and willing. This kind of work - if work we wish to call it - is not toil nor drudgery. It is better described as thought and art.

Aristotle, whose strange, uncanny reason seemed to lead him right so often, discusses this very subject. $\mathrm{He}$, too, makes happiness consist in the exercise of normal function; but he finds this in thought and art, not in work, for thought and art are the highest forms of human activity, and human welfare consists in the activity of our highest powers. "Two things," says Clive Bell, "above all give value to a civilization, thought and art."

How different is the work of the modern industrial laborer!

A large part of modern employment [says a recent writer] is an evident maladjustment to the worker. Due to technicalities and abnormalities of land-ownership or transportation or profits, the factory worker too often suffers a wearing outrage of instincts by being confined in a species of artificial inferno. The division of labor has committed the toiler to a monotony of task which is absolutely without warrant in his psychological economy; for a natural environment affords a range of experiences and draws upon all parts of the organism rather than overtaxes a nerve center or set of muscles. The forced production represented by slave labor and the difficulty of getting peo- 
ple to work with spirit suggest that there has been historically and is to-day an almost complete neglect of the organization of industry with reference to natural incentives. People cannot be kept from working, provided employment corresponds to nervous organization. Need there be so complete a divorce between spontaneity, preference, and play, and the job? It might seem difficult to introduce into a system of production a distinct recognition of the natural tendencies of experimentation, curiosity, sociability, leadership, and the like, but only by more fully conforming to natural interests may drudging labor be transformed into joyful effort. ${ }^{1}$

The work of the modern industrial laborer is, then, a species of drudgery in unhappy contrast with the spontaneous creative work which belongs to man's original nature. We should almost take it for granted, therefore, that if we are to have radical social and industrial reforms, the very first step would be to redeem the life of the laborer from that kind of work which is mere toil.

Since the creative impulse is so fundamental in human nature, and since it has given us precisely those things which we prize so highly in our modern world, the question at once arises what place it is to have in our society of the fu-

1 Arland D. Weeks, The Psychology of Citizenship, pp. 73, 74. 
ture. We should assume that it would have a very high place. The mind leaps forward at once to an idealized picture of society in which all work is to be of the spontaneous creative kind the labor of the craftsman. Would it be possible to reorganize our whole industrial system so that toil and drudgery should disappear, and in place should come the spontaneous activity of the craftsman?

But our current social-reconstruction schemes do not propose any such ideal order as this. For the most part what they picture is merely an intensification of our present industrial order. Human wants are not to decrease, but presumably ever to increase. There is to be still more wealth and constantly increasing production, so that every want may be satisfied; indeed, increased production is the demand we hear on every side, to the end, we are told, of reducing the cost of living. Let us have an end of strikes, let us speed up production, let us try to satisfy the wants of the world. And this is not merely a temporary situation resulting from the war. It is inherent in our social philosophy. Our demands are constantly increasing. We want better food and more of it. We want better clcthes, better houses, more comforts, conveniences, amuse- 
ments, and luxuries every year. "Even to-day," as Mr. Walter Weyl says, "we are developing new types of destitutes - the automobileless, the yachtless, the Newport-cottageless. The subtlest luxuries become necessities and their loss is bitterly resented. The discontent of to-day reaches very high in the social scale." 1

These many wants must be supplied somehow. Since now our population is rapidly increasing and the demands of all likewise growing, there is nothing for it but constantly increasing production and a constant enlargement of the industrial side of our life. We sce, therefore, in the years to come more and more thousands or millions of our people in the coal-mines, in the smelters, in the iron and steel works, at the blast furnaces, in the factories, in the workshops, in the repair-shops, at the looms, in the transportation systems, at the distribution centers, in the stores, at the counters, at the desks, at the typewriters, at the telegraph keys, in the telephone exchanges, at the press and the type-setting machines. If it is said that this colossal burden of industrial labor is to be lightened by the invention of new labor-saving machinery and by the participation of all the people in the work,

1 The New Democracy, p. 246. 
the reply is that these will not redeem the world from its self-imposed industrial labor, for this army of laborers can be only slightly reduced in this way. The machinery itself has to be made and the materials for it dug from the earth or hewn from the forest, and it has to be installed and repaired. Some one has to do this; and if we think that the burden of this toil will be lightened by the fact that all will take part in it, we must reflect that the present great army of brainworkers cannot be diverted to do this manual work, for under whatever system the work is done, whether by individual enterprise or state ownership or Guild Socialism, there must be superintendents, and directors, and managers, and overseers, and foremen, and supervisors, and inspectors, and surveyors, and bookkeepers, and accountants, and collectors, and bankers, and advertisers, and buyers, and sellers, and so on through the long list - a great army of brain-workers, then as now. When we think of the ever-increasing demands of our modern life for an immensity of things which we want to use and enjoy, and when we realize the corresponding magnitude of our industrial life in the years to come, and think of the experts necessary to organize and conduct this great industrial ma- 
chine, we can understand how idle is the dream that any of our proposed social revolutions will redeem the life of the toiler by substituting craftsmanship or creative work for mere toil.

It appears, therefore, that in the society of the future, whatever system of social organization we may have, there is to be no relicf from the burden of industrial life. The work is to be of the same kind and in ever-increasing amounts, and there are no plans in sight for humanizing this labor. The problems which seem to concern us are how to increase production and how to get our goods and our wealth more fairly distributed. The more important problem of adapting our industrial system to the mental make-up of the industrial worker seems to have had little attention. In our present system this adaptation is lacking. In the society of the future it ought to be attained. As Professor Weeks says, learning to drive a nail is a unique experience in a person's life, but continuing to drive nails all day is deadening. "How strange it is that the passing years sap the romance of life as well as the beauty, and how the new inventions - laborsaving devices, they call them, and multipliers of wealth - have taken the color, the creative zest, and the novelty out of work, and left it a 


\section{I36 SOCIAL RECONSTRUCTION}

husk, a dry, mechanical grind, a cut-and-dried function of physical drudgery without a soul." 1

It is this situation, no doubt, which is in part responsible for the labor troubles at the present time. The worker has been dehumanized by the new and unnatural system of industry which the discovery of iron and coal, together with the industrial revolution, have brought about, a system which has no sanction in the original nature of man.

One cannot but wonder how much of the unrest of the day and the friction between capital and labor is due merely to a kind of irritability which is the result of a life not according to nature. Our conditions of living involve too much strain and stress and tension. To hold one's self down to an uninteresting task by means of sustained voluntary attention results in rapid fatigue of brain tracts developed only late in human history and therefore especially subject to fatigue. This unnatural sustained effort is present in all the various kinds of industrial work where there is no immediate interest in the finished product, where it is necessary to hold one's self down to mere work for a certain number of hours each day. It is present in many

1 William J. Fielding, in The Nation, November 8, 1919. 
kinds of clerical and office work, and in routine tasks of all kinds. The resulting fatigue is both physical and mental. Release from it is sought again in unnatural ways, sometimes in narcotics or stimulants, such as alcohol, tobacco, narcotic drugs, tea, coffee, sugar; sometimes in amusements such as dancing, moving pictures, and vaudeville shows requiring no exercise of voluntary attention; sometimes in various forms of social outbreak such as strikes, anti-social agitations, revolutions against existing morality and the existing social order; sometimes merely in reading journals or magazines of revolt. There is too much confinement about our life. The young are confined in schoolrooms, even between seats and desks; the older are confined in the indoor life of our modern home, or in offices, stores, workshops, or factories. Our fathers and forefathers back for many thousands of years lived a more open life, a more out-of-door life, a more independent life, a more irregular life.

It is not discipline that we object to. Mankind has lived under the severest social discipline for long centuries. It is rather confinement, physical and mental confinement, that causes the trouble. We long for "the open road." But psychologically considered the open road is a life in which 
our instinctive interests have free expression. Specifically it is often a life in which we find relief from the dead-lift of will and constant sustained attention to an uninteresting task. In practice relief would be found in the life of the craftsman, in some kind of work crowned with success and social approval.

To jump to the conclusion that we in America are all living this cramped mental and physical life would be the greatest of mistakes. We shall see below to what a wonderful extent we in America are actually living the life of the open road. I am only showing here that the industrial life, which is growing more and more intense throughout the world, issues in a state of social irritability due not at all to our social and political institutions, not at all to any cramping moral conventions, but to our industrial conditions and our manner of daily living.

Professor Thorstein Veblen, in his book "The Instinct of Workmanship," has discussed in his engaging manner the relation of this instinct to our modern industrial system. ${ }^{1}$ Modern business

1 Professor Veblen's interest in the question as it is treated in this book is apparently more in its religious and philosophical aspocts than in its relation to our present social problems. 
enterprise, he shows, has worked disparagingly upon the instinct of workmanship. In the era of craftsmanship

industry is conceivea in the terms of the skill, initiative, and application of the trained individual, and human relations outside of the workshop tend also by force of habit to be conceived in similar terms of selfsufficient individuals, each working out his own ends in severalty. The position of the craftsman in the economy of that time is peculiarly suited to induce a conception of the individual workman as a creative agent, standing on his own bottom, and as an ultimate, irreducible factor in the community's make-up. ... With his slight outfit of tools he is ready and competent of his own motion to do the work that lies before him, and he asks nothing but an even chance to do what he is fit to do.... The man who does things, who is creatively occupied with fashioning things for use, is the central fact in the scheme of things under the handicraft system. ${ }^{1}$

In our modern industrial age all this is changed. In this era of the factory system, of large-scale machine industry, pecuniary benefit is the end in view. The price era has come, the era of "bargaining and of competitive principles in business"; price, profits, and gain are in the mind. Efficiency is understood as that which promotes profits, not that which produces perfect work as the result of perfect workmanship.

\section{Pages 234, 235. ,}


"Workmanship comes to be confused with salesmanship." "To do well" no longer means to execute some finished and perfect piece of work with one's own hands, but to be successful in business enterprise. ${ }^{1}$

So it appears that in our modern industrial system the whole motive of work is changed. That which was formerly interesting in itself, because of its direct relation to a finished and interesting product, is now of no interest in itself and has slight reference to any finished product. It is done for a price and for profit.

Thus it comes about that there are disharmonies and maladjustments in our modern industrial system. In the writings of the day these disharmonies are attributed to the insufficient wages, the long hours, and the unsanitary conditions of the laborer. But in the era of craftsmanship the wages were far lower, the hours far longer, and the conditions of living worse. Happiness is not found in wages nor in short hours, but in the fulfillment of function. "The joy of the workman is in the end, and that enlivens the act. Not work but drudgery kills." 2 The instinct of workmanship demands that the com-

- 2 Thorstein Veblen, op. cit., p. 349.

- William A. McKeever, Man and the New Democracy, p. 67. 
pleted product, as a definite, single object of art or craft, should be pictured in the mind of the workman and it should be pictured as the result of his personal and individual effort bringing him social applause.

This does not, however, mean that this instinct of workmanship has no social application, but it can be socialized only within very narrow limits or when the end to be attained is of immediate vital interest to the group. Thus the individual may take pride in the craftsman-like product of his family or his guild or his narrow social group. It could be extended to a large industrial group only provided there were a very lively rivalry with some other group making the same product. Here the instincts of emulation and rivalry come in to lessen the disharmonies of work which approaches the form of drudgery. It is conceivable, for instance, that railroad men might willingly and cheerfully perform their duties if only there were another rival railroad in visible competition with theirs. But let the State own all the railroads, and it is difficult to conceive of any psychological motives which shall redeem the work from drudgery. Even with state-owned railroads, however, it is possible that men will work willingly and loyally in times of 
national peril, especially if the danger be imminent. This was illustrated in our late war, when in a thousand factories men and women bent to the work of toil with zest and fervor.

It becomes, of course, an interesting question to what extent our great typical industries could be socialized and still give expression to the instinct of workmanship. This seems to be the vague hope in such movements as Guild Socialism and Syndicalism, 60 far as these have any positive plan and are not mere negative movements destructive of our present social values. This question I shall consider presently, but thus far it appears that industries cannot be socialized beyond very narrow groups without the loss of interest in the industrial product, except upon great epochal occasions, such as war, or in situations where there are vivid pictures of emulation and rivalry.

It would appear, then, that, if disharmonies are to be avoided, work must be natural; it must proceed from the instinct of workmanship. Or if it is in the form of drudgery, it must be vitalized by loyalty, emulation, or love. ${ }^{1}$

1 This appeal to emulation, loyalty, or love is quite different, of course, from the capitalizing of these sentiments referred to above, where the end in view is merely pecuniary gain os the increase of efficiency. 
Thus far it appears that man's instinctive needs do not find expression in the work of the modern industrial laborer. There is maladjustment on every side, and it further appears that in the industry of the future our present system is to continue much as it is now. None of the reconstruction movements, from the mildest theory of Coöperation or Profit-Sharing to the most extreme Anarchism, really propose any serious modification of the essential nature of modern industrial work. The only difference is in organization and management. There is to be a different social order, but not a different industrial order, nor any different kind of work.

What plans, then, do the reconstruction movements offer for the relief of the drudgery of industrial labor? Only these - the increase of wages, decrease of hours, and participation in profits or in management or collective ownership and operation. No hope is held out that the work itself will be essentially different. It is to be made endurable or attractive in the above ways. Whether it be by extreme Communism, or the more moderate Collectivism, or the still more moderate Agrarian Socialism, or merely by Coöperation or Social Democracy, we never get much beyond the conception of the more equi- 
table participation of the worker in the results of his work. He is to have more of the profits or he is to have more of the things produced. He is, perhaps, to be his own boss and manager and in this way see to it that he gets his full share. And this is the reason that he is to be collectively his own boss and manager, perhaps also the owner; not to begin the production of objects of worth and beauty, not to undertake the manufacture of goods whose workmanship one might be proud of, but bluntly and solely ${ }^{1}$ to see to it that each laborer and each participant gets his full and righteous share of the profits or the goods, to the end, indeed, that all shall attain to an adequate scale of living with comforts and luxuries and leisure and opportunity. And opportunity is always interpreted to mean, not opportunity to make one's work the expression of an instinctive love of beauty and art and workmanship, but opportunity for extraneous things, after the work of the day is done - opportunity for acquiring information, for culture, for recreation and amusement, for self-development. In other words, there is scarcely any attempt in these mavements to escape from the

1 There is, however, present also the laudable desire to be the master of one's own destiny. This I have discussed below, p. 147. 


\section{THE PSYCHOLOGY OF WORK}

philosophy of the pecuniary culture of the times. We hear of no ethical objections to the ideals which govern the business superman of the day - namely, to make money and enjoy the fruits thereof - but only to the distribution of the money and the fruits. There is still to be a pecuniary culture, only collective society is to be the superman. There is no thought, apparently, of organizing society upon a psychological basis such as that proposed by William Morris:

When will they see to this and help to make men of us all by insisting upon this most weighty piece of manners; so that we may adorn life with the pleasure of cheerfully buying goods at their due price; with the pleasure of selling goods that we could be proud of both for fair price and fair workmanship; with the pleasure of working soundly and without haste at making goods that we could be proud of? - much the greatest pleasure of the three is the last, such a pleasure as, I think, the world has none like it. ${ }^{1}$

To what extent will social unrest be quieted by the increase of wages? 'There is one thing now upon which all parties agree; namely, that the wage of the laborer and of all men and women working for wages or salary should be adjusted to the point at which they shall receive their just share of the profits of industry. The social con-

1 William Morris, Hopes and Fears for Art, p. 30. 


\section{SOCIAL RECONSTRUCTION}

scicnce has long since been awakened in this matter; and while such adjustments necessarily take a little time, there is no reason to doubt that the rightful share of the wage-earner may be determined and proportioned, and there is also no reason to doubt that the attitude of mind of the employer as well as the laborer is becoming more and more favorable to this change. ${ }^{1}$ But it is equally certain that a mere increase of wages will never redeem the evils of the industrial system. Unrest and disharmonies do not disappear with the increase of wages, and this would be particularly true in a social system where there were no opportunities for the individual investment of wages and savings for the winning of personal fame and fortune. It may well be that the era of great fortunes, of swollen fortunes, and all that sort of thing in our present sense of the word fortune, is drawing to an end. Society will have something to say about that. But no society based on psychological laws - that is, no progressive society - can exist in which there is not an opportunity and justifiable hope in the breast of each individual

1 "In recent months this "adjustment" has taken place so rapidly that in many trades hand workers, particularly mechanics, have perhaps already more than reached this limit, the increase of wages being merely added to the selling price of the product. . 
to win for himself some kind of fame or fortune.

In a decadent society the workman might submit to the drudgery of industrial labor for the sake of wages, but in a vital age like the present this is very questionable. Wages must be a means to some glowing ideal, not a mere means to an adequate scale of living. To save, to invest one's savings with the hope of gaining more, to get ahead enough to buy a home for one's self and one's mate, to accumulate enough to start out in business for one's self, to be one's own boss, to save and invest one's savings in some wholly new enterprise or undertaking which one has one's self planned, to get enough money or capital to carry out some pet scheme or idea all this is human, instinctive, and interesting. It is life. But your beehive-of-happy-workers theory of society, in which all are happy because all are at work and have hours of leisure and an adequate scale of comforts and luxuries, has scant foundation in psychology.

One of the fundamental needs of the human mind is the need for personal achievement ${ }^{1}$ and individual initiative. A man wants to do and dare, to risk something for the sake of great per-

1 Compare the article on "'l'he Right to Achicve," by Franklin H. Giddings, Unpartizan Review, Octuber-December, 1919. 


\section{I48 SOCIAL RECONSTRUCTION}

sonal gain. Thus the question of the relative advantages of Socialism, Communism, and Individualism are seen in a new light, and must be judged and decided on psychological grounds, not on social grounds alone. It is no longer a question as to whether any one of these forms of society is better, judged on theoretical grounds, to the end of conducing to economic production or to social welfare, where social welfare is interpreted in economic terms. It is rather a pragmatic question of which of these social plans will work; that is, with the human material that we have in hand. In the case of bees and ants, communism works, but the price is stagnation. If the idea of progress is eliminated and the mere perpetuation of the given species is the end, some such form of social organization would be ideal.

But your twentieth-century man is built on another plan. He does not care to sink himself in the community. He wants to achieve. The tremendous virility of the man of to-day, his powerful self-assertiveness, restlessness and aggressiveness, his will to live, his will to power, make this century the worst possible time to put in practice any socialistic or communistic plan. A certain degree of socialization of some of our great industries or natural monopolies becomes 


\section{THE PSYCHOLOGY OF WORK}

necessary by the conditions of our modern life, but we shall probably be disappointed if we hope that this will allay unrest. The more this simple and justifiable form of Socialism is extended so that the community does more and more things which the individual wants to do, the greater will be the unrest if vitality remains, and stagnation if it does not. We are so obsessed with the economic aspects of things that to many people the case for Socialism would seem to be proved if it could be shown that the community could do things more economically, more cheaply, than the individual, with less waste. But all this is changed when we realize that the best society is one which best furnishes a field for human activities, not one which is the most economical, which best eliminates wastc. That the time is coming when waste must be prevented, when conservation of all natural resources must be practiced, if great populations are to be supported, may well be true. To this end conservation seems to be more promising than radical changes in our social order. Perhaps we too readily take for granted the wholly unwarranted supposition that our own expansive and materialistic civilization is the only one to be thought of. There are other ways out of the dilemma, 
other paths to take than that of the eternal release of new desires and the ever-increasing hopeless attempt to satisfy them.

But now it may be said that it is altogether a narrow view of the reconstruction movements of the day to represent them as limited to the economic view of life. They, too, recognize the need of providing a field for human activities and for giving expression to human instincts. To this end the unrest of the present is to be relieved, not merely by the increase of wages, but also by means of two other plans: first, to provide more hours of leisure in which there shall be opportunity for the expression of all legitimate human interests, even the instinct of workmanship; and second, so to reorganize our industries that the workman himself shall have an active participation in, or actual management or ownership of, the industry with which he is connected.

As regards the second of these proposals, all the plans for Profit-Sharing, Coöperation, Collective Management, and even Collective Ownership, would seem to offer attractive means of escape from the deadening situation of the present industrial worker. Many experiments in the democratization of the means of production are 


\section{THE PSYCHOLOGY OF WORK}

now in progress, and for the most part with the very happiest results. In some of our large industries the problem of capital and labor seems almost to have been solved in this way. In some companies even the unionizing of the workmen has been found to be uncalled for and unnecessary, so satisfactory are the relations which have been established between owners and laborers. It is the vicious theory of the class war which has scattered far and wide the wholly gratuitous belief that there is a necessary antagonism between capital and labor.

In the democratization of industries there is, then, nothing inconsistent with our present social system and nothing calling for any revolution. There is already a healthy evolution in this direction.

Many plans for the democratization of industry have been proposed and many already put into successful operation. Compare, for instance, the Clark Plan, the Whitley Plan, the Colorado Plan, the Stotesbury-Mitten Plan, the Leitch Plan, the Endicott-Johnson Shoe Company's Policy, and many others. ${ }^{1}$ Compare also the fol-

1 For a description of the remarkable results in solving the labor problem which follow upon the institution of industrial democracy, sec the little book by John Leitch, Man to Man; The Story of Industrial Democracy. Compare also the pamphlet entitled Works Coun- 
lowing proposal by Dr. Charles W. Eliot, President Emeritus of Harvard University:

This plan involves on the part of employers the abandonment of every form of despotic or autocratic government in industries which deal with the necessaries of modern life; the universal adoption of coöperative management and discipline, the employer and workman having equal representation on managing committees; the adoption in industries of means of promoting the health and vigor of the employees and their families, with the continuing of education for adults; provision for dealing promptly and justly with complaints, in which foremen may be witnesses, but never judges; the use of well-trained employment managers; the adoption of a partnership system for equal distribution of profits between capital and labor, with representatives of employees in the directorate; the diminution of monotony and the increase of variety in occupation; the universal acceptance of collective bargaining; and, on the part of the employees, the abandonment of the doctrine of limited output; the abandonment of the idea that it is desirable for workers of any sort to work as few hours in the day as possible; rejection of the notion that leisure rather than steady work should be the main object of life; the selection of occupation with regard to the chance in it for interest and instructiveness and consequent satisfaction; abandonment of the idea that capital is the natural enemy of labor cils in the United States, published by the National Industrial Conference Board of Boston, and the articles in System, December, 1919, and Outlook, December 10, 1919. Compare also Meyer Bloomfield's book entitled Management and Men, and the Monthly Labor Review, January, 1920. 
and that unorganized laborers are traitors to their class; abandonment of all violence toward property and persons in industrial disputes; and, on the part of both parties to industrial strife, willing adoption of the methods of conciliation, arbitration, and ultimate decision by a National Government Board; recognition that a new and formidable danger threatens civilization in anarchy and violent socialism; general acceptance of the view that American liberties are to be preserved as they have been won by personal independence, industry, thrift, truthfulness, respect for law and family life, and a readiness to fight in defense of these things; and acceptance of the truth that democracy is not a dead level, but the free cultivation of infinitely diversified human gifts and capacities. ${ }^{1}$

The question of complete collective ownership of industries is, of course, another matter and the psychology of it is interesting. The instinct of ownership is individual, and collective ownership would seem to be a contradiction in terms. Its whole meaning would seem to be lost when it is socialized, its mainspring and motive gone. Nevertheless, instincts such as these may be socialized, as we have seen, within narrow limits and still retain their instinctive nature, as in the case of the family and in that of a very narrow and closely integrated group, or even with larger groups when the safety of the group

1 The Outlook, December 10, 1919. 
is threatened or when there is a vivid sense of emulation and rivalry with other groups. Whether ownership could be socialized in general in our big modern industries, it is difficult to say, as there seems to be no way in which the necessary spirit of rivalry or emulation could be retained which should make such socialization conform to psychological conditions. Otherwise there would seem to be little gain. The first flush of ownership would be a novelty which would lighten the drudgery of industrial toil by the hope of larger returns to the individual. $\mathrm{He}$ would see the promise of greater wages or more goods or increased independence.

Closer examination, however, shows that the situation would not really be humanized, or at least not greatly so. There are still to be big cities, big industrial centers, immense factories, increased production, more desires to satisfy and more goods to satisfy them. The economic idea is not to be changed; it is to be intensified. The workman will still find himself at the loom, or the lever, or the counter, or the desk, or the typewriter. The executive part of the work will still be in the hands of experts who will be sought out as now for their ability, and hired as now directly or indirectly, and the "toiler" will not 
find his toil greatly alleviated by the fact that at periodical intervals he may attend a directors' meeting and cast his vote for the management. There seems to be here little increased opportunity for invention, contrivances, dexterity, tact, or creative effort.

Such movements as Syndicalism and Guild Socialism sometimes dazzle us because they seem at first to offer something very different, and we feel that something very different from our present situation is necessary; but a careful examination of them shows that they offer nothing very different. They are by no means so radical as they sound. They still move quite within the sphere of current industrialized thinking. The distinctive features of Syndicalism, such as the general strike and a great social cataclysm, promise a social chaos which, in view of the things that have happened in Europe since the war, no longer seem so attractive as before, but cause us to shrink from them in dread and terror. The nearer view of cold and hunger and listless discouragement and inefficiency and the tyranny of new leaders has taken away the glamour of revolution. On the other hand, the constructive features of these movements are meager and disappointing. What we see is no actual return 
to an arts and crafts system, no real opportunity for the expression of the instinct of workmanship, but only the old gigantic industries, perhaps unified into guilds. One looks in vain for any real humanizing of the industrial system.

Incidentally, I may refer here to one peculiar feature of these movements which, in the light of psychological study, appears in quite a new light. I refer to the proposal sometimes made to "abolish" the State and let society be built around the industrial unit on a strictly industrial basis. This appears to be a complete reversal of the psychological method, since man's political instincts are deeply engrained by thousands of years of political life, while our present industrial system is not yet two hundred years old, and man has in no wise fitted himself to it. It is only in those Utopian schemes in which the units of the new society are not human beings with human passions and weaknesses, but such dehumanized and denatured angelic creatures as parade in Mr. William Morris's "News from Nowhere" and in many other Utopias, that the State is unnecessary. At our present rate of moral progress it will still be some time before there are no disputes to settle, no criminals to. 
restrain, no laws to make and enforce, no taxes to collect, and no armies to raise.

However, if we wish to put the new society on a human basis - to make it conform to psychological laws - the State is the very last thing which we should abolish. Man is by nature a political animal, and politics gives an ample scope to many fundamental human instincts. It is a safe guess that he will continue to be politically occupied for a long time to come. If any one should question this, it would only be necessary to observe the conspicuous rôle played by politics in the post-war history of the European nations, when, if ever, it was imperative that the people should settle down to work and the building-up of their depleted industries.

Ancient Athens, devoted as it was to art, literature, and philosophy, seethed with politics. In Central American republics, where it is too hot to work, political activity flourishes. I am here using the word "politics" in its strict sense, as activity in the affairs of the State, an activity which is fundamentally human and gives cxpression to many deep functional demands, such as thought, mental activity, organization, leadership, and loyalty. ${ }^{1}$ Perhaps much the same

1 "Political life is, as Aristotle later described it, an arena for distinguished action, a conspicuous jousting-place for contending 
might be said of party politics, which also seems to afford a field for human instinctive activities and enters actively into all our countless modern organizations, societies, and unions. It is becoming pretty clear that man finds his highest happiness, not in the ends for which his unions and organizations exist, but in the unions and organizations themselves. In the latter is found real life with all its restless strivings, hopes, and fears; in the former is the dead level of things acquired, or wealth and leisure and an adequate scale of living. It will be a long time before man ceases to be a politician and becomes merely a laborer in the industrial sense.

It is evident, therefore, that merely socializing our means of production will not humanize them, while substituting an industrial society for the State would dehumanize it still further. ${ }^{1}$

principles and men having much energy to discharge.... We are social and political creatures, at least in part, because we need to inject our reasons and our moral perceptions into the world's work. We build states, at least in part, because of this will to power." (W. E. Hocking, IIuman Nature and Its Remaking, p. 88.)

1 "That the industrial organization of society can supersede the political organization is perhaps no longer held by serious thinkers," says Mr. J. H. Harley in his book on Syndicalism. "There are signs that, whilst preserving their zeal for their own associations, the syndicalists of the world are forgetting the first fury of their opposition to the politician" (p. 9o).

The present position is rather this, that while the State shall be organized geographically as before, the several industries must be 
This brings us to consider the other part of the plan for making industrial life endurable and relieving the position of the toiler, and this is by adding to his hours of leisure. It seems generally to be admitted in all the reform movements that industrial labor is an evil of the nature of drudgery, and it seems pretty certain that the drudgery aspect of it, while it might be somewhat alleviated by collective management, cannot be greatly relieved in this way. At a meeting of the Boston Central Labor Union, a speaker who mentioned the "joy of labor" was met by the derisive laughter of the men, as Dr. Cabot says. The attitude of these working-men toward labor was the result of their actual experience, not a reflection of the old-time custom of regarding manual labor as lacking in dignity and respect. There seems to be comparatively little of this

independently organized and controlled by their workers. But here again we meet with difficulty. "Is it not the case," says the same writer, "that some industries, such as those which have to do with keeping open lines of communication, are so fundamental to the well-being of the community that the citizens generally can't leave them without heavy and adequate representation of the people at large?" (Syndicalism, p. 87.)

The relation of the political state to the guild state is further explained by Mr. G. R. Stirling-Taylor in his book The Guild State. To the former very important functions are conceded and still more sweeping ones would in the opinion of others necessarily follow. 
feeling left, although, as Professor Veblen shows, it has been the determining social element in the past. ${ }^{1}$ The remedy, therefore, for the drudgery of labor is sought, in our modern reconstruction movements, in lessening the daily amount of it and adding to the hours of leisure. The workman is to work at unpleasant toil for six or eight hours of the day; he is to sleep eight hours; and for the remaining eight or ten hours he is to be set free to do as he likes.

Here we are immediately confronted with the question, How will he use those leisure hours? And when we attempt to answer this question, we instantly idealize the working-man and we expect him to use his leisure as the intelligent, well-poised, and self-controlled laboring-man would do. We picture him again in his workingman's dress, tall, straight, clear of vision, and definite of purpose. Such a man will use his leisure wisely, in devotion to his family, in some kind of constructive workmanship, as in arts or crafts, in self-improvement, in spiritual development, in reading and study, and in the pursuit and enjoyment of art, science, and literature. But when we try to visualize the actual millions of workers, male and female, young and old,

1 Thorstein Veblen, The Theory of the Leisure Class. 


\section{THE PSYCHOLOGY OF WORK 161}

pouring from the shops, factories, offices, and stores, we see that the psychology of the leisure hours is a difficult problem. What most of these people will seek will be entertainment and amusement, and those perhaps not of a very high type.

This whole subject of leisure needs to be studied in its psychological, economic, and social aspects. In all our plans for improved social conditions it is almost uniformly taken for granted that leisure, resulting from a shortened workingday or from time-saving and labor-saving devices, will be an unmixed good. But leisure itself is not good; it may be a serious evil. There have, indeed, been epochs in history when men, released from toil by wealth or otherwise, have turned their thoughts to beautifying their environment and surrounding themselves with works of art. At such times, too, poetry, music, and the worthy drama have flourished. Is it quite certain that we are now living in a time when mankind can be trusted with leisure? It is probable that the time is far distant when our system of education and our sense of individual responsibility will be sufficiently developed to make added hours of leisure a safe social experimont. 
What, then, it may be asked, shall we do? Shall the laborer be kept at work ten or twelve hours a day in order that he may not misuse his leisure? But this question implies a complete misapprehension of the position taken by the psychologist or the student of social problems. The laborer is, no doubt, quite as able to use his leisure wisely as the so-called leisure classes; more able, perhaps. In ancient Athens the leisure classes made fairly good use of this opportunity. In our modern times they have often made ludicrous spectacles of themselves. The real problem is quite different from this. It is not a question of classes; it is a question of the relation of leisure to our whole industrial and educational system - the relation of leisure to our theory of life. It is probable that the safe use of leisure implies a degree and kind of education which our American people do not yet possess. In southern lands and among the southern races the problem is quite a different one. The pulse of energy which is now pouring into the nervous system of our northern people makes leisure dangerous. ${ }^{1}$

1 "To-day more Americans are seriously endangered by an un. wise consumption of wealth or by an inept use of leisure than by overwork or by evil conditions of work, although the latter, to a considerable extent, induce the former." (Walter E. Weyl, The New Democracy, p. 330.)

Dr. Charles W. Eliot, President Emeritus of Harvard Univer- 
Many educators, as we know, are now advocating doing away with the long summer vacations in our schools. Some favor a much longer school day, or school six days of the week, the school, of course, to be quite different from our present perfunctory study and recitation plan and to be more like real life. This furnishes us the key to the social problem of leisure. Most men are children, and what they want is not leisure, but life; and this applies to the rich as well as the poor, and to the poor as well as the rich, a distinction in which in these psychological studies we are not much interested. It is unnatural for a man to be engaged in toil or drudgery six or eight hours of the day and then be set free to fill up his leisure time. His work must be his life and his life his work. But this implies a different kind of work from that proposed in our present industrial system or the industrial system planned in our social reforms. It is altogether possible that if a man should find his work during his six or eight hours, something to

sity, in his proposed plan for the settlement or prevention of industrial conflicts recommends "the abandonment of the idea that it is desirable for workers of any sort to work as few hours in the day as possible"; and the "rejection of the notion that leisure rather than steady work should be the main object of life." (See above, pp. 152, 153.) 
call forth his best endeavors, something of vital interest, he could profitably fill his remaining time in healthful relaxation, play, gardening, home-building, etc.

Some writers on reconstruction, recognizing the importance of the instinct of workmanship and understanding that our industrial system does not find a place for this, suggest that this instinct might find its appropriate expression during the leisure hours; but this instinct is not of the nature of the thing which can be pursued as a pastime during leisure hours; it is life itself - and society, if it is to be reorganized, must be organized on the basis of this and other vital interests; but we propose to organize society on the industrial basis and make these instinctive interests a matter for our leisure hours.

It would appear, therefore, that none of the reconstruction movements of the day hold out any real hope for humanizing labor or promise any real expression of the instinct of workmanship. The picture is somewhat brightened by the good-will which may be introduced between employers and employees through the democratization of industries. But for increase of wages, or for leisure, or for collective ownership, psy- chological motives fail. 
Other plans have, of course, been proposed for redeeming the life of the industrial laborer, such for instance as industrial education and improving the conditions of living. Certainly these are necessary stages in our industrial growth, but as a solution of the problem of labor the futility of these means is evident. This has been so well expressed by John Manning Booker, in a recent article on "Industrial Partnership," that I quote from him at some length:

For three quarters of a century the social-uplift worker has been nobly engaged in bettering the conditions of living created by modern industry. With much to be done, he has accomplished much; ;but his most has failed to bring content. Even where he has secured the active cooperation of the State and the individual manufacturer, and, in 'consequence, succeeded in attaining or approximating his ideals, he has failed, we venture to say, to bring content.

Houses designed with a view to please the workman's eye and reduce the labor of his wife - sewered, drained, centrally heated, electrically lighted, equipped with "all the modern inconveniences," and with a stunted evergreen in a garden box on each side of the front door; hospitals and community nurses; schools that have theaters, refectories, gymnasiums, pictures on the walls, and even real teachers in the classrooms; libraries - open or closed shelf; parks and playgrounds with trained attendants, one to show the larger children how to use the gymnastic apparatus, another to lead the songs and dances 
of the middle-sized children, and a third to dust the babies; churches with every conceivable parishhouse activity and preachers who make using the Ten Commandments seem easy and natural - all this is paradise, but it is not content. And the real man would be just about as contented in such a community as he would be in paradise; which is to say, not much: unless, contrary to everything we have been led to expect, he should be permitted to tumble it down and build it over again. We could get used to walking on golden pavements in no time; but it would make us extremely nervous and depressed to know they were permanently laid.

The industrial education idea appeals to us as nearer the mark; but it falls short. It benefits too few. It benefits the real craftsman - the designers among laborers. But this element has decreased in proportion to the increase of quantity output. In past times every skilled workman was a designer or an apprentice to a designer; but nowadays the only survivor of the craftsman is literally one in a thousand. Tens of thousands engaged in making clothes for American men; and how many cutters! Industrial education is a splendid thing; but it is for the few, because under modern conditions only the few have a chance to use it.

The betterment of living conditions and the spread of industrial education, therefore, will not, in our opinion, suffice to content the workman and allay the industrial unrest.

At its present stage this discussion may be thus summed up: If the workman is to be happy in his work, his building instinct must be satisfied. This instinct, which formerly found relief in making a whole thing, has been choked by the processes of modern 
manufacture involved in quantity output. The machinery of modern industry has made a machine of the workman; it has brutalized him. But the industrial system is here to stay. The problem is how to humanize it. How can we change the workman's job so that while he is at it he will feel like a man building something? Like a man? Like a god. And then to find enough of such jobs. A large order - that. Profitsharing will not fill it, or betterment of living conditions, or industrial education. We cannot see how any of these things alone will correct the existing evil, because, to our mind, none of them is aimed at the root of it; namely, the industrial system's stultification of the individual workman's building instinct. ${ }^{1}$

This author believes that the only possible solution of this question - and that one by no means certain - is industrial partnership. I have referred above to the possibilities of industrial democracy. It can surely alleviate, though it cannot cure, the evils inherent in our industrial system. Collective management, like collective ownership, might relieve for a season the burden of industrial labor, but the "handleturner" will be the handle-turner still. The truth of the matter is that our whole industrial system, in its severer features, is less than one hundred years old, while human nature is several hundred thousand years old, and mankind

1 "Industrial Partnership," Yale Review, January, 1920, pp. 923-95. 
is adapted to a very different kind of life from that incident to our modern industrialism. It goes along with our steam-heated, air-tight houses, our gasoline and electric cars and burdenbearers, with our city and sedentary life, with our hospitals, doctors, and dentists. The twentieth century will perhaps determine whether we can adapt ourselves to this new, and for man unnatural, order, or whether our industrial system itself may prove to be the ruin of our civilization.

But there is one curious aspect of the situation still to be noticed. If we speak of the instinct of workmanship, not in its narrower sense of craftsmanship, but in the broader sense of planning, contriving, inventing, designing, including all forms of creative activity, we must recognize that our present social order gives large opportunity for its expression. This has been conspicuously true in America.

Never in the world's history has so large a mass of men, hundreds of millions of them, had so glorious an opportunity for the free expression of every latent energy, as have the pioneers and citizens of the Americas during the time since the discovery of the Western hemisphere. 
Our country has offered unparalleled opportunities for the instinct of workmanship in its wider meaning. America has been the paradise of the inventor, the discoverer, the entrepreneur, the organizer, the adventurer. "Enterprises," "projects," and "propositions" are the language of the country. It has been the place where all may adventure, speculate, and experiment; where they could think new thoughts and try them out. Plans, contrivances, and ideas have been everybody's privilege. Pursuits and undertakings of all kinds have been in order. Initiative has found here a ready market. It has been the home of achievement, of inventiveness, and of analytical thought - and all this is life. It is real life.

To what extent is this true at the present time and to what extent will it be true in the future? Our answer will depend much upon our point of view. If our experience has been in the great industrial centers where men are herded in monster factories, condemned to a life of mechanical drudgery, we may say that the opportunity is past. If, however, we picture our country as a whole including our great agricultural and fruit-growing States in the Middle West, in the South, upon the Pacific slope, our answer 
will be different. In general, our writers upon social and industrial reform have quite too uniformly concerned themselves with our great industrial centers. Let the observer ride through the cities, towns, and country of any great typical Western or Pacific State. He discovers first an endless succession of well-tilled farms, a large proportion of them cultivated by their owners. The farmers are, for the most part, prosperous and happy, enjoying abundance of food, living in neat and comfortable houses, rejoicing in many modern conveniences such as telephones, free delivery of mail, and transportation by means of motor-cars. They are free from dangers and oppressive taxes, both parents and children planning many ventures for gain, for pleasure, for advancement.

At short intervals throughout this great territory the traveler will find an interminable number of small towns and villages, all very much alike and all representing a high degree of comfort and happiness. A large proportion of the homes in these countless towns and villages will be found supplied with bathrooms and electric lights; daily newspapers, books, and magazines abound; the men and women are well-dressed and well-fed, the children regularly attend 
school, and the people of the whole community are safe and secure in the possession of homes, property, and children. They too are enjoying for the most part a life in which instinctive human needs for planning, thinking, speculating, initiating and trying new things and new ventures find full expression.

Again at greater intervals will be found large cities, and here again the teeming life of business and pleasure attests a people in which self-expression has attained a development never before seen in this world. If one doubts whether the instinct of workmanship finds expression in our modern cities, it is only necessary to take a single instance out of thousands and reflect upon the amount of inventive genius which in the last twenty years has been expended upon the automobile and the motor-truck alone; not merely upon the expenditure of genius in perfecting the mechanism of the cars, but in all the ramifications of this great industry - in organizing new companies, in planning and building great new shops and factories, in advertising and selling stocks and bonds, in designing new forms of insurance, in building and operating innumerable local garages, in enterprises designed to meet the new demands for motor fuel, and in countless 
other ways. If one will let his thought extend to the vast number of our cities, towns, and villages or think of the incredible activity of our millions of people in their various forms of undertakings, one will realize to what an extent in this land and in these days the instinct of workmanship has found expression. Even in our industrial centers we have become accustomed to fix our attention upon the life of the laborer and have forgotten the inventive genius expended in building up the industries themselves.

I am by no means unmindful of the poverty, and misery in our great cities and industrial centers, but the fact remains that for years we have had only one side of this picture presented to us; namely, the hardships and miseries of the industrial worker, and these have often been greatly exaggerated. While we must never relax our efforts until the last sufferer is relieved, still, when it comes to a proposed reconstruction of our social life, ordinary sanity bids us gain a balanced view of the whole actual situation. The assumption in all our social-reform movements of the day is that it would be possible, in a land of more than a hundred million people, whose gregarious impulses draw them into large and ever larger cities, many of these people being 


\section{THE PSYCHOLOGY OF WORK}

ignorant and improvident and many defective in mind or body, to devise some sort of government or industrial organization by which all should be well-fed, well-clothed, well-housed, comfortable, and happy. It is easy to think of social schemes by which this could be accomplished for a short time. 


\section{CHAPTER VI}

\section{OUR CENTRIFUGAL SOCIETY}

$\mathrm{N}$ the preceding chapters we have seen that the popular reconstruction movements of the day, fixing attention as they do upon industrial efficiency, increased production, an adequate scale of living, leisure, and opportunity, fail to provide either for the expression or sublimation of a large group of human instincts and propensities that go to make up what we commonly call life. In this and the following chapter we have to consider another omission in these plans for a new society, namely, the omission to provide for social integration and solidarity; that is, for social discipline. ${ }^{1}$

We have seen that that social order is best which best provides a field for human activities and the expression of human instincts. Up to this point we have considered man as if he were an individual seeking a field for his activities and his interests. Now a new factor appears, which

1 I wish to acknowledge my indebtedness throughout this chapter to Professor Irving Babbitt, Mr. Paul Elmer More, and the Italian historian, Ferrero. Mr. More's Platonism, Professor Babbitt's Rousseau and Romanticism, and Ferrero's Ancient Rome and Modern America are certainly wholesome reading for the "votaries of the god whirl" in this centrifugal age. 
greatly modifies and complicates the situation, namely, the social factor. We live in society, and furthermore a society which is getting yearly more and more crowded. Other people demand a fair field for their activities, and other and coming generations demand it. Our problem, therefore, becomes this: How shall we live so that all in this and in succeeding generations shall have a fair field for their activities?

Although so many persistent dispositions are not provided for in our social-reform movements, there are certain primary instincts which are to be given full expression. All these movements operate quite in the spirit of the prevailing philosophy of the day, the philosophy of the full, free, and abundant life, the philosophy of self-expression, as it is commonly called. In this respect the popular reconstruction movements are neither better nor worse than the current philosophy of the day. They simply reflect it, take it for granted, and hope to provide a social order in which it may find complete fruition. There is no attempt in any of the reconstruction plans to check the flamboyant centrifugal tendencies characterizing this early part of our century.

As I said in a preceding chapter, there is a 


\section{6}

SOCIAL RECONSTRUCTION

certain current popular philosophy of life underlying all our social movements and all our economic theories. It is the philosophy of the full, free, and abundant life. It is this philosophy which is at the basis of our current views of economic value as that which satisfies human wants and desires. It is at the basis of much of our ethical theorizing, which finds the final ethical motives to be the largeness of conscious life, a life that is rich, full, and satisfying, ministering to the whole circle of our organic and spiritual needs. Social welfare is then defined as a state in which all shall enjoy this richness and fullness of life. Even Nietzsche, the patron saint of the full and abundant life, knew that this would not work out as a social philosophy, and hence advocated it only for the chosen class of Masters, while the great body of the people were to practice the Christian virtues of self-denial.

We see at once and in advance that while we talk freely of self-expression or self-realization, what we have in mind is not complete self-expression nor is it self-realization in any adequate sense. It is expansion rather that we mean; that is, it is the expression of a certain narrow group of sentiments and instincts, especially the sentiments of freedom and equality and the instinct 
of revolt at any kind of restraint or confinement. Professor Babbitt uses the word "eleutheromania" to indicate the almost pathological passion for freedom and self-determination which marks the modern man. Real self-expression is a very different thing from this and involves the outgoing of the whole personality, including not merely a narrow group of primary self-regarding instincts, but the whole class of our innate dispositions, some of which we have studied in a former chapter; while self-realization is found not in the expression of our peculiarly egoistic sentiments at all, but in the harmonious exercise of all our powers, instinctive, intellectual, and æsthetic, in the cultivation of social relationships, and even in the suppression of such instinctive propensities as may be necessary for social existence. When we begin to talk about "self-expression" and "self-realization," we must keep constantly in mind the "larger self" and the "totality of interests."

Let us, however, examine this philosophy of the day, this centrifugal, expansive conception of life, and see what its merits and possible defects may be. It is the view which puts special emphasis upon self-determination; upon frec- 
dom from every kind of autocracy or class rule or oppression or repression; upon equality of opportunity; upon freedom for self-development and culture; upon complete liberty to realize one's own inner needs and one's own personality; upon escape from all old and cramping conventions and institutions; upon naturalness, will, and efficiency.

These are our ideals, and to most of us they are so obvious that they seem to need no discussion. They have found expression in our current drama and fiction, in our moving pictures, in our books and magazines, and in all our plans for social reform. We have come to take them quite for granted.

Perhaps it may be worth while to examine these ideas with a little care. As ideals they are obviously good. This may pass unchallenged. But it is not self-evident that they are the highest ideals, nor is it self-evident that they are alone sufficient as a foundation for social welfare. It seems rather that the present age is merely obsessed with these ideas, just as other epochs of history like that of the ancient Hebrews, or that of Greece and Rome, or that of the Middle Ages, were obsessed with a wholly different set of ideas. 
For instance, in the Middle Ages, poverty, chastity, and obedience were the monastic virtues, and every ambitious boy aspired to be a monk. We look in vain now for many ardent devotees of either poverty, chastity, or obedience. Our attitude toward these mediæval ideas is one of humorous superiority, not perhaps fully justified by the relative differences in the two civilizations as measured by such standards as social stability or the development of the fine arts, such as architecture, painting, and poetry.

Still another set of ideas ruled in the best period of Grecian civilization, likewise wholly different from ours. These were temperance in the sense of balance and moderation, measure, limitation, order, form, harmony, symmetry, and beauty. Francis Galton perhaps spoke with some exaggeration when he said that the average intelligence of the Athenian race was at least two grades above our own. But while we may smile at the ideals of the monks, we must take very scriously those of the Greeks as long as we are still using as models so many of their masterpieces of political philosophy, poetry, sculpture, architecture, eloquence, and literature. It is all a matter of historical perspective. Some future period may smile at our childlite devotion to 
liberty, equality, and fraternity, or self-expression, or the full, free, and abundant life, to the neglect of many other equally important ideas.

In all our discussion now about social reconstruction and a new social order, is it not a little peculiar that the ideas which we are trying so hard to realize in this new social order - liberty, equality, efficiency, opportunity, self-expression, and self-determination - are just the ones that already mark this period when compared with other past periods and past civilizations? We may be deficient in these virtues, but we have them in profuse abundance as compared with other times, and we have them in excess as compared with other virtues, such as love of beauty and of symmetry, proportion, moderation, measure, and limitation of desires. Is it safe to enter so passionately upon the remodeling of our social institutions with our eyes fixed so exclusively upon any one circle of ideas?

Self-expression is perhaps the best single term defining our present-day philosophy of lifeor, possibly, self-realization, or initiative, or energy. The keynote of modern painting, music, and poetry is expression, and that of modern sculpture is energy. In our educational systems our aim is to develop all the latent energies and 
possibilities of the child. He must express himself, bring out the full richness of his personality, give full scope to his individuality, develop to the utmost his genius and his talent. When manhood and womanhood are attained, old social conventions must not stand in the way of this inner need of self-realization and self-expression. Our laws must be remade and our social institutions reconstructed so that each individual may enjoy his full rights and come into possession of his full share of the world's goods. It would be a shame if others had superfluous wealth while any lacked the means of self-development and self-culture.

This is the expansive philosophy of the age, the centrifugal motive in society, moving from within outward. But the ancient Greeks thought it better to draw from without inward, to observe limits and measure, to strive for inward poise and harmony. This is the centripetal motive in society, the unifying and integrating tendency.

It is important to understand the meaning and value of this new idea of the full and exuberant life. Its value we all recognize. Its limitations perhaps we do not realize. To many in the present day it seems like the very word of prom- 
ise. It emancipates us - so we think - from all the narrow and cramping and dwarfing and galling restrictions of the past and sets us free to enjoy, to live, to breathe deeply, to develop as we please. It emancipated our slaves. It is emancipating our women. It will emancipate our laborers. If there is any one idea prevalent now it is that there is something intrinsically sound and helpful in this renouncing of old authorities and traditions in favor of an individual selfrealization.

This modern gospel of self-expression takes innumerable forms. With Nietzsche it is the will to power, gained through tragic suffering and pain. In Christianity it is the triumphant realization of an essentially divine and spiritual individual life revealing itself in the typical modern expansive virtues - faith, hope, and charity. In Bergson it appears as the exaltation of instinct and primal creative impulse. In Goethe it is pictured as salvation through successive forms of objective experience. In Browning it is seen in the wild joy of living, in buoyant faith, optimism, and love. Even in the modern mystic it is no longer passive resting in God's encompassing arms, but, as in "Jean Christophe," an intoxication with the madness and fury of living. In the 
modern psychological novel it is the coming into some mysterious larger and fuller life through the conflict of motives and through rich subjective experience. In the modern drama, sometimes nothing but the experience of sin itself will bring it to complete fruition. For instance, in Sudermann's "Magda" we read:

Magda. "Pastor, if you had a suspicion of what life really is - of the trial of strength, of the taste of guilt, of conquest, and of pleasure - you would find yourself very comical with your clerical shop-talk."

Heffterdingt. "I have had to stifle much of my nature. My peace is the peace of the dead. And as you stood before me yesterday in your freshness, your natural strength, your - your greatness, I said to myself, 'This is what you might have been, if at the right moment joy had entered into your life." "

Magda [in a whisper]. "And one thing more, my friend - sin! We must sin if we wish to grow. To become greater than our $\sin$ is worth more than all the purity you preach."

In all these forms of self-expression, the common motive is the centrifugal motive, marked by a craving for excitement, impatience with restraint, a longing for freedom and expansion, for the enhancement of life, for the intensification of consciousness.

With this note dominant in our modern life and literature, it is foolish to speak of social decadence. Clearly, the world is not suffering from 
age and decadence. It has the virile enthusiasm of youth, but with it also the defects of youth, an almost childish impetuosity and imprudence, a tendency toward no remoter end than the mere intensification of the momentary mood of joy and strength.

What is lacking in all these forms of self-expression is the "inner check," the motive of restraint and reserve, the discipline of the wise man who looks beyond the present. ${ }^{1}$ In Platonic phrase, it is "justice," the justice which the young man owes to his coming years, the justice which each generation owes to the next, the justice which each individual owes to society. Every young man is free to live the full and abundant life up to the point of not infringing upon the strength and integrity of his coming manhood. Every generation is free to live the full and abundant life up to the point of not infringing upon the health and happiness of the next generation. Every individual is free to live the full and abundant life up to the point of not infringing upon the full and abundant life of all the others in the group.

But the limitations come quickly and fast. Therefore, restraint is necessary; and will be in-

1 Compare Paul Elmer More, Platonism, chap. v. 
creasingly necessary. In fact perhaps the virtues of the future will be not expansion, not selfexpression, but self-control and limitation. And can we be sure that these latter may not be the surer road to peace and happiness? Possibly there is a higher kind of self-realization than that found through self-expression. Self-realization may indeed be the highest goal of human endeavor, but the self to be realized may be the larger self of our collective being, including succeeding generations.

This is nothing, of course, save the age-old antagonism between liberty and justice. It is merely the habit of our modern thought that we have become so enraptured with the first of these that we have overlooked the vital importance of the second. Of course, we hear a great deal now about justice, but it is social justice that we have in mind, that glorious social state in which each class shall enjoy all the fullness and richness of life that any other class enjoys. It is not at all that kind of justice which Plato taught us, consisting not in having, but in doing one's full share. Plato understood, as all the older teachers did, that the centripetal forces in society must balance the centrifugal forces, if we expect stability in our social life. With Plato justice was the 
centripetal integrating principle. It was realized when every class, and every individual, performed its function in the State - in plain terms, did its duty. It was a socialistic State, but evidently the fundamental purpose was different from that of our modern socialistic State, in which the attention is focused more upon our rights than upon our duties.

Socialism as it exists in theory to-day involves, unfortunately, no radical change in our current spiritual ideals. It accepts without much question the philosophy of the full and abundant life, and proposes usually a series of administrative and industrial changes, which it is hoped will do away with certain evils of the time, such as inequality of wealth and opportunity, and the selfish exploitation of the laboring classes. The emphasis in all these modern movements is put upon getting one's full share of the good things of the world - food, clothing, wealth, leisure, and opportunity - to the end always of comfort, happiness, self-expression, self-realization, self-development. It is an attempt to satisfy human wants, rather than human needs. The man of to-day wants more than he needs.

The ancient socialistic State, on the other hand, was one in which the attention was fo- 
cused, not on the individual benefits to be enjoyed, but on the loyal part in the whole undertaking, which each was to play to the end of having a healthy and permanent society. And they well understood that in the long run the individual found his greatest happiness, his highest good, when he fixed his attention on the permanence, stability, and health of the social group. Only in this way can successive individuals find a fair field for their activities. A social group in which the human units focus their attention upon getting each his full share will not bring to its members as full and abundant a life as a group in which the attention is fixed upon doing each his full part.

Our modern conception of the perfect State is one in which certain "evils," such as poverty, inequality, intemperance, clashes between classes, and wars between States, are to be absent. Poverty is to be abolished, not by selfdenial and a limitation of desires, but by the increase of wealth through efficiency, scientific management and new mechanical inventions, and by new laws regulating the production and distribution of wealth. War between nations is to be abolished, not by curbing our instincts of pugnacity, not by education in restraining our 
expansive desires, but by some new political contrivance such as a League of Nations. Intemperance is to be done away with, not by making men strong to resist temptation, but by an act of legislation removing the occasion of temptation. Disease is to be abolished, not by assisting nature in providing powers of resistance to disease, but by devices to protect men from the causes of disease. Inequality between the sexes is to be removed, not by fostering respect for womanhood and motherhood, but by votes for women and political privileges.

All these institutions are no doubt of value, but we are planning to rely too much upon such social and political machinery and we underestimate the importance of physical health, education, and the sense of individual responsibility. No society will survive without the integrating motive - the presence of justice in the Platonic sense. The world is stirred to-day by powerful centrifugal forces. Like a whirling wheel, it will fly into pieces, unless it is held together by equally powerful centripetal forces. These integrating forces are measure, self-control, obedience, respect for law and authority, restraint, limitation of desires, the feeling of obligation. As one writer has said, "We have a 
superabundance of vital energy; what we need is vital control."

We have had occasion to see how the Freudian psychology enriches our conception of the springs of our mental life. The Freudian ethics, too, with its message that the sublimation and redirection of our instincts is better than their suppression, is helpful both in individual and social direction; but here we may possibly go astray, and this ethical system may be perverted to allow any individual caprice to run riot because of the danger of its repression. To repress our impulses and desires, even our egoistic and anti-social ones, is dangerous, we are told. Why, yes - dangerous now and then for the individual, but singularly wholesome for society!

In preceding chapters I have emphasized the fact that no social order can prevail that does not allow of the expression of our healthy instincts, that does not provide a field for the exercise of all our powers. But when our egoistic impulses clash with the public welfare, then comes the necessity for the "inner check," for an instantaneous and unconditional exercise of. the "veto power in the human breast." The 
Freudian ethics must not be interpreted as the abandonment of "the spirit that denies." Whoever so understands it had better read the words of a certain wise teacher, who said, "If any man will come after me, let him deny himself, and take up his cross and follow me."

Furthermore, it is wholly according to sound psychology, this prompt and uncompromising inhibition of anti-social impulses. It is natural, not unnatural. ${ }^{1}$ Mankind has been subject to social discipline through all the ages. Certain instincts he has had to curb for the sake of social safety. Social unrest is not going to increase because of social discipline. We must not forget that among the instincts there is also the instinct of loyalty, of subordination and submissiqn. ${ }^{2}$ Never was it more imperative to keep

1 "Conscience is native to human nature in the sense that it is within the capacity of human nature to be thus self-conscious in perceiving and controlling its own cosmic direction. It is not an instinct. It is the latest and finest instrument for the self-integration of instinct. And it is an instrument characteristically human." (Italics mine.) (W. E. Hocking, Human Nature and Its Remaking, p. 99.)

2 Since I have quoted Carleton H. Parker in quite another connection, I may quote him also here: "In contrast to leadership, man longs at times to follow the fit leader. Soldiers joy in a firm captain, workmen quit a lax though philanthropic employer, instructors thresh under an inefficient though indulgent department head. Eternal independence and its necessary strife are too wearing 
these facts in mind than at a time like this " in which the traditional inhibitions are constantly growing weaker."

Perhaps the first lesson which this twenticth century of ours needs to learn is that there are values higher than comfort and leisure and material goods, and other virtues which we need to emphasize more than faith, hope, and charity. In an age of despair and depression for the masses of people such as the beginning of the Christian era, the expansive, outward and upward-looking Christian virtues were like a great light from Heaven. In a vital, expansive, centrifugal period like the present it may be necessary for us to return to the integrating and harmonizing virtues of the Greeks - wisdom, temperance, moderation, and restraint; and it may be necessary for us to revise our list of highest values, and in place of wealth, leisure, liberty, equality, and opportunity, write for a while conservation, limitation, integration. The great things of life, wisdom and art and literature and

on the common man and he longs for peace and protection in the shadow of a trust-inspiring leader. To submit under riglit conditions is not only psychically pleasant, but much of the time to be leaderless is definitely distressing." (Carleton H. Parker, "Motives in Economic Life," Procedings, American Economic Association, 3oth Meeting, December, 1917, p. 225.) 
heroes, have sprung from periods of storm and stress. It is such periods that have given birth to opportunity; but it was not opportunity for self-development, but opportunity for self-control, yes, even for heroism and for love.

To be sure, we hear much about love, but it has come to take the forms of sympathy and charity. Of both of these we have a great and abundant measure. What we are trying to do in all these modern forms of social reconstruction is to hit upon some social or political device by which we may live the full and abundant life and allow our neighbor to do the same. There never was so much world-wide sympathy for the neighbor who does not live the full and exuberant life as there is now. We love and sympathize with every oppressed class and every downtrodden man. We are taught to love our neighbor, and we have learned to love him with such intensity that we allow no one to exploit him but ourselves. As Professor Babbitt says, "Our twentieth-century civilization is a singular mixture of altruism and high explosives." We love our neighbor and we wish him every joy. In his need we shower him with charitable gifts. If others abuse him, we are ready to fight for him; but our conception of love does not quite extend 
to the notion of limiting our own desires for our neighbor's good. It does not quite suffice to check the megalomania of our capitalistic classes, nor persuade them voluntarily to bear their just proportion of public taxes, nor teach them willingly to share their profits with their workers. It does not quite suffice to lead our laboring classes, when once they find power in their hands, to use this power in accordance with reason and moderation.

It is owing to accidental reasons that the necessity for restraint and limitation has not been laid upon us in recent times. The discovery of America, the industrial revolution, the $\mathrm{Pa}$ cific frontier - all these have opened to us a new world which has allowed the human spirit an indefinite expansion foreign to its long history. There has been for a short period in human history little need of the "inner check," and it has been almost forgotten.

To be sure, this wild display of centrifugal forces has brought no essentially valuable human product, no great literature or art, no Grecian temples, no Gothic cathedrals, no Shakespearean drama; nor has it brought peace among men, nor physical stamina of race, nor freedom from vice and misery and crime, nor 
justice, nor reverence. In the midst of plenty, it has not abolished greed, nor graft, nor strife. But these defects have been little noticed, and meanwhile there has been stirred within us only a restless desire for still more expansion.

Only lately have the first signs appeared to teach us that limitation belongs to the nature of things and cannot be escaped. In the crushing defeat of Germany, the first emphatic "No" was spoken to this cult of universal expansion. The whole world awoke to its senses and recorded its ancient and instinctive protest against that ultimate injustice which flows from the theory of limitless expansion in the case of nations, but it has not thought of applying this to the individual.

Our little world is getting filled up, and the need for the practice of restraint and the limitation of our desires increases yearly. The rapid growth in the population of Europe and its still more rapid increase in the Americas, makes selfcontrol and self-denial increasingly necessary if social order is not to give way to anarchy.

Nietzsche was well aware that the full and exuberant life which he preached involved a "trans-valuation of all values." But the trans- 
valuation of moral values is a hazardous business. It is life itself which has determined these values, and they cannot be revoked by the mere will of heralds of revolt. The values which they would revalue represent the residual experience of long ages of human life and society, during which mankind has discovered that there are certain rules of conduct which are necessary if men will live in social relations in peace and security. The trans-valuation of these old racial values has been attempted many times and always something unpleasant happens. These unpleasant happenings may be deferred for many years. They may light upon one's mother, one's family, one's children. They may. affect society or posterity - but they happen.

One would think that many of our hasty writers of recent fiction and drama regard our old rules of conduct, our moral codes, as the arbitrary pronouncements of some external authority, God or the king or parents or the Church. We always think of our laws as being "handed down," and we resent having our laws handed down. We want to make them. But what we forget is that we have made them and that it has taken centuries - ages - to do it.

The following, for instance, was taken from a 


\section{SOCIAL RECONSTRUCTION}

page of current fiction: "The individual must be free from conformity and (as he saw it) the attending hypocrisy, by breaking the yoke of the home. It must be the individual, the glad, free individual, the will to live, to feel, to express." In actual practice such an individual might be free - but he would not be glad, at least not for very long. Or if he were glad in his youth, he might be sorry in middle life. Or if he were free and glad all the time, his neighbor might be sorry. Or if both he and his neighbor were free and glad all the time, their children might be sorry.

What the prophets of the full, free, and abundant life forget is the unity and continuity of life, the organic unity of the family, of society. And even when we have learned this lesson, we have still to understand the organic unity of this generation and the next. The hero or heroine of modern fiction or of the modern drama breaks the sanctity of the home and finds the larger freedom - discovers a great "self-realization." Yes, but in real life somebody has to pay the bill - perhaps the children or the children's children. Possibly just another link is severed of that social integration which is necessary for social welfare and stability. "I am beginning to 
find out," said Byron, "that nothing but virtue will do in this damned world." 1

To which, of course, it is replied, these old conventions we have now outgrown. We live in a new age, under new conditions, and our new age must have new rules of morality. There is no absolute moral law. Everything moves, flows, changes, develops. We must adapt ourselves to the new order.

Yes, moral laws change, no doubt; but our fundamental moral laws, those relating to justice, integrity, honesty, veracity, and those involving the purity of the family and obedience to law, change exceedingly slowly, not much faster than the physical and mental constitution of man changes, and for practical, present-day purposes, that is not at all. It is easy for us to understand that the laws of thought as expressed in our logics are the same now as in the days of Aristotle - but when inclination leads that way, it is easy for us to believe that the laws of conduct are changeable. They are, however, tolerably safe guides to action in our personal life and our social relations. If violated, there are ways, no doubt, to escape

1 Prothero's Byron. Letters and Journals, vol. 1, p. 272. Quoted by Perry. 
"punishment" in the popular sense, but no way of escaping "consequences."

For the individual, in all concrete cases of action, the rule given us by $\mathrm{K}$ ant is sound and wholesome and eminently good: So act that thou couldst wish that the principle of thine action should become a universal principle of action. But when a critical people, not satisfied with a pragmatic precept, demands the eternal Why, then we must begin a deeper inquiry concerning the grounds of social integration and solidarity. In the following chapter some reference will be made to this question. 


\section{CHAPTER VII \\ SOCIAL DISCIPLINE}

7 THE application of psychological principles 1 to the problems of social reconstruction seems to have shown us that the standardized world proposed for the future, in which efficiency, an adequate scale of living, comforts and conveniences, regular and universal work and daily leisure for self-development, are the great ends to be attained, will not allay social unrest except at the price of social stagnation. These are not the things that men really want; that is, real men. What they want is life. What we have to do, therefore, in social reconstruction is to discover a social order in which the totality of human interests may find expression. It is the exercise of their powers that men want. Man is a being who strives, not primarily one who eats and sleeps and works. What he wants is to build something - a house, a busincss, a reputation, a fortunc. If there are any natural rights, the "right to achieve" is an essential one.

This "will to power" is psychologically fundamental in man as a behaving organism. But 
here we discover that no one absolutely best form of government or social order can be ordained for north and south, east and west, ancient and modern. In the northern Occidental modern man the spirit of energy is triumphant. The "objective significant structures" whose "appropriation" satisfied the ancient Greek or the early Christian saint does not satisfy the man of the East and North to-day. He must create, initiate, venture and adventure.

\author{
"Der Mann muss hinaus \\ Ins feindliche Leben, \\ Muss wirken und streben \\ Und pflanzen und schaffen, \\ Erlisten, erraffen, \\ Muss wetten und wagen, \\ Das Glück zu erjagen." 1 .
}

For this energetic spirit of our age, our free democratic institutions of America furnish, as we have seen, the best possible field for endeavor. And if we are still disheartened because any of our people lack many opportunities, or because of the poverty and want in our congested cities and great industrial centers, we must not be deceived by the illusion that some other wholly different social or political system could be de-

Schiller, Das Lied von der Glocke. 
vised in which a larger proportion of our one hundred million people would be prosperous and happy. Utopianists picture such conditions, but the men and women with whom in fancy they people their ideal communities are made to order like the communities themselves. Our recent army draft drew out from every corner of our land the real men who constitute society, many strong and brave, some physically deficient, some illiterate, some mentally and morally defective. That with the actual material which we have, the early twentieth century should attain so high and unprecedented a degree of comfort and prosperity will perhaps be explained by the historian of the future as due to the immediate and temporary effects of the industrial revolution, together with the vast resources of a new and unexploited land.

There are, to be sure, evils enough, even in our America; and before these words are printed it is altogether possible that they will increase. The war will have to be paid for. But these evils are not inherent in our social and political system, and the people have only to will the deed and they can be cured so far as laws and institutions can cure them; for it is just this that our republican form of government permits; it is for this 
that democracy exists. But the real cure lies deeper; it lies in morals and education and depends a good deal on the physical stock we have to start with.

But now there is one other important matter in which psychology may make some contribution to social reconstruction. It is the matter of social integration touched upon in the preceding chapter. A good social order must be one which shall provide not only a field in which man's totality of interests may find expression, but it must also offer a degree of social integration that shall secure the presence of justice within the State, justice in the Platonic sense, where each individual does and has that which belongs to him to do and to have, and does not do or have what belongs to another to do and have; and this "other" refers not merely to one's neighbor and fellow citizen, but to those who are to follow in the order of time. Social integration involves, therefore, a degree of social stability and permanence.

In this brief chapter I have no further thought than to suggest a possible better method of approach to this ancient problem than the more usual ones. It is certainly strange that in our 
popular social-reconstruction movements this most basal matter receives so little attention. We are so wholly occupied with securing immediate justice to all classes in the other sense of the word "justice" - where each one shall have his share of the goods and his share of the opportunities - that we give little attention to this older and larger problem.

The critical importance of such questions as wars between nations, the equitable distribution of wealth and opportunity, political justice toward our women, intemperance, etc., has blinded us to other problems which affect the very existence of society; namely, social discipline and social stability, and physical and racial health. And since the whole world at present is in a very radical and iconoclastic mood, halting at no thoroughgoing change in political and social institutions, it has become vital that we shall turn our thoughts to these other problems.

What are to be the elements of order, the centripetal forces in the new society? The forces working toward chaos and anarchy are many. Any newspaper page reveals them. The intense individualism inherent in all modern thought, the disintegration of States and of old established political programmes, the constantly 
growing lack of respect and reverence for old institutions - in fact the suspicion of anything that is old and established - the critical and cynical tendencies of some of our modern fiction and the modern drama, the loss of the religious faith with which our moral sanctions have been closely associated, and the pragmatic philosophies of all kinds that rule in the present these are some of the forces working against social integration.

This is not to say that any of the old ideas or the old institutions are perfect or holy, or even good. It is only that the obedience to laws, the restraint and self-control which are necessary for social order, have been in the human brain associated with these things. A wholly new set of motives for social order is perhaps conceivable; resting upon none of these old institutions; but the human brain changes slowly, and an entire civilization might collapse in the process of a crude and reckless attempt at readjustment.

The disintegrating forces in society are many, and apparently increasing. It is necessary, if our civilization is to be saved, to turn our attention very seriously, and at once, to the integrating forces, to the forces which look to social stability, to law and order. 
In the past there have been three great institutions which have acted as powerful forces of integration - the State, the Church, and the Family - the integrating power of these institutions depending not merely on external sanctions, but on the powerful motive of personal loyalty and allegiance. Since in the popular social reform movements of the day no emphasis is placed upon the Church and the Family as integrating social forces, and since the implication is that internationalism is to take the place of nationalism, it becomes of the gravest importance to inquire what is to take the place of these ancient and successful sources of discipline.

In particular we must inquire what is to take the place of nationalism in the new order. When the State is small and its emblems are ever present to the senses, or when it is unified by art and religion, as in ancient Athens, or when the very existence of the State is threatened by rival States, as in the recent war, then social integration within the State is relatively perfect. Then the group spirit, the community spirit, keeps the group itself a healthy organic unit, the members of the group all loyally, willingly, eagerly performing severally their proper functions. Then justice prevails within the group, laws are 
obeyed and order is preserved. A League of $\mathrm{Na-}$ tions, to prevent that form of social suicide which a modern war has become, seems, as it truly is, a great step forward in human progress, but in the long history of human development social integration and social order within a State have depended to a large extent on the menace of danger to the State from without. When that menace shall be withdrawn, social integration within each State will be increasingly difficult.

The spirit of nationalism at the moment, to be sure, burns brightly; but the whole trend of the time is toward internationalism, due to the community of world interests in international labor movements, international commerce, banking, science, and education.

In our new society, therefore, as it is pictured by our social reformers, it would appear that loyalty, neither to the State nor to the Church nor to the Family, is going to be a powerful integrating force. The vital things now are labor unions, workingmen's councils, women's federated clubs, manufacturers' unions, trusts and combinations, and countless other self-protective organizations and combinations of every sort. The old loyalty to the State and the Church and the Family has been in large measure replaced 
by loyalty to these countless social groups; but unfortunately there is no promise that loyalty to these groups is going to be in any sense a principle of social integration. On the contrary, it appears often to be a source of social strife.

What, then, do our social reformers propose as an integrating principle in the new society? We hear a great deal about coöperation; it is, I believe, to take the place of competition. "The good of all is to be the aim of all." This teamwork, this morale, this human brotherhood, surely is an end devoutly to be wished. But the psychologist, like any other scientist, deals with facts and puts his theories to the test of facts, and he wants to know under what conditions this new concept - the good of all to be the aim of all - can be realized. Under the inspiration or frenzy of a great war you can for a short time mobilize a nation of a hundred million people for team-work, and, barring the thousands of profiteers who will spring up even during the war, the good of all will become the aim of all while the war lasts, if it does not last too long. But the question is under what other conditions than of war can a nation be mobilized in this way, and with how large a nation can it be done, 
and for how long. Judging from our own experience since the war, in the light of the almost universal profiteering, price-boosting, bank-robbing, etc., it would appear that it is a slightly different motto that we have adopted: namely, The goods of all shall be the aim of all.

The assumption is very common in our socialreconstruction writings that economic injustice is the cause of social wrong-doing. When once you grant to all men an adequate share of the world's goods and complete opportunity for the fullness and richness of life, why, then, we are told, peace and brotherhood will reign and the good of all will be the aim of all. But the profiteers and the price-boosters and the bubble-promoters and the bank-robbers are not men suffering under the curse of wage slavery; they are persons with criminal tendencies, or, at the best, anti-social motives. It is a case of defective brain patterns, not defective economic conditions; and these anti-social brain patterns will be found pretty evenly distributed whether in a group of financiers sitting around a table or a company of laborers pouring from a factory. Perhaps some of the latter lack "opportunity" for predatory practices; but the potential ratios will be much the same. It is not a question of classes. 
Our problem, then, is a problem of mobilizing a nation for team-work. This is the problem for any form of collectivism to solve, whether it be the moderate collectivism which we have at present or the extreme collectivism which is planned for the future; and in solving it we must keep constantly in mind the material we have to work with. It is easy to point out, as do such writers as Mr. L. T. Hobhouse, that social progress lies in the direction of extending the "area of the common good" from narrow social groups where we have seen it exhibited, such as the family or the clan, to the broader social groups such as society and humanity. But they overlook the fact that in these narrow groups there are powerful motives for "mutual service" which do not apply to the larger groups.

"The true line of social progress," says Mr. Hobhouse, is "the development of that rational organization of life in which men freely recognize their interdependence, and the best life for each is understood to be that which is best for those around him." 1

This, of course, is a wise and virtuous remark, but we have to inquire how men are brought to recognize this interdependence in the smaller

1 International Journal of Ethics, vol. vur, p. 150. 


\section{SOCIAL RECONSTRUCTION}

groups and whether it will apply to the larger groups. The football team may be taken as an illustration. Here we have integration, solidarity, discipline, obedience, team-work; morale all in perfection. But it is because there is an immediate glowing end for which the discipline is obviously and patently indispensable, and the end is in the immediate future. So it is with the small political group threatened by war with a visible rival group; so it is with the larger group in time of war. But with the larger group in time of peace the glowing end is not there. A civilization in which discipline, virtue, and obedience fail will no doubt go down after some generations; but what cares the individual for that? Even personal health and welfare, if they are just a few years in the future, are quite insufficient as motives in a young man's life if they come in conflict with strong passion or desire. It is hardly likely that our egoistic impulses are going to be effectively checked by the abstract idea of the common good; even of the present generation, to say nothing of the next.

A moralist might write a book on ethics and prove conclusively that self-realization is found in the common good, in the perfection of the 
larger social self, in social service, duty, etc., and if he could take every one of our hundred million people into a lecture-room he could no doubt demonstrate all this to them or to those capable of following a line of argument. But in the first place, judging from the statistics of illiteracy in our drafted army, twenty-five per cent even of our mature young men would not be able to follow the line of argument; another twenty-five per cent, including our defective and delinquent classes, would be morally unable to modify their conduct in reference to social motives; and the majority of the remaining fifty per cent would still pursue their accustomed mode of response to their accustomed stimuli. Groups of hand-picked men, the intellectual élite, have tried communistic and collectivistic experiments, as we have heard, now and then; but they have usually failed, and when they have not failed, it has been because they have been under the constant direction of a few shrewd and efficient leaders. In all such experiments the unexpected cranky behavior of these chosen spirits has been the cause of failure.

So we come back to our original question. In 
the society of the future what are to be the sources of integration, of social solidarity, of that spirit of coöperation, that team-work, that discipline, which distinguishes the social group from a mob, which is necessary for such law and order as will make possible the enjoyment of the things that we wish to enjoy, such as trade, commerce, the cultivation of our fields, schools, libraries, peaceful holidays, and which will make society a field for our human activities, thought, art, constructive work, and wholesome play? To some of our more radical thinkers the expression "law and order" is repellent because they have come to associate law and order with the miscarriage of justice; but nevertheless when they picture in their minds a reconstructed society of the future, they always think of it as having order in some way, imagining very likely that order will be spontaneous; our new society will be a kind of love feast.

It is because in our whirling and shifting modern world this question of social discipline is so difficult to answer that many are now predicting the downfall of our civilization.

In dealing with such a problem as this, history and psychology would seem to be our only guides, safe or unsafe. Germany, for instance, 
succeeded for many years in mobilizing a great people by means of "aggressive gregariousness." 1 A great idea, Weltmacht, and a spectacular leader were all that was necessary. During many hundred years the Church in the Middle Ages mobilized nearly the whole of Europe by the symbol of the cross. For some centuries, longer ago, Rome mobilized the whole world after a fashion by brute force. But the hope is dim for any onewho would now propose nothing but a strong central government and the policeman's club. We may go back to the head-breaking method, but if we do, it will be only when revolution and anarchy have reduced us to despair and have destroyed all other hope.

Political groups from time immemorial have been mobilized by the constant menace of danger from outside the group. The members of the group must present a solid front to the enemy; hence harmony, discipline, obedience to law, rule within. When the external menace disappears, internal discipline is relaxed, and disintegration begins. Church or State, then, it would appear we must have. The modern Church is doing a great work in its chosen field of serv-

1 Compare the luminous treatment of this subject by W. Trotter, Instincts of the IIerd in Peace and War, pp. $166 \mathrm{ff}$. 
ice, but its control upon the millions is lessening. Can the modern State command the allegiance necessary for social integration? Whether such movements as the League of Nations can harmonize conflicting group interests, time alone can tell; but if so, then we have lost that ancient and powerful motive for internal morale which the constant menace of war has provided; if not, then we face the ruin which modern warfare brings in its train.

It is curious how oblivious to these historical conditions of discipline our social reformers are. They seem to think that if their particular reforms could be carried out, then the same morale would exist in society as a whole that now exists within the segregated reforming group. Within these groups we hear a great deal of "tireless persistency," "a great sustaining faith," "voluntary gifts of hard-earned money," "a self-sacrificing devotion to the cause." What these reformers forget is that the magnificent morale which they experience within their various organizations is merely an instance of "aggressive gregariousness," which, in the nature of the case, will be lost when the cause is won; but they innocently carry over this morale to the whole reorganized society. Even such a 
writer as Mr. Trotter, who has no special cause to promote, belicves that a third type of society ${ }^{1}$ is possible, namely, that of "socialized gregariousness," of which England is an example, where, after the manner of the bee and the ant, some mystic power of integration brings unity and harmony. But the morale of the bees and the ants is merely a case of instinct. Nature has told them to work in harmony or perish, and those who did not have perished, and there is no evidence that the English or any other people possess such an instinct. Social integration has been gained in other ways.

It is useless to mention in this connection the various sources of social integration enumerated by the sociologists, such as public opinion, law, education, social suggestion, religion, etc., ${ }^{2}$ and say that we shall have all of these in the future as we have in the past; for it should be remembered that our changing social order renders the old traditional means of control of uncertain value and in any case they all imply either some standard of order and morality, which the State

1 The other two being the aggressively (lupine) and the protectively gregarious societies. See op. cit., p. 204 et al.

2 See the brilliant treatment of this subject by Professor E. A. Ross in his Social Control. In the bricf concluding chapters of Professor Ross's book will be found material for profound reflection. 


\section{6 \\ SOCIAL RECONSTRUCTION}

or the Church or public opinion are to perpetuate, or else they imply the presence of farseeing leaders who shall direct and control the lives of the people. In other words, these means of social control are for the benefit of wayward individuals; but the attitude of the modern man is not such as to make him submissive to either of these authorities. He has been "emancipated" by the "liberators" and the "heralds of revolt" from any kind of authority. Tradition, convention, morality, even law and order, are suspect to him. Institutions are not sacred, government is a source of irritation. For such a person even history has no lessons. ${ }^{1}$

It is clear, therefore, that in our modern democratic society we cannot rely very much on the traditional means of control which textbooks on sociology enumerate and classify so religiously. The great social problem of the near future is not the industrial problem, nor the problem of capital and labor, nor of socialism versus individualism, nor of progress; it is the problem of social discipline. As wars diminish in frequency, as nations become large and their populations mixed, as the sense of freedom and

1 A popular hero, much admired for his "success," is reported to have said, "History is bunk." 
the lack of individual responsibility increase, the question of social stability looms up as the great problem of the age.

We are told that in primitive societies children do not need to be punished by their parents. Social life is too precarious in these communities to waste time and strength on internal dissensions; but in our civilized society children have to be disciplined and our university students have to be chaperoned. The latter seem naively to think that any excess, as for instance in dancing, is permissible provided only it infringes no university rule. In society at large it is apparently only the stern, restraining hand of the law which places any limit on the amount of profiteering, smuggling, selling worthless stocks, automobile stealing, ${ }^{1}$ and predatory practices of all kinds. The sense of individual responsibility is lacking. ${ }^{2}$ It becomes thus a serious question to what extent and for how long social order can be maintained merely by external sanctions; and

1 It is estimated by a prominent automobile journal that fully one tenth of the cars manufactured annually fall a prey to thieves.

2 This lack of individual responsibility is shown in the fact that the kind of dancing that is practiced in some of our homes and even in some of our college dances is not permitted in our city dance halls. Those trying it are put out. When it requires a policeman's club to keep us from indecent dancing, it is time for pessimism. 
the problem becomes much more acute when one raises the further question how long and for what reason the law makers themselves will have the vision and the sense of right necessary to make and enforce these laws. In a democracy this difficulty appears in its most serious form.

Can discipline be maintained under a union of democracy and socialism? ${ }^{1}$ The tendency in our modern life is toward the constant widening of the functions of government. The sense of individual responsibility becomes less, the function of the group becomes greater. The life of the individual is supervised and regulated to the minutest degree: he is told what he may drink and what not drink; how much sugar he may buy and not buy; his food is inspected and its distribution controlled; his house is examined and its structure regulated by law; his business is supervised, his income scrutinized and controlled, and so on through the familiar list of the interferences of organized society with the individual's life. And all of this is made necessary by our modern conditions and in the end really increases the liberty of each man. But the reason it is necessary and the reason that it adds to the

1 Compare L. P. Jacks, "Democracy and Discipline," Hibbert Journal, vol. xI, p. I. 
sum total of freedom is because of the absence of the veto power in the breast of the individual.

But meanwhile the number of our rules, regulations, and laws increases daily. As the functions of the State increase, taking over perhaps our transportation systems and our natural monopolies - not to speak of the whole machinery of production - the strain upon society in its corporate aspect becomes greater. In a democracy the people make the laws themselves. The problem of the future thus becomes this: Will the people obey all the laws which they themselves make, and if so, why? The notion that they will obey them because they have made them is naive and innocent of psychologic insight. Sometimes the people will obey the laws from habit, sometimes from loyalty to the king or emperor, sometimes out of reverence for the priest, the Virgin, the Pope, or the Bible, or from the love of God; but none of these motives seem to promise much for our immediate future. Professor Ross, in his book "Sin and Society," has shown us how our new industrial and commercial life has given birth to a whole new brood of very lively sins. A threatening host of silk-hat sinners and syndicate sinners and big business sinners and corporation sinners has 


\section{SOCIAL RECONSTRUCTION}

descended upon us, while all the old-fashioned sins mentioned in the Decalogue are as interesting as ever.

What are to be the forces which are to control these sinners in our future society? The making of endless new laws, jail sentences instead of fines, etc., etc. - to depend upon all this sort of thing presents a discouraging outlook. Teamwork and morale are not gained in this way. They depend upon organic unity and they depend upon fellow-feeling and sympathy.

The conditions of team-work within a group appear to be that the group as a whole is about to prey upon another group, or is in danger of being preyed upon by another group, or is united in a common devotion to some great cause or some religious idea or some national symbol or some spectacular leader. Loyalty there must be to something above or beyond or outside the mere collective body. These are the things which bring about that sympathy and fellow-feeling which are the conditions of solidarity.

Human beings are so constituted that they need a cause to work for. They need something to look up to, something to be loyal to, some king or qucen, some leader, some prophet, some 
Napoleon, or Peter the Hermit, to follow, some society or concrete organization, something rather near and striking, and, still better, something rather new. A religion like the Christian religion containing great vital, soul-compelling truths will when it is new capture the world, overturn an empire, reform the lives and save the souls of millions. In our plans for social reorganization we have assumed too readily that the unit of society is an industrial worker and we have forgotten that he is also a knight

"Who in many climes, without avail, Has spent his life for the Holy Grail."

Boys of a certain age listen with indifference to the advice and commands of their father, but they will follow with great loyalty the unwritten laws of their gang. College students look with suspicion sometimes upon the wisdom of their parents, but the discipline of their fraternity they submit to with enthusiasm. The daughter sniffs at the admonitions of her mother, but is wholly loyal to the fashions of the day or the rules of her set. The loyalty of the industrial worker to his labor organization is sometimes greater, I fear, than to his country. And fraternal societies of all kinds have little trouble with the matter of discipline. 
The problem would seem to be to get the same loyalty, devotion, and enthusiasm in the larger group - that is, the State, society, humanity - that we get so easily in the smaller group. But the very psychological conditions which make this possible in the smaller groups are absent in the larger groups, except in the small State or the large State in time of war or preceding a proposed war.

The dilemma, therefore, is a very serious one. It is especially serious in America because of the vast size of our land, so that the element of protective gregariousness is not to be relied upon. Lord Macaulay predicted that

the civilization of the United States would be destroyed by lawlessness engendered within her own institutions. The Chief Justice of the Court of Appeals in Georgia recently said: "If this prophecy is not to be fulfilled, the tide of lawlessness which is sweeping the Nation must be arrested, and the cause of it destroyed. Our laws and Federal Constitution stand like a dike to arrest the tide, but if there is a single break in the dike it will disappear and we will be engulfed in the rushing waters of lawlessness." For officers or the people to permit laws to be violated is a deadly attack upon the Government. Its contagion spreads from one law to another. It distills its deadly poison into the arteries of our jurisprudence. It palsies the power of honest officials. It assassinates the vital processes of orderly control. It is a prolific 


\section{SOCIAL DISCIPLINE}

source of disease to the whole social order, and jeopardizes the life of the race. ${ }^{1}$

This is excellent and wholesome doctrine, but in a democracy like ours whence is to come the vital flame which shall make this respect for law effective?

I believe there is no solution of this great problem except through education. In the next chapter I shall indicate a few of the ways in which science may be applied to a new kind of social reconstruction. In the immediate future, however, perhaps we must still rely upon nationalism. It is still possible to draw upon the instinct of devotion and loyalty to the State for the discipline which is necessary for social integration. In nationalism we have an ancient, instinctive, psychological motive for social solidarity and obedience to law. War or no war, Our Country must still be the motive which shall appeal to our allegiance, loyalty, and devotion to the end of team-work and social morale. The arguments for internationalism are commercial and industrial rather than social and moral. The larger the group the more difficult the integration. It is for some prophet of 1 Quoted in The Outlook, January 28, 1920, p. 146. 
social reconstruction to come forward with a plan, not for increased production of goods, not for increase of comforts and luxuries, not for more equality and more freedom, but for a social order based on small and closely integrated communities in which there shall be a powerful community spirit with its accompanying discipline and morale. The instinct of aggressive and defensive gregariousness, no longer acceptable to the modern mind, must be sublimated and redirected. It will be still a long time before we shall have that degree and kind of education which shall make it possible for us to substitute humanity for the State and internationalism for nationalism. It is doubtful whether we are even progressing toward that goal except in theory. Those who dream of some other form of world organization, not political, which shall unify and integrate humanity, such, for instance, as the industrial guild, the labor union, the friendly society, or the family, ${ }^{1}$ are still reckoning without the psychological element and are ignoring the all-powerful and ancient instincts and interests of the human mind.

1 See L. P. Jacks, "The International Mind," Allantic Monthly, March, 1920. 
But patriotism, powerful as it is, will not under modern conditions be sufficient. For the rest we must depend upon education. At the present time knowledge is causing us to lose faith in our religion, in our established institutions, in our ancient laws of conduct, in our social conventions, but it is because it is only partial knowledge. It is still true that a little knowledge is a dangerous thing. Having started in now on the programme of universally disseminated knowledge, we must carry it through. At the present time the world has just enough knowledge to endanger it, not enough to save it. Education must be universal, thorough, adequate. So long as our automobile mechanics command larger salaries than our teachers, we are on the wrong road to social welfare. So long as we expend twice as much for tobacco as for schools, we waste time trying to save our country by means of religion or politics or by means of Socialism or any other system of social reconstruction. What we must have is knowledge, knowledge of the real sources of welfare, happiness, and self-realization. Knowledge alone will enable us to solve the problems of social reconstruction; knowledge will restore both religion and morality, and knowledge will save society. 
We shall have to wake up to the fact that in this country of amazing wealth it will no longer suffice to set aside a mere insignificant pittance for our schools, but really large sums will have to be spent, and we shall have to revise our concepts of what education is. Reading, writing, algebra, arithmetic, geography have been emphasized in our schools because morals, citizenship, health, industry, thrift, and obedience to law were supposed to be taught at home. We can no longer rely upon the home for these things. ${ }^{1}$

1 The serious situation in regard to the schools in the United - States may be partly understood by reading Professor William C. Bagley's article entitled "Education, the National Problem," in the New Republic for December 17, 1919. Our teachers, he says, are rapidly diminishing in numbers and deteriorating in quality. One fourth of them are scarcely more than boys and girls. No longer are the best of our high-school and college students drawn into the public-school service, but those of lower grade. "Sixty thousand of our teachers are reported as unable to meet the very meager standards of the lowest grade of teachers' certificates."

Professor Bagley shows further, and this is very significant, that nearly sixty per cent of the next generation of American citizens will have all of their schooling in rural schools taught by mere boys and girls, mostly girls, who have themselves received scarcely a rudimentary education. Of our three hundred thousand rural and village teachers, an overwhelming majority have not passed the age of twenty-one and at least one third of them are sixteen, seventeen, or eighteen years of age. In one typical Middle-Western State one half of the rural-school teachers are twenty years old or younger. Furthermore, nearly a million of children are out of school because teachers cannot be found for them.

Many of these figures are based upon pre-war statistics and the situation at the present time is even worse than here shown. 
And another thing which we shall have to learn is that public schools and public education are two very different affairs. The teachers of the American people to-day are not the young women who for five or six hours a day during a part of the year hear recitations in grammar, arithmetic, geography, and spelling; the teachers of to-day are the metropolitan newspapers which find their swift way into every corner of the country, and the bulky Sunday papers sent out by the carload, and the agricultural papers which the rural mail brings to every farmhouse, and the great weeklies whose wealth of advertisements makes it possible to scatter them by the millions broadcast for a nickel or a dime a copy, and the weekly and monthly magazines found in every home, and the books of current fiction so easy of access and so absorbingly interesting, and the moving pictures attended by ten or fifteen millions, mostly young people, daily - all these are our teachers of to-day and they are moulding the thoughts and habits of our young and old.

To appraise the value of the education received in this gigantic "school" would be a task which few would be bold enough to undertake. That it contains an immense amount of good 
no one will question; that it likewise contains an immense amount of evil few will deny. But the thing which is most evident is that a colossal burden of social responsibility rests upon the shoulders of our journalists, news reporters, writers of fiction, and moving-picture makers of to-day. It is very possible that there are many editors and reporters who have never even thought of or reflected upon the fact that they are the teachers and the leaders of the people and that they hold a position of grave responsibility for the moral health of the community. Possibly some regard their work as a business enterprise.

Journalism can no longer be left to mere accident. We shall have to recognize that those who conduct our newspapers and magazines are public teachers, having an infinite responsibility for public morals and manners.

It is evident, therefore, that, when we speak of education as the cure for our social ills, we shall have to enlarge our notion of what education is. We have no longer to do simply with schools in the ordinary sense. We must begin to think of some vast new plan of education which shall vitalize and moralize and mobilize for the common good every source of educational in- 
fluence, our religion, our press, our fiction, our art, our drama, our music, our moving pictures.

The deluge of bad music that is pouring over our country is due to ignorance. Some of this music is demoralizing, very little of it is moralizing, most of it is merely poor. Our people would enjoy and appreciate good music if it were offered them, if they had a chance to know it. ${ }^{1}$ It is doubtful whether there is any real demand for the so-called comic pages in the Sunday papers; the children would be equally pleased with something better and adults would be spared these weekly nauseas. It is probably true also that the demand for sensational news in our daily papers is much exaggerated by the press. Readers would appreciate and would be willing to pay for a higher kind of first page than that bold-print display of every kind of wrongdoing which is now justified on the ground of publicity and demand. But the real lesson we have to learn is that it is not a question of demand and supply at all, but a question of moral obligation to the community. We must learn

1 This has been shown, for instance, in the case of the good music furnished by the Strand Orchestra at the Strand theaters in New York and Brooklyn in connection with the moving pictures. It is enjoyed and appreciated by the thousands of patrons who hear it daily. 
who the educators of our people are and what their responsibility is.

It has been naively proposed to use the moving pictures as a means of education. They are that already with a vengeance, and they reach the young people and hold their attention, not five days of the week and thirty weeks in the year, but daily and Sunday throughout the year; and what they offer is that which will draw, and that which draws is the thrilling. These pictures present, therefore, a series of thrills, and the thrilling is the unusual, the new, the startling, the very latest, the very biggest, the very fastest, the very best, the very worst, and the most interesting. Love is interesting, heroism is interesting, sex is interesting, crime is interesting; all these abound. Sometimes great moral lessons are taught, but life is here so schematized that the lessons are hardly applicable to our actual life; the suggestions, however, remain and bear fruit. 'There is no remedy for this evil but education. What the makers and promoters of the pictures lack is moral taste; what the people lack is dramatic taste.

One would suppose that, since the stage in America has been degraded to the level of the moving pictures, some dramatic representations 
of a high order would be offered in every town and city for the bencfit of those who care for better art. In rare cases this is true, but gencrally throughout the land the moving pictures alternate with a degraded vaudeville, with its "amazing display of shoddy sallics at marriage, and women, and Congress, and prohibition, and bedroom farces." Shall we correct these things by law? But in a democracy the people make and enforce the laws. Evidently education is our only hope. Socrates was right when he said that virtue is knowledge.

After all, when we have said that universal education must be the secret of social discipline, we have not said the last word on the subject, for the question, of course, ariscs, who is to educate the educators? Social discipline, like social progress, must depend in the last analysis upon gifted and far-seeing leaders. The springs of progress do not come up from the people, they come down from Heaven. The ultimate problem seems, therefore, to be how to give our scers, our wise men, and our prophets the authority necessary for social control. This implies a respect and confidence which in the past has been gained through religious, social, or political status. In our social democracies of the future 
this means may not avail. There seems to be, therefore, nothing for it but to gain this authority through the respect and reverence that we have for science as such. It would seem, therefore, that our seers and leaders of the future must be scientific experts after the manner of the rulers in Plato's Republic, but supported by all the people merely because they are men who know.

But the constitution of our modern society is such that education alone will not suffice for social discipline. With our ever-increasing numbers of subnormal individuals, including the feeble-minded, insane, epileptics, and hereditary criminals, to say nothing here of the increasing proportion of the physically unfit, modern society carries a mass of impedimenta which is going to make social integration exceedingly difficult.

Let me make this concrete by a single illustration: A normal-school teacher, writing of types of boys with whom he has had experience in reform schools, mentions this typical case.

On Boy No. 5 I have never felt it quite safe to turn my back. I can call him nothing else than a "coldblooded" criminal. A complete coward himself, as 
afraid as death of any physical suffering for himself, he will inflict pain on animals or on other persons without the slightest qualms of either flesh or conscience. I have seen him hold mangled but living birds against a hot stove, "just to see them squirm." I have overheard him retail with great glce his frequent use of the "blackjack" upon the victims of his "hold-ups." "Pom!" he would tell it. " Ugh!' says the guy, and down he gocs all in a heap, and right away I have some more mon' to spend. No, I never plunk a feller who can't stand it. No, you bet I'll never kill a guy. I know where to hit 'em."

My own conviction is that Boy No. 5 ought to go on the surgeon's chair and have something done to the inside of his skull, for I feel absolutely certain that there is something fundamentally wrong there that accounts for his cold-blooded heartlessness toward the sufferings of anything or any one else than himself. My attitude toward him has been the one a person takes toward a venomous snake - a sort of watchful loathing or repulsion. Lacking the operation suggested above, society would be safe from his dangerous preyings only through his confinement within strong walls - and cven then the guard would have to be ever on the watch against his "Pom! and down he goes all in a heap!"

If we remember that a case like this is merely a type of thousands, and if we think of the countless numbers of feeble-minded men and women permitted by our social customs to scatter broadcast their defective heredity, and if we think still further of the increasing numbers of 
our other defective and delinquent classes, we begin to understand the tremendous problem of social discipline in modern society. Some day - let us hope it will not be too late - we shan wake up to the necessity of social self-protection against these enemies of morale. It is true that our experiments in eugenics both in its positive and negative forms have not been very successful. Neither were our first experiments in flying. When we get ready to apply to this problem a fraction of the thought and care which we are now applying to the perfection of the automobile, then something will be done. ${ }^{1}$

In Professor C. A. Ellwood's book, The. Social Problem, one finds a sane treatment of these problems and a clear and comprehensive statement of the conditions of our social salvation. In place of our narrow individualism and our fond materialism must be substituted the service of humanity, rather than the service of the indi-

1 A definite and concrete plan for the salvation of society from physical degeneracy has been presented by Mr. Seth K. Humphrey in the last chapter of his recent book, The Racial Prospect. It is only necessary that the collective group should have the resolution to carry it out. His plan for the final elimination of the defectives and ineffectives would seem to be practicable. In place of his further rather bizarre proposal for conserving the heritage of the now childless select individuals, some other more natural means could be devised. 
vidual, class, nation, or race. To this end there must be a revaluation of religion, morality, and education, as well as of government, law, and family life. Religion must be socialized and revitalized. Education must be moralized. There must be a rational, eugenic programme, a just cconomic order, and a healthy social atmosphere.

This is excellent fatherly advice, but will the children heed it? This is a typical expression of the best social philosophy of the present by one of its able exponents, but at the same time it reveals the fatal defects of this same social philosophy -its lack of a psychological foundation. What is wanting is the motive power to put this ambitious programme into effect. The flame, the glowing. end, is absent. Given wise leaders and a submissive and obedient people and it could be done. It assumes a relatively small community of rational beings ready to reason and listen to reason. In the Age of Pericles or Socrates it might work. In our surging masses of northern people something more concrete is needed. "The Northerner," says Professor Marvin, "is not hardheaded, is not a lover of order and form, is not 'classic.' Rather he is sentimental, romantic, venturesome, restless, undisciplined and dis- 
orderly." 1 Professor Ellwood comes nearer to a "solution" of the social problem when he says that it depends upon the finding and training of social leaders. It may, however, be doubted whether leaders are either found or trained. They just appear, - that is, the kind of leaders that can lead.

Perhaps with our headstrong and wayward northern races, and our increasing populations, and our large social groups, there is no solution of the problem of social discipline apart from that defensive or offensive gregariousness which can no longer be invoked because it leads to war and ruin. Possibly modern civilization has come to an impasse. Probably what we need is some new interpretation of religion which shall sweep the world and snatch us out of our devotion to self and our narrow class interests. That failing, education and the organization of intelligence will be our only hope. In the following chapter we shall consider some ways in which organized intelligence may be applied to this and to certain other problems of social reconstruction.

1 Walter T. Marvin, The History of European Philosophy, p. 247 . 


\section{CHAPTER VIII}

\section{THE NEXT STEP IN APPLIED SCIENCE}

T'T was long ago that Plato taught that sci1 ence should not be applied to the mechanical and industrial arts, but to education, social culture, and social health. And a century and a half has passed since Rousseau's celebrated essay, in which he tried to show that the arts and sciences had done nothing to advance human happiness. From our modern point of view these were the pathetic mistakes of great men, so richly, as we think, has science vindicated itself in its practical applications.

Consequently, when the term "applied science" came into use not many years ago, it was heralded with great joy, for we were weary of Plato's theoretical ideas about justice and truth, and skeptical about his plan for racial culture, and we longed for something practical and immediate. We welcomed, therefore, the direct application of science to our everyday needs, and when, in response to this demand, science began to shower its practical applications upon us, it 
seemed to many that a kind of golden age had come at last. It revealed to us the only god worthy of our worship - the god of social welfare, social welfare being generally interpreted to mean the comfort, happiness, and convenience of the present generation.

While we may not question the almost unlimited possibilities in the application of science to social welfare, nevertheless, we may raise the question whether science has thus far been applied to the right things. The war has shaken the foundations of so many of our accepted opinions that even our faith in applied science may receive a rude jolt. Since we are now entering upon a period of reconstruction, which many believe will involve not only our social and political ideals, but also our ethical and religious beliefs, it is legitimate enough to ask whether applied science has vindicated itself by its results and what place it is to occupy in the coming order.

Our first thought is that applied science has been not only a stupendous success, but perhaps the crowning achievement of the human mind. The story of its triumphs is known by heart to every school-girl. Applied science has made the world over, making it a decent and healthful 
place to live in. We press a button and our houses are filled with light. Scientific heating, ventilation, drainage, and sanitation have made our homes places of cheer, comfort, and health. The motor-car, smooth, noiseless, and swift, saves our time and our nerves. Time-savers, too, are the typewriter, the dictograph, the multigraph, and the adding machine. Communication is facilitated by the wireless telegraph, the telephone, and the aerial mail.

It is needless to go through the familiar list. Lest, however, it should be thought that applied science has given us only comforts, conveniences, and time-saving devices, we are reminded of its triumphs in the conquest of disease, in public sanitation, in surgery, dentistry, and preventive medicine, and in the application of chemistry to agriculture. And most manifest of all are the countless applications of science to the industrial and mechanical arts, increasing the efficiency of labor, thereby shortening the hours of the laborer, as well as ministering to his comfort and health. Certainly applied science has made the world a tidy place to live in and contributed an untold sum to human happiness and welfare. Surely, had Rousseau lived in the twentieth century he would never have written, even for the 


\section{SOCIAL RECONSTRUCTION}

sake of a brilliant paradox, an essay questioning the value of the arts and sciences to civilization.

We may not, indeed, question the potential value of applied science, nor even its actual value in countless directions. What we may question is whether there has been a mistaken conception of the general end to which science should be applied, in respect to real social welfare. To what extent has science, as it has actually been applied, contributed to human good?

First, applied science has surrounded us with comforts, conveniences, and luxuries of every kind. But just what will be the effect upon a race of men, disciplined through a hundred thousand years of hardship, of this sudden introduction to comfort? This question puts the whole subject of applied science in a new light. Perhaps we have been applying science to the wrong ends. Possibly science should never have been applied to making man comfortable, but to making him perfect. It may be that there is great danger in comfort. The biologist holds it in grave suspicion; degeneracy is its sequel. It was through struggle and warfare and the overcoming of obstacles that man fought his way up to manhood. With infinite effort he gained an upright position 


\section{NEXT STEP IN APPLIED SCIENCE 24I}

the better to strike down his enemies. Strong legs and stout arms were the correlates of his growing brain, the latter itself finding its necessary support in a powerful heart and vigorous digestive system. There is an especially intimate connection and interdependence between the brain and the muscular system, making the latter indispensable to the proper functioning of the former. Now, applied science has shown us how machinery may take the place of the stout arms and the motor-car may be a substitute for the strong legs, while science itself and the applications themselves draw more and more heavily upon the powers of the brain. The harder the brain has to work in the pursuit of science and the mechanic arts, the more it stands in need of the physiological support of the muscular, digestive, and circulatory systems. But, for maintaining the health and integrity of these, our present manner of living is not well adapted.

"Oh, well," it is replied, "there are no signs of physical degeneration yet. Look at our armies in the World War. Finer physical specimens never marched out to meet an enemy." Yes, but they were picked men, the very flower of "a vast nation. They were from the upper tenth physically. They were the young males. They were the 
sixty-five per cent of the young males not rejected by the examining boards. The germplasm of the best of our race could not suffer deterioration in the short time of the "comfort" régime. But upon biological grounds we must believe that the disastrous consequences of such a régime upon society as a whole may be serious in the highest degree.

Another of the most brilliant triumphs of applied science is seen in our countless and wonderful labor-saving devices. The effect of these is either to decrease the amount of labor or by increasing its efficiency to increase the products of labor. But we simply assume that increased wealth and decreased labor are human blessings, although both may be quite the opposite. It has been seriously questioned whether civilized man has gained enough moral and physical poise to be trusted with the immense wealth which applied science, working upon our suddenly acquired store of coal and iron, has supplied. The war did not count the poverty of the nations among its causes, and if greed is the root of most modern evils, it has not been shown that increasing wealth and increasing comforts have lessened it.

And then there are the time-saving devices. It is no doubt because of the temper of the day 


\section{NEXT STEP IN APPLIED SCIENCE 243}

that so few of us have ever questioned their intrinsic value. But with all these time-saving devices it is not quite apparent that we have any more time than formerly. Sometimes it seems as if we have less. Leibniz lived before the time of typewriters and dictographs, yet he is said to have had a thousand correspondents, and in addition to his duties as court librarian, diplomatist, and historian, he found time to discover and perfect the differential calculus and to write great works on philosophy. In any case the value of time-saving devices will depend upon the use of the time that is saved. As it is, it appears to be used very largely for carrying on more business, to make more money, to buy or invent more time-saving devices. Even if there results a certain amount of leisure, much depends upon the manner in which the leisure is spent. If it is spent in sitting quiescent in a darkened moving-picture room, gazing spellbound at a tawdry drama, the gain is not great.

To all such arguments as the above it will be replied that modern science has nevertheless made the world a decent and comfortable place to live in and that there has never been so much happiness in the world as at present. But, since 19I4, Europe has not been a decent nor a com- 


\section{4}

fortable place to live in nor has there been general happiness, although Germany excelled in its development of science and in the application of science to the mechanic arts. A good civilization must insure some degree of stability.

In this connection we are reminded that there is one field in which science has distinguished itself beyond all others, and that is in the art of war. To the exquisite perfecting of this art every science has been called upon to contribute its very best and latest results - mathematics, engineering, physics, chemistry, metállurgy, mechanics, optics, radio-activity, electro-dynamics, aeronautics, economics, zoölogy, psychology, and many others. An immeasurable weight of the best and keenest thought of the world has been expended in the application of science to the paraphernalia of war, resulting in an amazing progress in the development of this art to the highest conceivable degree of perfection.

In former times wars acted to purify racial stocks by eliminating weak races. Modern wars have precisely the opposite effect, owing to the fact that a modern war kills or disables the best young men of all the warring nations, and so, by destroying the most valuable germ-plasm of 
the race, causes irreparable damage to society. Applied science has devised every conceivable means to make the destruction complete. Would it not be well, therefore, in the years to come for science to apply itself directly to the problem of preventing wars? It is idle to say that they cannot be prevented or that science has nothing to do with this problem. It lies distinctly within the field of such sciences as biology, psychology, sociology, and education. For applied psychology it offers a most alluring field. It may be an immense problem, but the possibilities of science are immense.

At present we are deeply impressed by the waste and folly of wars between nations and are still hoping for an effective League of Nations to lessen their frequency; but the menace of civil war will be ever present. A great nation may be torn asunder by a dispute about slave labor or a quarrel over religious creeds; mere rivalries between families, clans, and classes may cause the streets of great and beautiful cities to run with blood, or a whole nation may simply lapse into civil war as a result of the disintegration of outworn political institutions. Any of these causes seems less promising for war than the conflict of labor and capital which is facing us. 
We have thus in the preventing of war a real problem for applied science, especially for applied psychology. Let us, by all means, make over our laws and our international relations to the end of preserving order, but let us direct our main endeavors to making over our men and citizens so that they will have sense enough to settle all their disputes and controversies in some more rational way than by blowing out each other's brains with high explosives or by dropping bombs from aeroplanes to destroy buildings that they have erected with infinite labor. Education will be efficient here, but it is an especially attractive field for applied psychology. The source of war is in the human brain, where the instincts of combat lie deeply embedded, sanctioned through the warfare of thousands of years of human history. To eradicate these instincts may be difficult. To substitute some other form of expression for them may be possible. At any rate it would be worth while to turn in these directions a fraction of the brain power which has been expended in the invention and circumvention of the submarine boat or in the transmission of messages by means of the ether.

But it may be said, if applied science has not contributed as much to human welfare, as first 


\section{NEXT STEP IN APPLIED SCIENCE 247}

appears, in the field of mechanic arts, nevertheless there are other fields in which its contributions are unquestioned, notably in hygiene, sanitation, and agriculture.

The deep obligation which the world owes to applied science for its work in social and domestic hygiene, in applied bacteriology, in surgery, dentistry, and preventive medicine, is appreciated by everybody. But the question arises whether even here science has been applied in just the right direction.

Let us take dentistry as a convenient illustration. This highly perfected modern art has given us beauty and symmetry of the teeth, replacing the deformities which formerly were so unsightly, particularly among older people. But obviously we have here not a remedial art, but a patching-up process. Crowns and bridges and artificial substitutes, themselves often the source of infection disturbing the health of the whole body, have replaced the sound white teeth which Nature should supply. At one time in our racial history sound teeth were necessary for the survival of an individual. They are scarcely so at present, for with artificial teeth and soft prepared foods one may get along very well and one's children may inherit the inner defects. 
This process cannot go on forever. Under the old régime, before the rise of modern dentistry, there was at least a force, powerful if not always effective, working to the end of sound natural tecth. The dentist's art has to a large extent displaced this force. Is it too much to conceive of a new dentistry which shall have for its object not to make people look better, but to make them really better? If it is replied that this is precisely what the most recent dental art aims at in its teaching of oral hygiene, it is still true that this work relates largely, if not wholly, to the individual, for such acquired characters are not inherited, so that dental degeneration may be going on unchecked, as has been shown to be the case in England. The problem may be a difficult one, but not necessarily beyond the power of applied science.

Then there is the conspicuous instance of the apparent triumphs of applied science in the conquest of modern diseases, particularly those of bacterial origin. Science has discovered, for instance, the cause and cure of tuberculosis. What greater boon to humanity could there be than this discovery, with its keen diagnostic technique, its therapeutic methods, and its fresh-air cult? It would appear, however, from no less an 
authority than Professor Karl Pearson that the death-rate from tuberculosis has been decreasing as far back as our records go, and that since the introduction of the new methods of treating this disease, which date from about I890, the decrease in the death-rate has been less rapid than before. ${ }^{1}$ Neither is this startling situation due to an increase in urban or factory life, as is shown by the recent rapid ravages of this disease in rural districts. Even though the accuracy of Professor Pearson's statement may be questioned, and even though it be true that many diseases are now diagnosed as tuberculosis which were formerly classed under other names, nevertheless it is becoming clear that this branch of applied science has not been so sweepingly successful as was at first hoped, and that it may be well to supplement Nature in her efforts to produce a degree of immunity to this disease by strengthening constitutional resistance. Methods

1 Karl Pearson, Tuberculosis, Heredity, and Environment, p. 28.

Dr. V. C. Vaughan of the University of Michigan Medical School said in an address before the Tuberculosis Congress at St. Louis in April, 1920, that "while before the war the mortality from tuberculosis decreased, the morbidity from this disease, as determined by post-mortem examinations and by the application of the tuberculin test, increased." On the increase of tuberculosis since the war, compare the article by Homer Folks entitled "War, the Best Friend of Diseasc' in Harper's Magazine for March, 1920. 
of accomplishing this end are well understood now, since the Mendelian laws of heredity became known. It is only necessary to apply this branch of science.

In respect to general social hygiene, the benefits conferred by applied science seem certainly at first sight to be unimpeachable. One thinks immediately of our clean houses and our clean cities, of our comparative freedom from the scourges of smallpox, cholera, typhus, and malaria, which in former times decimated the people. One thinks, too, of the marvelous triumphs of sanitation in the Panama Canal Zone and in our colossal national army, army camps and cantonments during the war. One thinks of our efficient and sanitary hospital service, of our wonderful restorative surgery, our orthopedic art, and our discovery and application of anæsthetics to the relief of pain.

The benefits, at least to the present generation, of this social hygiene are so patent that few of us have stopped to question whether it is, strictly speaking, social hygiene at all, or, if it should be so called, whether it is the highest kind of social hygiene. Social hygiene must have as its end a really healthy people, not a weakened race which at every turn must be corrected 
and protected by artificial means. Our method of combating epidemic diseases has had for its two main objects the protection of the individual from infective agencies and the discovery of neutralizing antitoxins. Little attention, one might say almost no attention, has been given to making the individual constitutionally resistant to these agencies. It is perhaps a losing game to try to protect the human race from toxic and infective agencies. Brilliant temporary results may be gained, but a new swarm of microscopic enemies will ever be on the scene to take advantage of their weakened victims. So while we gain control over smallpox and typhus by constantly repeated devices, epidemics of infantile paralysis, influenza, and pneumonia cause us to renew our Sisyphean labors.

In the meantime, while we are making headway against typhus and malaria and perhaps against tuberculosis, we hear of the increase of cancer, venereal diseases, diseases of degeneration, diseases affecting the heart and arteries, diseases of the digestive and eliminative organs and of mental diseases and diseases of the nervous system. We are perplexed to hear that the percentage of mothers who are willing or able to nurse their own babies becomes yearly smaller. 
While applied science has shown us how to quadruple our wealth and increase indefinitely the fertility of our soil, it has shown us how to decrease the fertility of our women; and since the new art is becoming fashionable among our best people but not among our worst, we have the unhappy prospect of actual racial deterioration, already evinced by an increase of feeble-mindedness, insanity, and crime. When bank robberies flourish during a time of unlimited prosperity, at a time when almost any person can get work at almost any wages, it would appear that the trouble is not in our social institutions, but in the convolutions of our brains.

Nature seems to have discovered many ages ago that the way to make any race of animals or men strong and hardy was not to shield them from their enemies, but to give them power of resistance against their enemies. As Professor Todd says: "A pasteurized, sanitized society is not necessarily progressive or dynamic." 1

Is it too much to hope that in the period of reconstruction to which we are looking forward, science may be applied less to shielding us from all manner of dangers and evils, and more to making us strong to overcome evils; less to the

1 Theories of Social Progress, p. 122. 
production of comforts and conveniences, and more to the encouragement of hardihood and vigor; less to the increase of efficiency and the piling-up of wealth, and more to the production of racial health and stability?

Science has always been applied, and successfully, to our immediate needs as they were understood. The immediate needs of our present time are not more wealth and more luxury and more efficiency, but more racial and constitutional power of resistance to physical disease and more individual power of resistance to every alluring immediate joy which threatens the permanent welfare of society. We need steadiness and self-control and the limitation of our desires. The centrifugal motive which has ruled the world for the last fifty years has gone far enough. The world is small and there are limits to the expansive opportunities both of the nation and the individual.

This, of course, will be applied science in a broad sense, applied psychology, applied ethics, applied sociology, applied biology, applied philosophy - and the growing interest in these sciences is one of the fine things of the present time.

There is finally another field where there is an 
immediate and imperative demand for the application of science, and that is in our industrial labor disputes. One wonders to what extent the conflicts between labor and capital may be due to sheer ignorance. At any rate, it was evident enough in the coal strike in the fall of 1919 that there was shameful ignorance throughout the whole country, and in the highest places, of the actual facts about the coal industry. On every side there was a superabundance of feeling, sympathy, anger, indignation, mistrust, greed, fear; but a serious lack of knowledge. We abounded in the Christian virtues of faith, hope, and charity, but our stock of knowledge, which in the Socratic philosophy is the beginning and end of virtue, was perilously low. In the merely mechanical part of coal-mining, as in other industries, applied science is everywhere in evidence; in the sociological and psychological aspects of these industries, it is conspicuously absent. In this age of organized labor and organized capital, it is a wonder that we have not bethought ourselves of the experiment of organized intelligence. ${ }^{1}$ There is plenty to think about in the following quotations from a recent article by Felix Frankfurter in the Yale Review:

1 Compare Will Durant, Philosophy and the Social Problem, part ts, chap. utr. 
The recent coal strike reveals shortcomings that not even the largest headlines of "law and order" can conceal. The strike was called off but its causes persist. This is not the time for a scrutinizing study. Whatever negotiation may accomplish, whatever ameliorations will be sought for the distempers which have been aroused by the shallow recklessness of invoking the injunction under plea of the war power, the fundamental lesson of the strike will be lost unless out of it comes the common consciousness of the sin of ignorance and the failure to fashion instruments of knowledge for action. Inevitably, every one had an opinion about the strike. But who had justification for such opinion founded on knowledge of the coal industry, and, especially, knowledge of the conditions of life that confront those 400,000 workers?

The indictment of our civilization is that some of the facts vitally affecting the coal problem are not to be had. To a large extent any decision as to hours and wages is "a game of blindman's buff" - blindman's buff tempered by force and necessity. Here is, indeed, not only one of our greatest industries, but (as it is insisted upon as though it were the solution instead of the statement of the problem) "a basic industry" - the very flame of life. Yet have we sought to know it, to master it, in a sensible and forethoughtful way to avoid being trapped by our dependence upon it?... We should get what help we can from the workings of the Whitley Councils in England, similar councils in this country in the clothing and printing industries, the very hopeful results already achieved by the Government through its new methods in the Rock Island Arsenal, where men produce primarily because they want to. Every successful experiment must be explored with the scientist's 
faith that a promising exception can be made the rule.

In a word, we must see these industrial difficulties as a challenge to social engineering, to be grappled with as the medical and the physical sciences meet their problems. Epidemics were once deemed to be visitations of God, but now Dr. Simon Flexner summons his profession consciously to master epidemics. The Rockefeller Institute, by a steady and systematic process, first seeks to state the problems of disease and then persists until it finds answers. A transcontinental telephone was not the product of a sudden flash of genius nor the gift of happy accident. On the contrary, it was a task definitely set to mathematicians and physicists. Human will and intelligence and persisting faith achieved the miracle. So it must be in industry. The present obstacles to production the lack of right human relations, the evocation of the creative impulses in workers - are problems to be solved; for upon their solution depends the quality of our civilization. ${ }^{1}$

Specific directions in which science may be applied to human welfare are found in conservation and education, and in eugenic control. Science has already been applied to the conservation of our soils and forests. It must be more widely applied to the conservation of all our physical and mental resources and particularly to the conservation of racial values. It may be feared, however, that both these forms of con-

1 Felix Frankfurter, "Law and Order," Yale Reoicw, January, 1920, pp. 227, 234. (The italics are mine.) 
servation imply a degree of self-control and self-sacrifice which is foreign to the spirit of this individualistic age.

In the reconstruction era which we are approaching, the danger is that in the spirit of the times we shall attempt to solve the profound social problems which confront us mainly in two ways: first, by the further development of the mechanical and industrial arts, and, second, by the manipulation of political institutions. We shall try, by means of new labor-saving and time-saving devices and new mechanical appliances, to multiply still further the wealth of the world. We shall try, by means of some form of Socialism or Syndicalism, to provide that this wealth be more equitably distributed than it is at present. We shall try by the further extension of democracy and by equal votes for women to provide that justice prevail more widely than now. We shall try by sumptuary laws to see that drunkenness is prohibited. Certainly many of these proposals are of the highest value; it is only that we shall rely too much upon this machinery for the salvation of society, and shall insist too little upon such other factors as education, conservation, self-control, and the limitation of desires. 
It would appear, therefore, that in the reconstruction programme of the future, we must proceed along other lines than those of our present popular movements. We must cease our efforts at trying to make men comfortable and begin to make them better. Civilization does not depend upon the increase of wealth, or its equal distribution. It depends upon the proportion of dominant and effective men and women; upon the production of leaders possessing initiative, daring, creative and constructive power; and it depends upon discipline, poise, loyalty, devotion, and mental and moral health. Most of all, perhaps, it depends upon the conservation of moral values.

Perhaps one of the most distressing signs of the times is the increase of inefficiency - at the very moment when we have laid so much stress upon efficiency. We have indeed acquired a kind of efficiency in business, which has no value except to further enhance our wealth. But it would appear that vital efficiency and physical efficiency are lessening. It is a bad sign when people dread the hard work of the farm and seek the easier jobs and the shorter hours of the city, or refuse to work at all if they have a little money in their pockets. With our increase of 
wealth on the one hand and on the other the decrease of vitality or vital efficiency, our glittering civilization may be near the fate of other civilizations of the past. Its complete breakdown is not impossible, with unrest increasing to the point of violent revolution with its accompanying anarchy, misery, starvation, depopulated cities, and neglected fields. And if our present civilization does go down, there are apparently no reserves of vital power in the outlying districts of the earth, as there were in the days of Rome, to replenish the impoverished blood of the people; for the effectives of all races are now drawn to the great industrial and commercial centers and their vigor exploited for the glory of the present day, not for racial conservation. ${ }^{1}$

Probably nothing so cataclysmic will happen. In free America at any rate such an outcome is improbable. The great body of our people are sober-minded and level-headed. At heart they appreciate the joy and freedom of democratic America. After the disturbing influences of the war are past - influences which may indeed for a time bring about real suffering and distress -

1 Compare Seth K. Humphrey, The Racial Prospect, chaps. vili and IX, and Brooks Adams, The Laws of Civilization and Decay, chap. XII. 
260 SOCIAL RECONSTRUCTION

our country will right itself. We shall go forward on our way - and then we shall be face to face with the real evils that threaten an industrial age, an age actuated by industrial and materialistic motives, namely, stagnation and the loss of the higher values of life.

THE END 
INDEX 



\section{INDEX}

Achievement, 54, 94; a funda- Babbitt, Irving, 177, 192; Rous. mental human need, 147-48, seau and Romanticism, $174 \mathrm{n}$. 199.

Bacon, Francis, vii, 26.

Acquisition, instinct of, 75, 77, IO2.

Activity, source of happiness, $47,52,56,150,175,187$.

Adams, Brooks, The Law of Civilization and Decay, $259 \mathrm{n}$.

Adams, G. P., Idealism and the Modern Age, 53, $95 \mathrm{n}$.

Adventure, love of, 78, 79, 85, 200.

Agrarian Socialism, 143 .

Alcohol, 1, 3, 71, 74, 109, 137; dry laws, $4 \mathrm{I}$.

Altruism, 192.

America, as a field for opportunity, 102, 105, 112, 138, 168$73,200-01$.

Amusement crazes, $3,88$.

Anarchism, 27, 143.

Anarchy, 9, 213 .

Anderson, B. M., Social Value, $56 \mathrm{n}$.

Arbitration, 153.

Aristotle, 47, 52, 130, 197.

Art, 107, 108, $1110,161,179,191$, 193, 205, 229.

Athenian race, intelligence of, 179.

Athens, ancient, 205.

Authority, respect for, 188 .

Autocracy, 178.

Augustine, St., City of God, 32.

Bagley, W. C., 14 n., 226 n.

Balked disposition, 64,76 .

Barnich, G., Principes de politique positive d'après Solvay, $49 \mathrm{n}$.

Bell, Clive, 130.

Bentham, J., 36.

Bergson, 51 n., 182.

Birth control, 42.

Birth-rate, decline of, $12,24,7 x$.

Bloomfield, Meyer, Management and Men, $152 \mathrm{n}$.

Bolshevism, 9-10, 27, 100.

Booker, J. M., 165.

Brain, modern demands upon, $24 \mathrm{I}$.

Brain patterns, defective, 208.

Brotherhood, 207.

Browning, 182.

Building instinct, 166, 199.

Butler, N. M., Is America Worth Saving? $20 \mathrm{n}$.

Byron, Letters and Journals, 197.

Cabot, R. C., 159; What Men Live By, $119,122$.

Cannon, W. B., 38.

Capital and Labor, 19, 29, 32, 120, 152, 216, 245, 254.

Capitalism, psychological aspects of, $75-78$. 
Carlyle, Past and Present, 122.

Centrifugal forces in society, chap. VI, 181, 183,188, 193, 203-04, 253.

Centripetal forces in society, 181, 188, 199-236.

Changing social order, 18, 197.

Chaperons for university students, 217.

Charity, 192-93.

Chastity, 179.

Chautauqua plan, 85-89.

Child labor, 19, 42.

Christian civilization, 17.

Christian Endeavor, 53 n.

Christian virtues, 182; 191, 254.

Christianity, 182.

Church, 204, 213, 216.

Cigarette habit, 92.

Civilization, at the cross-roads, vii; Christian, 17, 104; dangers threatening, 9, 259; downfall of, 6, 212; has it come to an impasse? 236 ; is it worth saving? 13, 15, 115 ; modern, 2, 3, 5, 7, 14, 23; tests of a good civilization, 244.

Coffee, 53 n., 137.

Collecting, instinct of, 63 , 102 .

Collective bargaining, 19, 50, 152.

Collective management, I44, $150,167$.

Collective ownership, 143-44, 150, 153, 167 .

Collectivism, 27, 143, 209.

Comfort régime, 242.

Comforts and luxuries, 109,115 ,
116, 117, 132, 147, 191, 224, 232-40; danger of, 240 .

Communism, 9, $27,148$.

Communities, small, 224 .

Community spirit, 205.

Conative impulse, $5 \mathbf{I}$.

Conflict, love of, 86.

Conscience, social, 17.

Conservation, 34, 94, 149, 191, 256-57; of racial health, 9394, 259.

Control, social, 215-16, 220, 231.

Coöperation, 27, 143,150, 207 , 212.

Craftsman, man as, 127, 132, 139.

Creative impulse, 94, 127, 131, $155,200$.

Creative work, I15, 135, 139.

Crime, 193; waves of, 9, 107.

Criminals, instinctive, 232-33.

Cross, symbol of, 213.

Culture, pecuniary, 140, 145 .

Dancing, 3, 96, 137, 217, $217 \mathrm{n}$.

Dancing craze, 1,12 n., 107.

Danger, love of, 83 .

Decadence, 25, 183; moral, 12; physical, mental and moral, I1-12.

Defectives, 12, 13, 173, 201, 211, 232-34.

Degeneracy, 11-13, I18; diseases of, 251; physical, 241; racial, 252.

Delinquent classes, $21 \mathrm{I}$.

Democracy, 21, 202, 218-19, 223, 257; indus̀trial, 50, 15053, 167; social, 143 . 
Democratization of industries, I50-53.

Dentistry, modern, 239, 24748.

Desires, human, $48,49,55,150$; limitation of, 187-88, I93-94, $253,257$.

Devotion, 96-100, 258.

Discipline, 210, 213 $25^{\delta}$; social, $47,137,174,190,199-236$.

Disease, I 88; conquest of, 239 , 248-53; diseases of degeneration, 251.

Disintegrating forces in society, 203-O4.

Dominion, love of, 78,82 .

Drama, I78, I93; modern, 183 , 204.

Drudgery, I15, I30-31, I40-42, I 54 .

Durant, Will, Philosophy and the Social Problem, $254 \mathrm{n}$.

Duty, 186, 2 II.

Economic age, 35 .

Economic conditions of poverty, 104.

Economic forces, 109.

Economic injustice, 208.

Economic motives and the war, $83 \mathrm{n}$.

Economic value, 49, 176 .

Economics and social reconstruction, 35,38 .

Economics, influence of, 56 .

Economics, new character of, $55 \mathrm{n}$.

Economists, 40-43.

Education, II5, I62, 215, 223,
225-32, 236-37, 245, 256; deficiencies shown in draft statistics, 14; industrial, 165-66; moralized, 235; outside of schools, 227.

Efficiency, 120, 139, 180, 187, 258.

Eliot, Charles IV., 152, I62 n.

Ellwood, C. A., The Sacial Problem, 234.

Emulation, instinct of, I4I, I42, I54.

Endeavor, Christian, $53 \mathrm{n}$.

Energy, vital, I99; spirit of in western races, 200.

English peasants, 16 .

Equalitarianism, I Io.

Equality, I80, I9I.

Eugenics, 38, 42, 234-35, 256.

Everett, W. G., Moral V alues, $56 \mathrm{n}$.

Exercise, of normal function, I25, 199; of powers, vii, 56 , 189.

Expansion, 194; as a modern tendency, I09, 177, I83, I85; expansive age, 191, 193; expansive virtues, 182.

Exploited classes, 43.

Extravagance, 9 .

Fairchild, H. P., Outline of Applied Sociology, 7 I n.

Family, 91, 204.

Farmers, prosperity of, 15-16, 170.

Feeble-minded, 232-34.

Feeble-mindedness, increase of, 252. 
Feminism, 27, 94-96.

Ferrero, G., Ancient Rome and Modern America, 95 n., 174 n.

Fiction, modern, 204, 227.

Fielding, W. J., 136.

Fine Arts, 107-08, 1 10, 161, 179, I91, 193, 229.

Flexner, Simon, 256.

Folks, Homer, 249 n.

Football, example of discipline, 210.

Fourteen Points, 17.

Frankfurter, Felix, 254.

Fraternities, college, 221.

Fraternity, 180.

Freedom, over-emphasis of, 177, $183,219,224$.

Freud, 38.

Freudian ethics, 189-90.

Freudian psychology, I, 5, 6, 40, 189.

Function, normal function of man, 125.

Galton, Francis, Hereditary Genius, 67 n., 179.

Gambling, 78, 80-81, 111 .

Germany, 194, 212, 244; beıore the war, 82 .

Giddings, F. H., I47 n.

God, 105, 107, I23; the God idea, 106; Greek gods, 123; not a laborer, 123.

Goethe, 182.

Gothic cathedrals, 193.

Government, widening of functions, 218.

Grant, Madison, Passing of the Great Race, $67 \mathrm{n}$.
Great Britain, 7.

Grecian civilization, 179.

Greed, 16, 17, 194.

Greek gods, 123.

Greeks, ancient, 181, 191, 200.

Gregariousness, 63,68 , 172; aggressive, 213-14, 215 n., 224, 236; socialized, 215; defensive, 215 n., 224, 236.

Group solidarity, 100, 205, 213.

Group spirit, 205.

Guild, industrial, 224 .

Guild socialism, 134, 142, 155 .

Guild State, 159 n.

Happiness, found in activity, 52; highest, 187.

Harley, J. H., Syndicalism, $15^{8} \mathrm{n}$.

Health, racial, 14, 34, 91, 193, 253; mental and moral, 258; national, 42, 104; physical defects, 14 .

Hedonism, psychological, 55 .

Heroism, I92.

History, 50, 212; economic interpretation of, 37, 124, 216.

Hobhouse, L. T., 209.

Hocking, W. E., Human Nature and its Remaking, 36 n., $61 \mathrm{n}$., 115,158 n., $190 \mathrm{n}$.

Holt, E. B., The Freudian Wish, $52 \mathrm{n}$.

Huddleston, Sisley, 9 n.

Human nature, 10; plasticity of, $64-68$.

Humanity, service of, 234 .

Humphrey, Seth K., The Racial Prospect, 13, 259 n., 234. 
Hygiene, $7 \mathbf{r}$; application of science to, 247-53; social, 250.

Idealism, modern, 16, 17, 103. Illiteracy, 2 I I.

Impulse, see Instinct.

Impulses, egoistic, 189-90, 210; inhibition of, 190-91; inventive, 127; repression of, 70 , $74,76,189$.

Increased production, 36-37, 132-33.

Individualism, $148,216,234$; individual age, 257; individual responsibility, 217-18.

Industrial age, 139-40.

Industrial arts, 237-44.

Industrial democracy, 21, 27, $164,167$.

Industrial education, 165-66.

Industrial labor, I 15, I 21, 124$25, \mathrm{I} 38$; as drudgery, 143 .

Industrial organization of society, 125 .

Industrial partnership, 167.

Industrial revolution, 23, 193.

Industrial system, $\mathbf{1} 68$.

Industrialism, 83 n.; its psychological foundation, 124 .

Industries, democratization of, 150-53; socialized, 142.

Inequality, 84, II 7, 187-88.

Inhibition, of impulses, I90; weakening of our traditional inhibitions, 191 .

Initiative, 169, I7 I, 200.

Inner check, 184, 189, 193.

Instinct, 46, $5 \mathrm{I}, 6 \mathrm{I}-70$; building instinct, 166, 199; capitalized,
I20; its relation to work, 126; of exploration and invention, 127; of workmanship, I21, I26, I29, I42, I56, I68, I7I; opportunity for expression of in America, 102; sublimation of, 189 .

Integrating forces, 188.

Integration, social, 174, 18r, 202-36.

Intelligence, organization of, 25 , 236,254 .

Intemperance, 187.

Internationalism, 205-06, 223.

Inventive impulse, 127, 169, I 71 .

I.W.W., 27, 100.

Jacks, L. P., $224 \mathrm{n}$.

James, William, 59, 86; Principles of Psychology, 6r n.

Jean Christophe, 182.

Jesus, sayings of, 108, 190.

Journalism, 228-29.

Jung, C. G., The Theory of Psychoanalysis, $52 \mathrm{n}$.

Justice, 184-85, 197, 202-03, 205-06; Platonic, 31, 202.

Kant, his rule of action, 198.

Katharsis, 6.

Keynes, J. M., Economic Consequences of the Peace, $\mathrm{I} 7 \mathrm{n}$.

Knowledge, lack of in industrial disputes, 254, 256; source of social welfare, 225 .

Labor, 87-88, I19; creative labor, 115, 135; crisis, I18; 
drudgery, 115, 130-31, 140- Loyalty, 96-100, 105, 107, 187, 42, I47; hours per day, II 2; humanized, 164; industrial, 121, 254; labor-saving de'vices, 242; place of in man's life, 120-73; productive, 44; unions, 206, 224 .

Law and order, 204, 212; respect for, 188 .

Laws, of thought, 197; obedience to, 219; sumptuary, 257.

Leaders, social, $235^{-} 36,25^{8}$.

Leadership, instinctive need of, 76.

League of Nations, 21, 27, 5859,69 n., I88, 206, 214, 245.

Leibniz, 243.

Leisure, 57, 109, 117, 126, 150 , 158-64, 191, 243; leisure classes, I62.

Leitch, John, Man to Man; the Story of Industrial Democracy, $15 \mathrm{I} \mathrm{n}$.

Liberty, 180, I85, I9I, 218-19.

Life, 26, 45, 78, 89, 107-08, I 19; dynamic conception of, 56 ; enhancement of, 183; what real life is, ror, 105, 1 I9, 128 , I58, 164, 169, I99; its real prizes, II6-17; the full, free, and abundant life, 175-76, I8I, I84, I86, 192.

Limitation, 179,185 , I9I of desires, 187, 193-94, 253, 257.

Lippmann, Walter, 55 n.; $A$ Preface to Politics, $36 \mathrm{n}$.

Liquors, beer, wine, etc., 2,3 .

Literature, I93.

Love, I19, 182, 192. 190, 206-07, 220-22, 258; group, 69; to state, 223 .

Luxuries, 109, I15-16, 133, 147, 240.

Lynching, 73.

Macaulay, vii, 222.

Man, the real man of the present, III-I2; a being who strives, I12; as creative genius, 129.

Marot, Helen, Creative Impulse in Industry, $36 \mathrm{n}$.

Marvin, W. T., The History of European Philosophy, 235-36.

Masculine age, 53 n., 94.

Masterman, C. F. G., 7 .

Materialism, 234.

McDougall, W., 38, 42, 57 n.; An Introduction to Social Psychology, 51 n., 55 n., 58 n., 59, 6i n., 75 .

Mechanical arts, 237-44.

Mechanic and industrial arts, 257.

Medicine, preventive, 239.

Military impulses, 80 .

Minimum wage, $19,50$.

Mitchell, W. C., 36 n., 41, 54 n., $55 \mathrm{n}$.

Mobilizing a nation, 207, 209, 213.

Moderation, I9I.

Monks, virtues of, 179.

Morale, social, 207, 210, 214, 220.

Morality, IIO, I97; revaluation of, 235 . 
More, Paul Elmer, Platonism, Osborn, H. F., Men of the Old $174,184$.

More, Sir Thomas, Utopia, 32.

Morgan, J. J. B., 49 n.

Morris, William, Hopes and Fears for Art, 145; News from Nowhere, 156.

Moving pictures, 4, 96, 109, 137 , 178, 227, 229-31; craze, 107; remedy for poor pictures, 230.

Münsterberg, Hugo, Pyschology and Industrial Efficiency, $120 \mathrm{n}$.

Stone Age, 67.

Our Country, loyalty to, 223.

Ownership, instinct of, 75-76, 102; collective, 143, 150, 153$54,167$.

Pain-economy, 43, 45, 88.

Parental bent, 90 .

Parker, Carleton H., 38, 40, 42, 6r n., 62, 77, 129 n., $190 \mathrm{n}$.

Partnership, industrial, 167 .

Patriotism, 110, 225.

Patten, S. N., 4I, 5 I n.

Murray, Gilbert, Four Stages of Greek Religion, 123 n.

Music, wave of bad music, $12 \mathrm{n}$., 229; jazz, 12 n.

Mystic, the modern, 182.

Napoleon, 22I.

Narcotic drugs, 88, 137.

Nationalism, frenzied, source of social integration, 205-06, 222-24.

News, demand for sensational, 229.

Nietzsche, 83, 176, 182.

Non-Partisan League, 27.

Northerner, traits of, 235-36.

Obedience, 188, 210; to laws, 204, 213, 226.

Old Stone Age, men of, 67.

Opportunity, 14, 33, 37, 43-44, 49, 57, 191, 192; America as a field for, 102, 105, I12, 138, 144, 168-73, 180, 186, 200, 208. Organization, craze for, 99 .

Peace societies, 2.

Pearson, Charles H., National Life and Character, 110.

Pearson, Karl, Tuberculosis, Heredity and Environment, 249.

Peasants, English, 16.

Pecuniary culture, 140, 145 .

Perry, R. B., 197 n.

Philanthropy, modern, 12.

Philosophers, 25.

Philosophy of life, 28, 176.

Philosophy of reconstruction movements, 28.

Plato, 184-85, 237; Republic, 32, 232.

Platonic justice, 31, 202.

Play, 53 n., 83, I 28-29, 164, 212.

Pleasure-economy, 43-45, 88.

Political impulses, 157.

Political institutions, manipulation of, 257.

Population, increase of, 71, 194 . Posterity, provision for, 47,50 , 202, 210. 
Poverty, 37, 103, 117, 172, 179, 187, 200, 242; causes of, 104. Powell, E. A., 4.

Predatory practices, 217.

Price boosting, 208.

Production, increased, 36-37, I16, 132-33.

Profanity in American army, 72.

Profiteering, 4, 207-08, 217.

Profit-sharing, 150, 167.

Progress, 6, 216; springs of, 231; modern, 15-23.

Prohibition, 21, 27, 39.

Proletariat, 124.

Prostitution, 90.

Psychogenetic method, 50; psychogenetic standpoint, 28.

Psychology, of social reforms, 28; behavioristic, 40-4I; recent, 50-52; primary importance for social sciences, $54 \mathrm{n}$.; of collective ownership, 153; possibilities of applied, 245, 253.

Public good, 46.

Public opinion, as source of control, 215-16.

Pugnacity, 58-59, 69, 187.

Purity of the family, 197.

Putnam, James Jackson, $H u$ man Motioes, $97 \mathrm{n}$.

Racial slackers, 13 .

Racial values, 34 .

Recreation, 89.

Relaxation, psychology of, 88 n., I64.

Religion, I10, 205, 225; as source of control, 215; Christian, 221; new interpretation of, 236; revaluation of, 235 .

Repression, method of, 96; of native impulses, $70,74,76$, 189.

Resistance, needed power of, 253.

Responsibility, of journalists, fiction writers and moving picture makers, 228; individual, 217-18.

Restraint, 183, 188, 193-94, 204.

Revolt, heralds of, 216 .

Revolution, 213.

Rome, how mobilized, 213.

Ross, E. A., 38; Social Control, 124, 215; What is America? 20 n.; Principles of Sociology, 29 n.; Sin and Society, 219.

Rousseau, 237, 239.

Russell, Bertrand, Why Men Fight, 56 n., 83 n.

Sacrifice, 108.

Sanitation, 239; application of science to, 247-53.

Scale of living, adequate, II6.

Schiller, Das Lied oon der Glocke, $200 \mathrm{n}$.

Schmucker, S. C., The Meaning of Eoolution, $18 \mathrm{n}$.

Schools, 226; deficiency of our school system, I4 n., 226; vacations, 163 .

Schopenhauer, $51 \mathrm{n}$.

Science, applied, 237-60; and mechanic arts, 7,36 ; as basis of social control, 232; ques- 
- tion of its practical benefits, chap. vi11.

Scott, W. D., Increasing II uman Efficiency in Business, $120 \mathrm{n}$.

Sculpture, 179-80.

Self-control, $24,47,95,185,188$, I92, 204, 253, 257 .

Self-expression, I71, 175-78, I $80-85$.

Self-realization, $45-46,176-77$, I $80-82$, I $85-86,2$ I0.

Self, social, 2 I I.

Sex consciousness, new wave of, 96 ; instinct of, 90-9r.

Sexes, equality of, 91-92.

Shop councils, 50 .

Sin, Magda's theory of, 183 ; see also Sinners.

Single tax, 27.

Sinners, silk hat and syndicate, 219.

Social control, 23, 215-r6, 23 I.

Social democracy, 27, 143 .

Social discipline, 47, I37, I74, I90, I99-236.

Social diseases, 90.

Social evils, 20, 2I, 29; our peculiar consciousness of, 122 .

Social integration, I74, I8I, 202-36.

Socialism, 21, 27, 39, 100, I28, $148,149,186,2$ I 6,2 I 8,225 , 257; agrarian, 143; guild, 134, $142,155$.

Socialized industries, I42, I 58 .

Social justice, I9, 3 I.

Social order, changing, r8-20, 68 ; profound changes in 20 th century, 22.
Social problem, solution of, 236.

Social reconstruction, and economics, 35, 38; a new kind of, 223; Apostles' Creed of, 31 ; complexity of, 58 ; programme of, 30-34; romantic tendencies, 37 .

Social solidarity, 212; conditions of, 220.

Social stability, I 16, 202-03.

Social system, defects of our present, 15.

Social unrest, I4, III-I2, I46, I90.

Social welfare, $46,116,148,176$, 238.

Sociology, 215.

Socrates, 235.

Sombart, $55 \mathrm{n}$.

Sorel, G., $88 \mathrm{n}$.

Spencer, Herbert, Autobiography, $125 \mathrm{n}$.

Spiritual and economic values, I08.

Stagnation, social, I I 8, 148 .

St. Augustine, City of God, 32.

Statc, 204-06, 213-15, 219, 222; proposals to abolish, ${ }_{156}-58$; state-owned railroads, I4I; socialistic, I28, I86; the perfect, 187 .

Stirling-Taylor, G. R., The Guild State, $159 \mathrm{n}$.

Strand orchestra, 229.

Strikes, 81, 11 8, I32, 137, I55; recent coal strike, 225-56.

Striving, 52, I I 2, I99.

Students, university, 217; fraternity, 22 I. 
Sublimation of instinct, $70, \mathbf{7 4}$, $76,189$.

Subnormals, 12, 232.

Sudermann, Magda, 183.

Sugar, increased consumption, 53 n., 137.

Suggestion, as source of control, 215.

Sympathy, 192.

Syndicalism, 21, 27, 100, 142, 155, 158, 159 n., 257.

Taussig, F. W., Incentors and Money-Makers, $36 \mathrm{n} ., 4 \mathrm{r}, 6 \mathrm{I}$. Teachers, inadequate salaries of, $65-66 \mathrm{n}$., $226 \mathrm{n}$.

Tead, Ordway, 38 ; Instincts in Industry, $6 \mathrm{I} \mathrm{n}$.

Team-work, 207, 210, 212, 220. Temperance, as a Greek virtue, 179, 191.

Thomson, J. A., 88 n.

Thorndike, E. L., 38, 55 n.; Educational Psychology; the Original Nature of Man, 6r n. Time-saving devices, 242-43.

Tobacco, 53 n., 92 n., 137, 225. Todd, A. J., Theories of Social Progress, 64 n., 252.

Treaty of Versailles, 16.

Trotter, W., Instincts of the Herd in Peace and War, $36 \mathrm{n}$., $61 \mathrm{n} ., 213,215$.

Trusts, 206.

Tuberculosis, effect of modern methods of treating, 248-50.

Unfitness, physical, I4. Union labor, 224.
United States, danger to our civilization, 222.

Unrest, 14, 111, I18, 136, 150; social, III-12, 146, 190.

Utopias, 32-33, 84 n., I05, 117 , I 56, 201 .

Values, real, 116.

Vaudeville, 231.

Vaughan, V. C., 249 n.

Veblen, Thorstein, 38, 4I, $55 \mathrm{n}$.; Instinct of Workmanship, $6 \mathrm{I}$ n., 64 n., 68 n., 123 n., 138-40; The Theory of the Leisure Class, 160.

Veracity, 197.

Versailles, treaty of, 16.

Vice, 193.

Virtues, Christian, 191.

Vital impulse, 47, 5x n.

Vitality, decrease of, 53 n., 259.

Votes for women, 19, 32, 39, 9092, 188, 257.

Wage slavery, 208.

Wages, increase of, 164 ; relation of to unrest, 145 .

Wallace, A. R., Social Environment and Moral Progress, $2 \mathrm{I}$. Wallas, Graham, 55 n.; Human Nature in Politics, 36 n.; Social Environment and Moral Progress, 21; The Great Society, $36 \mathrm{n}$.

Walling, W. E., $55 \mathrm{n}$.

War, 2, 21, 29, 58-59, 69, 80, 86, $106-07,109,187,207,210$, 214; arbitration treaties, 2; art of, 244; civil, 106, 245; 
effects of modern wars, $244^{-}$Will to live, $5 \mathbf{1}-52,148$.

45; effects upon victors, II; Will to power, 5I-52, 148, form of social suicide, 206; I99.

means of preventing, 246; Wish, Freudian, 5; wish pulse, menace to civilization, Io; source of in the human brain, 246.

Ward, Lester F., 36, 43-44; Applied Sociology, 125.

Watson, John B., 38; Psychology from the Standpoint of a Behaviorist, $62 \mathrm{n}$.

Wealth, and leisure, 109-10, I 17 , I9I; danger of our modern, 242, 259; equal distribution, 44, 55, I09, 203, 258; increased production, 55 . $5 \mathrm{I}$.

Woman, adoration of, 105; enfranchisement of, 19, 32, 39, 92, I 88 ; outgrown the doll stage, I09; physical training, 20; value to civilization of feminine traits, 94; women's federated clubs, 206.

Work, 57, 87-88, I I9; brain workers, I34; and wages, I Io; creative, I I 5, I26, I4O; hours per day, I I 2.

Workingmen's councils, 206.

Weeks, A. D., The Psychology of Citizenship, I3 I n.

Weyl, W. E., The New Democracy, 20 n., $84-85$ n., 103 n., $133,162 \mathrm{n}$.

Whitley Councils, $15 \mathrm{I}, 255$.

Workmanship, constructive, 63 ; instinct of, $121,126,129,142$, I56, I68, I7 I.

World War, 4, 8-9, 38, 44, 69 n., 142, 201, 205, 238, 24I, 259; cost of, 4 . 
(ebe thiberdite pres

CAMBRIDGE - MASSACHUSETTS

U . S . A 




\section{$12=1+12$}

92
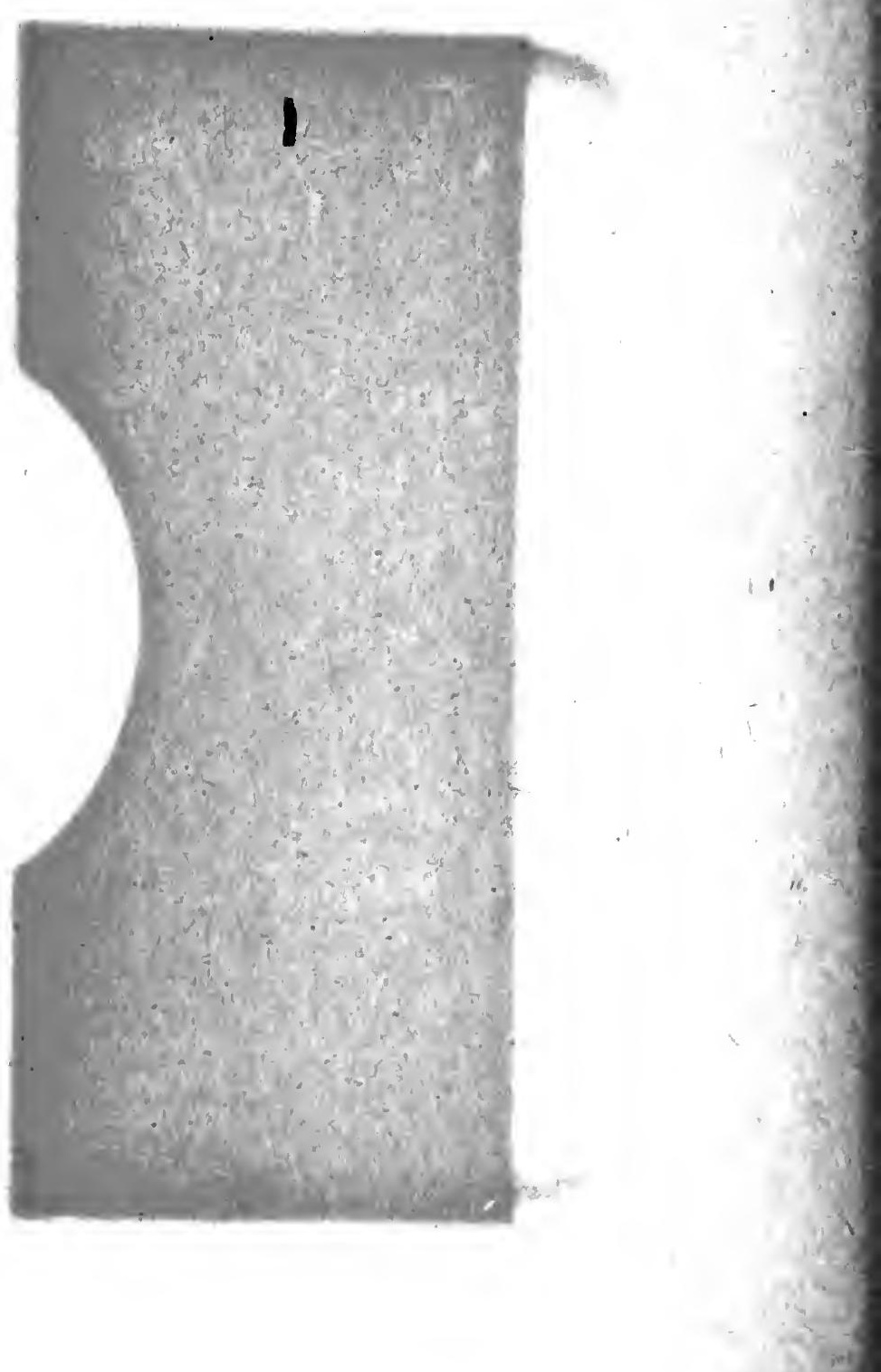


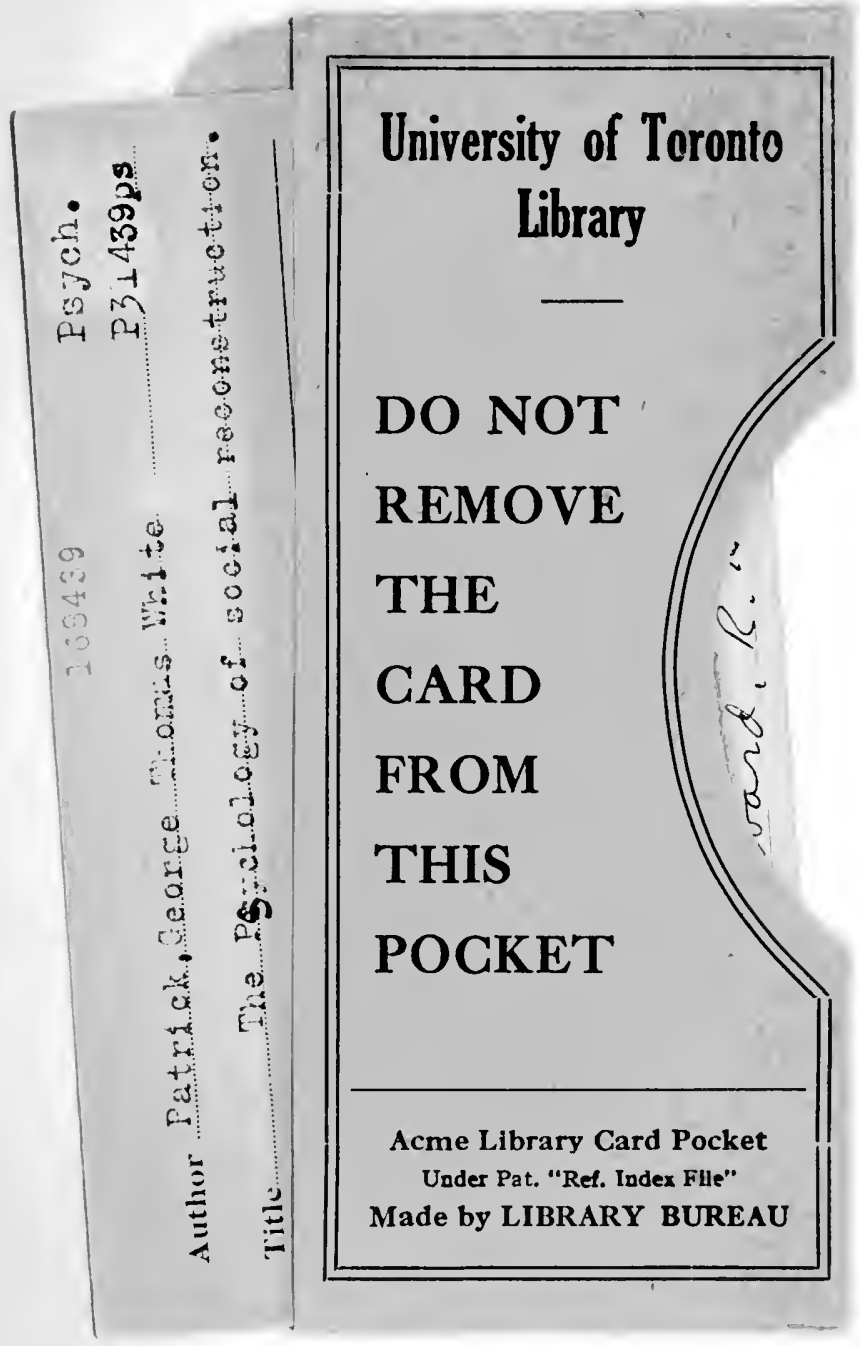


